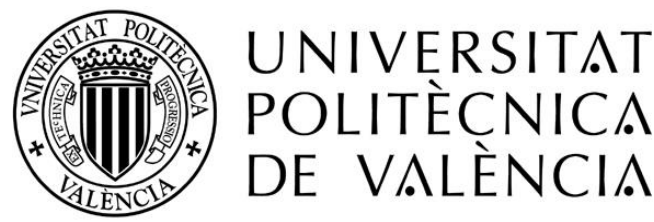

Universitat Politècnica de València

Departamento de Ingeniería Hidráulica y Medio Ambiente

Programa de Doctorado de Ingeniería del Agua y Medioambiental

\title{
Evaluation of the risk due to fluvial flooding in vehicles and road infrastructures at basin scale
}

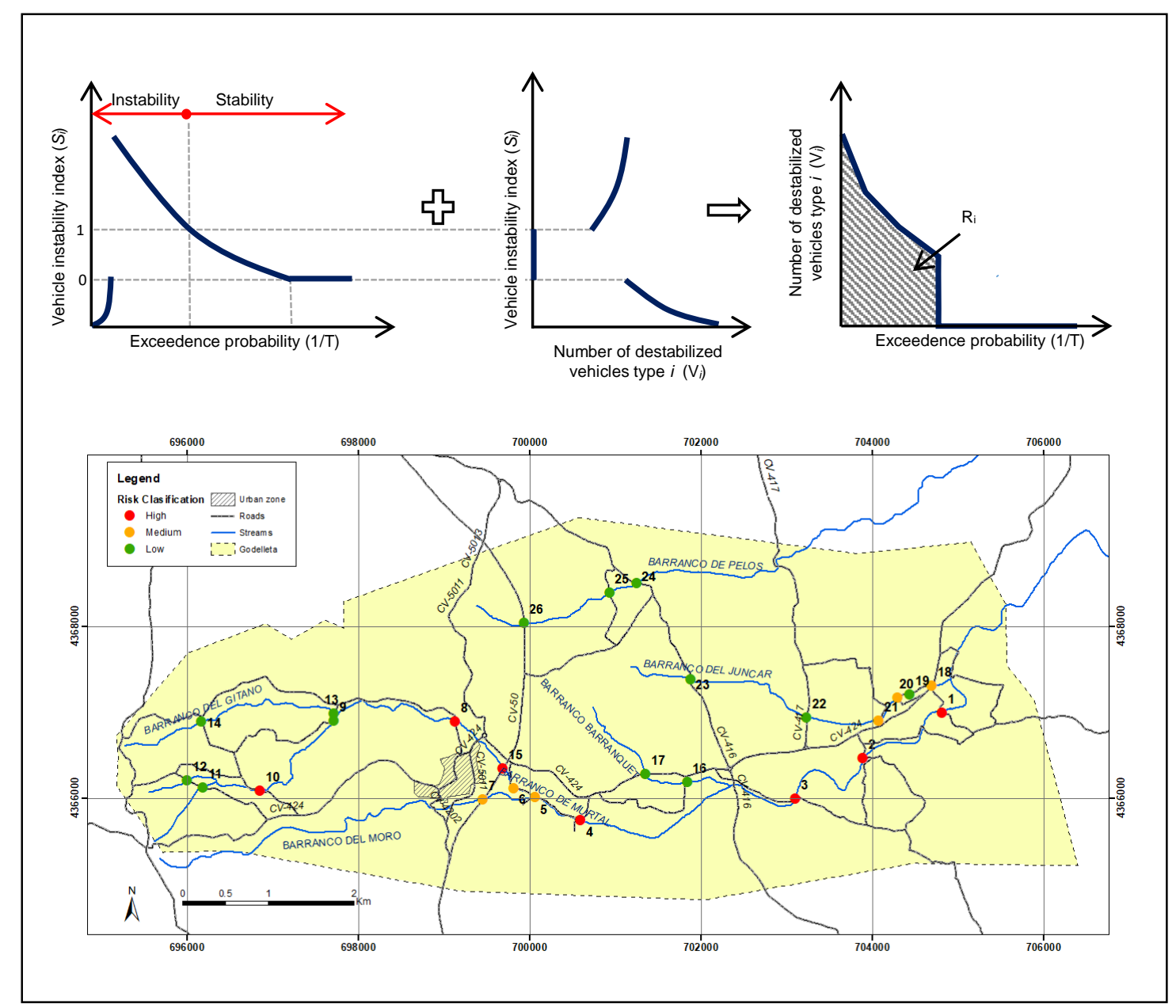

AUTHOR: RICARDO ANDRÉS BOCANEGRA VINASCO SUPERVISORS: DR. FÉLIX FRANCÉS GARCÍA DR. FRANCISCO JOSÉ VALLÉS MORÁN 



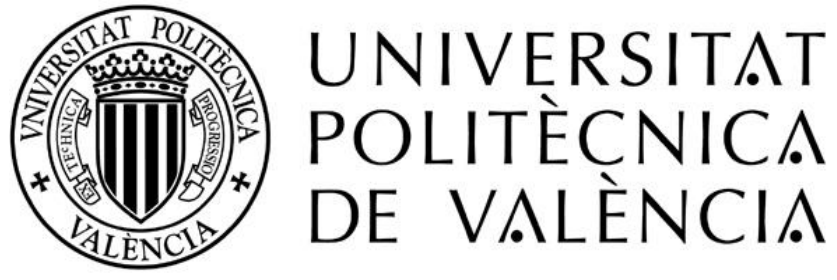

Universitat Politècnica de València

Departamento de Ingeniería Hidráulica y Medio Ambiente

Programa de Doctorado de Ingeniería del Agua y Medioambiental

\section{Evaluation of the risk due to fluvial}

flooding in vehicles and road infrastructures at basin scale

AUTHOR: RICARDO ANDRÉS BOCANEGRA VINASCO SUPERVISORS: DR. FÉLIX FRANCÉS GARCÍA

DR. FRANCISCO JOSÉ VALLÉS MORÁN VALENCIA, JULY 2020 



\section{ACKNOWLEDGEMENTS}

I would like to thank professors Félix Francés García and Francisco José Vallés Morán for their advice, suggestions and guidance in conducting this research.

I would like to thank my colleagues in the GIHMA group, especially Shantosa and Claudia, who offered me their friendship during this period.

I also thank Colciencias for financing this research through call 728-2015.

Quisiera agradecer a María, mi esposa, por su acompañamiento y apoyo incondicional en todo momento y a Sarita, mi hija, por entender que yo también tenía que hacer deberes. También quisiera agradecer a mis padres por sus enseñanzas. Finalmente, no encuentro palabras para manifestar mi agradecimiento a mi tía, sin su apoyo firme y decidido no hubiera podido recorrer el camino que me ha traído hasta aquí. 



\section{TABLE OF CONTENTS}

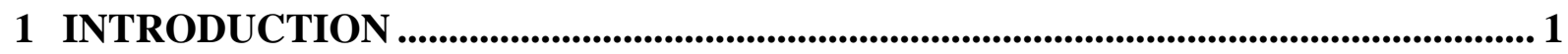

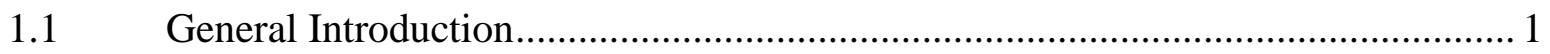

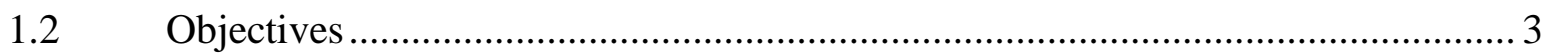

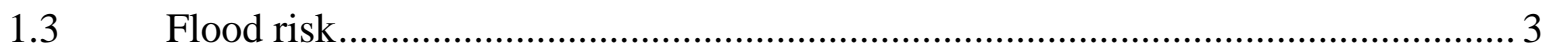

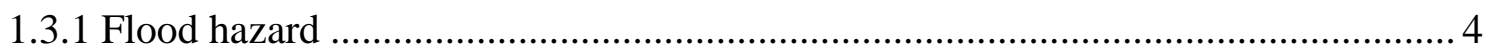

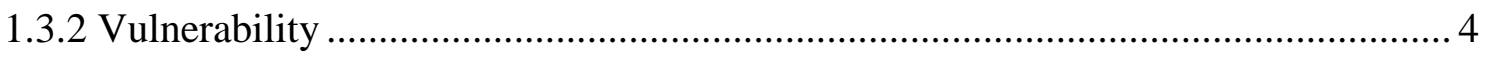

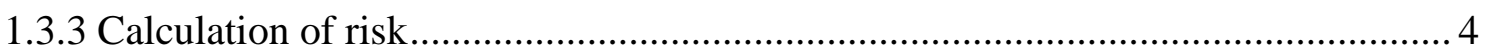

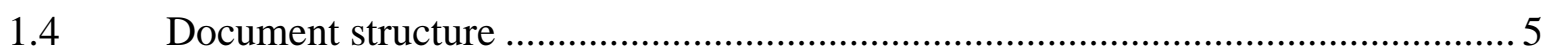

2 REVIEW AND ANALYSIS OF VEHICLE STABILITY MODELS DURING

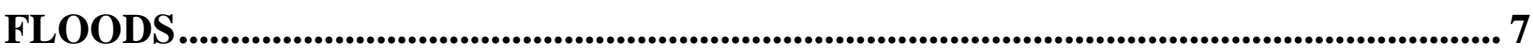

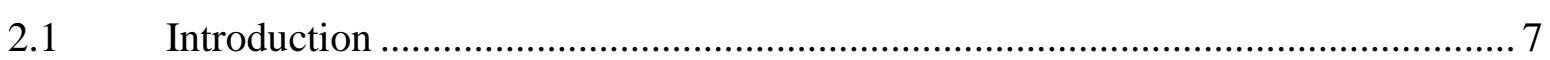

2.2 Description of the studied stability models ...................................................... 7

2.2.1 Stability models that consider non-watertightness of vehicles during floods ......... 8

2.2.2 Stability models that consider vehicle watertightness during floods ...................... 9

2.2.3 Stability models that consider watertightness and non-watertightness of vehicles

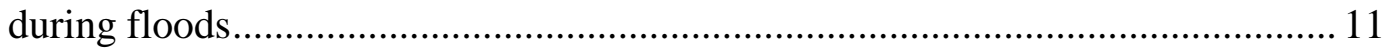

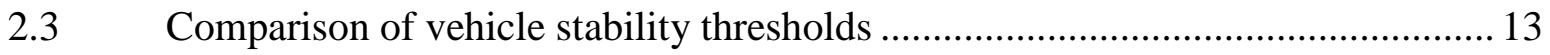

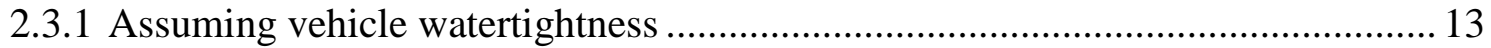

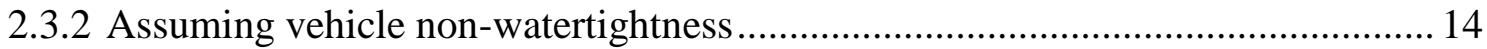

2.4 Comparison of vehicle stability thresholds with experimental data..................... 15

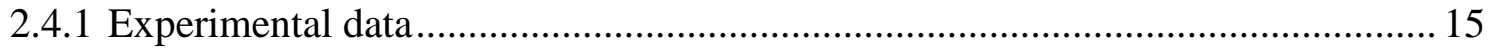

2.4.2 Comparison between experimental data and stability models ............................. 16

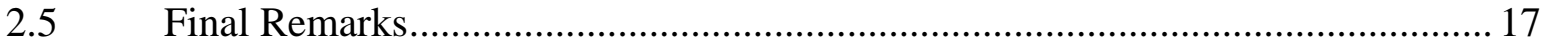

3. ASSESSING THE RISK OF VEHICLE INSTABILITY DUE TO FLOODING....... 20

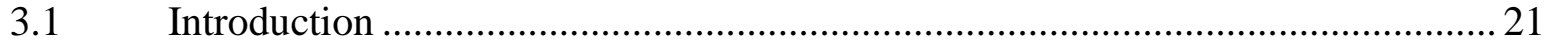

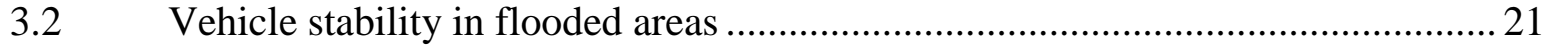

3.3 Methodology to estimate the vehicle instability risk using formal statistics ........ 23

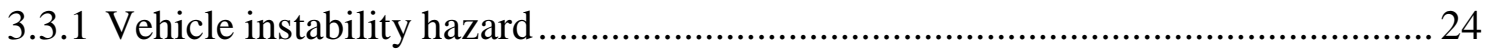

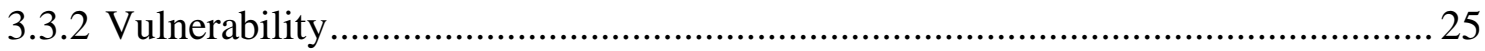

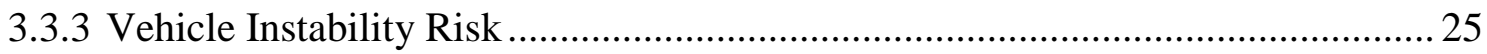

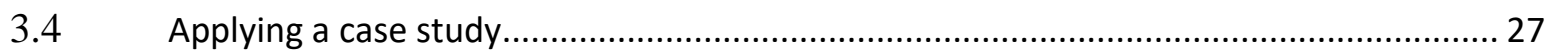

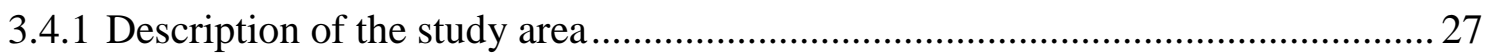


3.4.2 Characterization and exposure of the vehicles in the study area......................... 27

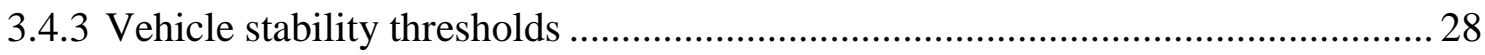

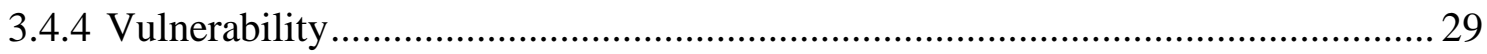

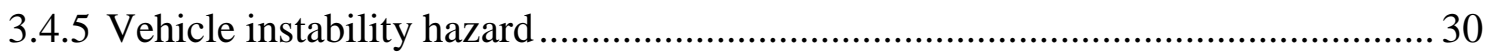

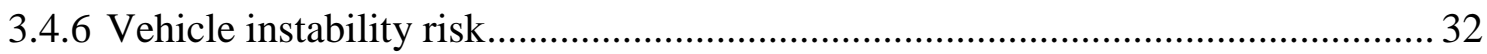

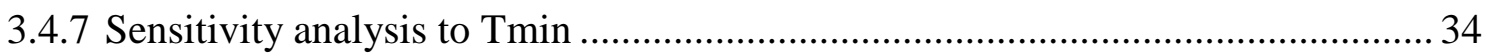

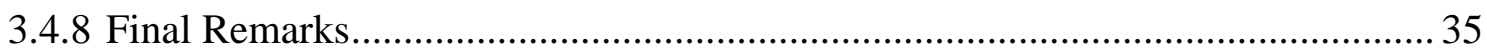

\section{DETERMINING THE VEHICLE INSTABILITY RISK IN STREAM}

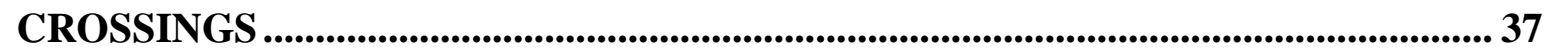

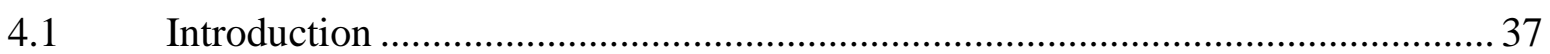

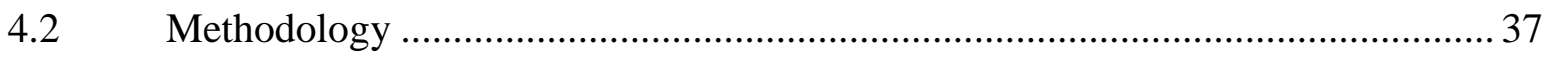

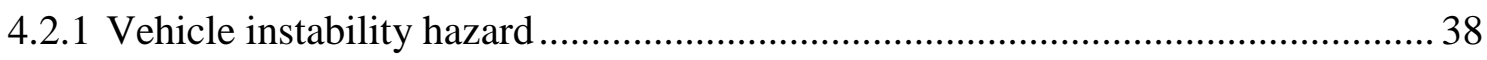

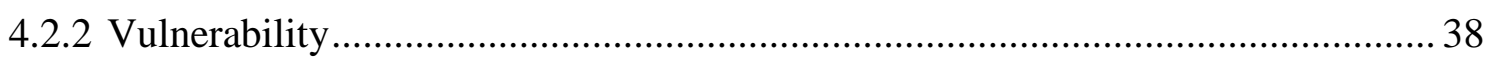

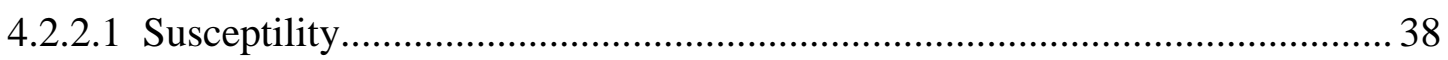

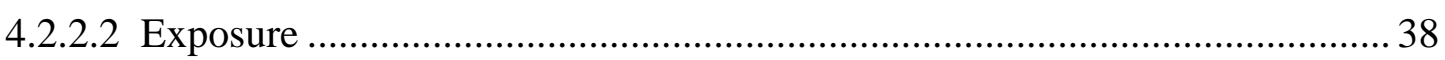

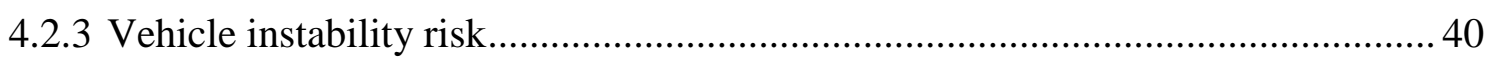

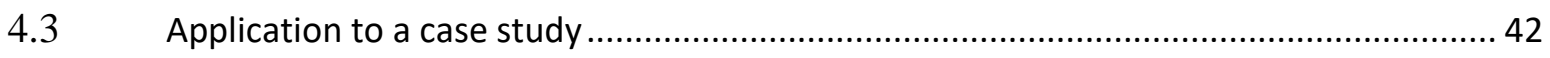

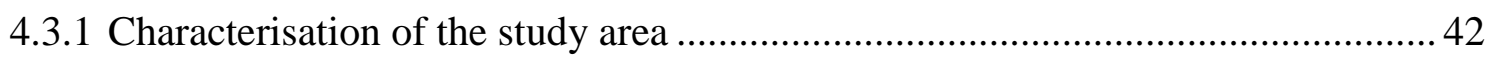

4.3.2 Characterisation and exposure of the vehicles driving through the study area ..... 43

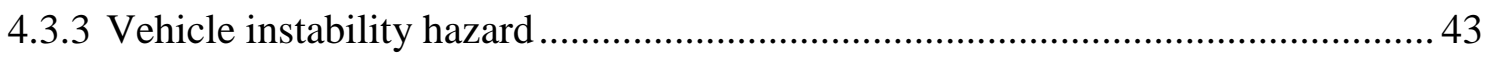

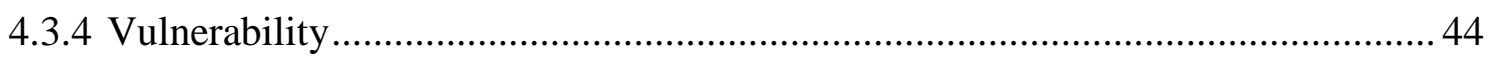

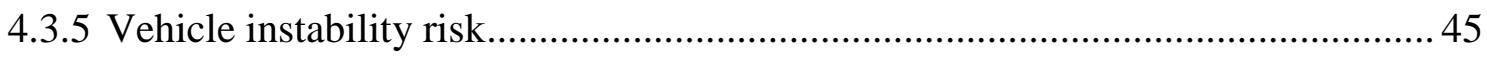

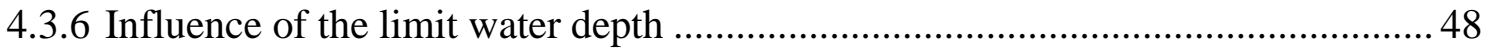

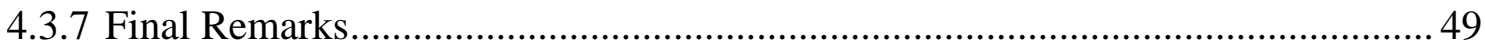

5 RISK ASSESSMENT OF BRIDGE FAILURE DUE TO RIVER FLOODS .............. 51

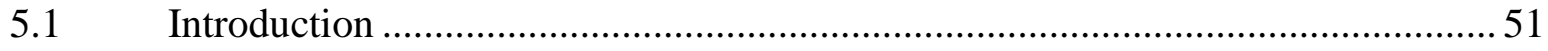

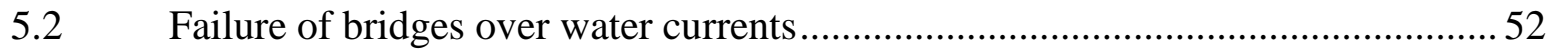

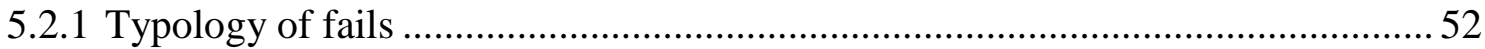

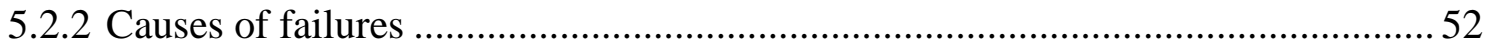

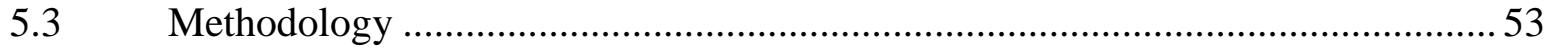

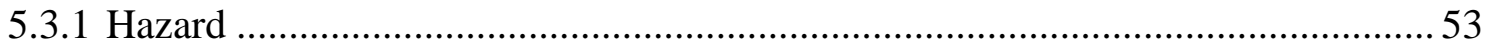

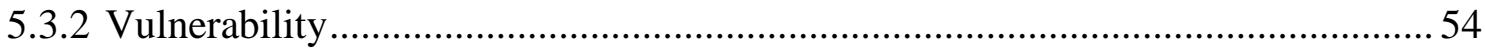

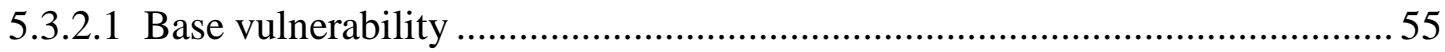

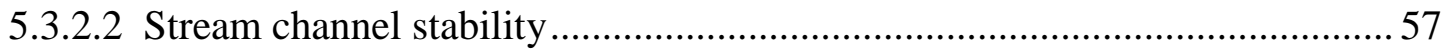

5.3.2.3 Potential of the structure to accumulate debris .............................................5 58 
5.3.2.4 Deterioration of the structure due to its age and the environment in which it is located 60

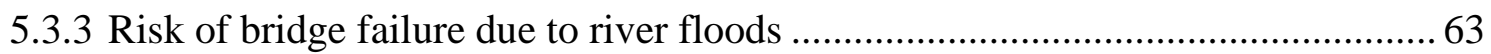

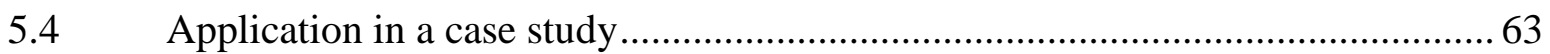

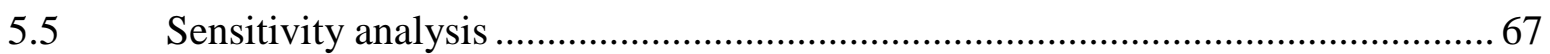

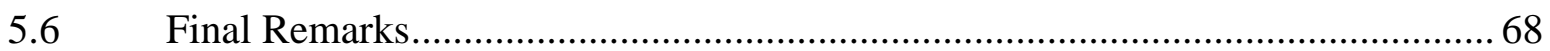

6 CONCLUSIONS AND FUTURES RESEARCH LINES ....................................... 69

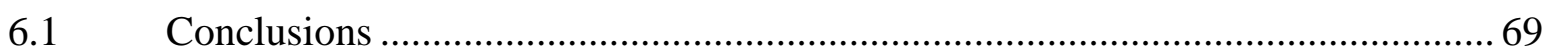

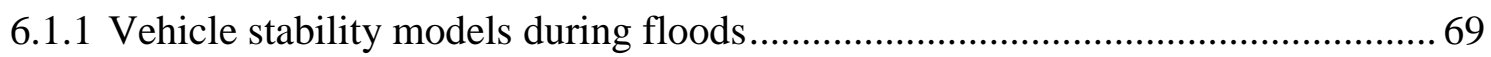

6.1.2 Assessing the risk of vehicle instability due to flooding .................................... 70

6.1.3 Determining the vehicle instability risk in stream crossings .............................. 70

6.1.4 Risk assessment of bridge failure due to river floods ...................................... 71

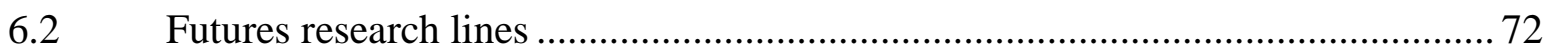

\section{REFERENCES}





\section{LIST OF FIGURES}

Figure 1.1 Diagram illustrating the process that must be implemented to calculate the risk.... 3

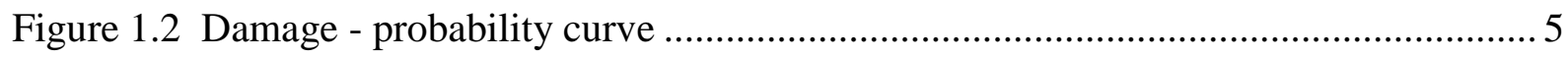

Figure 2.1 Stability thresholds for vehicles in flood events ............................................. 12

Figure 2.2 Comparison of vehicle stability thresholds during floods proposed by stability

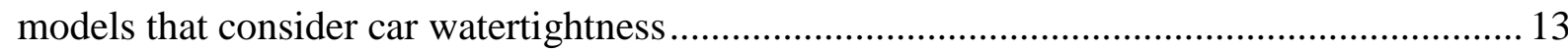

Figure 2.3 Comparison of vehicle stability thresholds during floods proposed by models that consider large 4WD vehicles and car non-watertightness

Figure 2.4. Comparison of proposed stability thresholds for vehicles under watertight

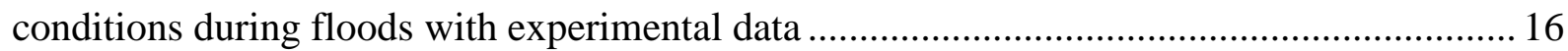

Figure 3.1 Geometry of the car used to determine mobility parameter $\theta \mathrm{v}$. ............................ 22

Figure 3.2 Diagram of the mobility parameter $\theta \mathrm{v}$ vs Froude number................................... 23

Figure 3.3 Diagram illustrating the process that must be implemented to calculate the

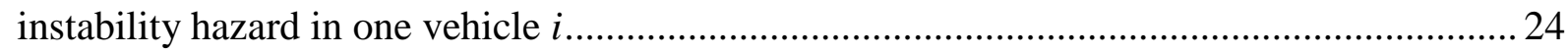

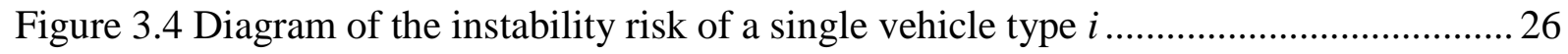

Figure 3.5 Location of the Rambla del Poyo basin and the study area ................................. 27

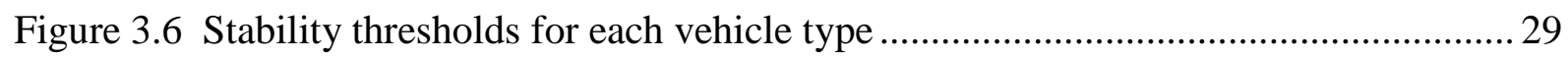

Figure 3.7 Flood hazard: maximum water depths and their corresponding flow velocities in the study area due to the la Rambla del Poyo flooding with a 100-year return period ............. 30

Figure 3.8 Hazard maps of vehicle instability in the study area for floods with return periods

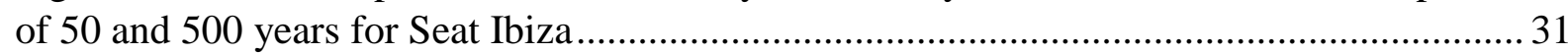

Figure 3.9 Risk map of instability for each vehicle type studied in the study area without considering their proportion in the vehicle fleet ................................................................ 33

Figure 3.10 Map of the instability risk for vehicles in the study area................................... 34

Figure 3.11 Number of cars at risk of instability in the study area when considering different Tmin values

Figure 4.1 Outline of the process to follow to determine the exposure function of vehicles type i.

Figure 4.2 Outline of the procedure to follow to obtain vulnerability of vehicles type $i$ in the event of floods....

Figure 4.3 Outline of the process that must be set up to calculate the instability risk for flooding vehicles type $\mathrm{i}$ in a stream crossing

Figure 4.4 Location of the Godelleta municipality, ravines, main roads

Figure 4.5 Vehicle instability risk due to floods in the stream crossings in the Godelleta municipality..... 
Figure 4.6 Number of vehicles at instability risk in the Godelleta municipality by considering different water depth values from which vehicle traffic could cease. 48

Figure 5.1 Scheme representing the bands into which the cross section of a watercourse is divided for the purpose of the magnitude of a flood 54

Figure 5.2 Location of the bridges to which the methodology was applied 64 


\section{LIST OF TABLES}

Table 2.1 Studied models for the determination of vehicle stability ................................... 19

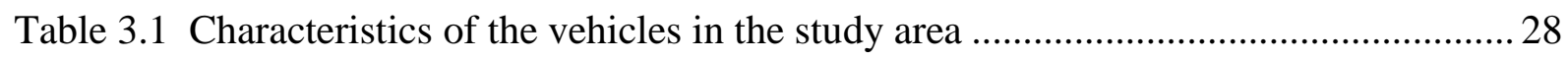

Table 3.2 Mean annual number of at-risk vehicles for instability in the whole study area in line with the two fleet hypotheses: only one type and with the present proportion ............... 34

Table 4.1 Vehicle instability risk due to floods in the stream crossings of the Godelleta municipality.

Table 4.2 Vehicle instability risk by taking a limit water depth of $0.3 \mathrm{~m}$ and vented fords with circular vents and a diameter less than $1.0 \mathrm{~m}$, or equivalent geometries, being unblocked or completely obstructed

Table 5.1 Base vulnerability of the substructure (VBb) and superstructure (VBs) of a bridge in floods adopted in this proposal ....

Table 5.2 Proposed values of the base vulnerability multiplication factor due to the stability of the water current $\left(\mathrm{F}_{\mathrm{s}}\right)$.

Table 5.3 Proposed values of the base vulnerability multiplication factor due to the potential of the structure to accumulate debris (Fd).

Table 5.4 Proposed values of the base vulnerability multiplication factor due to the deterioration of the bridge structure $(\mathrm{Ft})$

Table 5.5 Specifications of the bridges to which the developed methodology was applied... 64

Table 5.6 Stability of water currents and condition of the structures of the bridges analysed

Table 5.7 Risk of failure of bridges located on Spanish roads due to river floods 66

Table 5.8 Fail Risk Sensitivity Test .68 



\section{ABSTRACT}

Flooding can destabilize vehicles which might, in turn, exacerbate the negative effects of floods when vehicles are swept away by flows, leading to economic loss and fatalities. The main cause of death in cities during flood events corresponds to cars being swept away when they are driven by flooded roads (Jonkzman and Kelman 2005; Drobot et al. 2007; Kellar and Schmidlin 2012). In developed countries a high percentage of these deaths occurs during flash floods when drivers try to cross overflowing water bodies instead of avoiding them (Fitzgerald et al. 2010; Kellar and Schmidlin 2012). Hence, in areas subject to flash floods almost half of the victims are passengers trapped inside their own vehicles (Versini et al. 2010a).

Among the parts of the roads that are most affected by floods are bridges, which are very important infrastructure works for society. Because of this, a high percentage of bridge failures worldwide occur as a result of river floods, which has highly negative impacts for vehicles and transportation systems.

Therefore, in order to suitably manage floods, it is necessary to determine the risk of instability to which vehicles in flood-prone areas are subject. However, Despite the negative impact of floods, very few studies have centred on determining the negative effects of floods on transport systems (Molarius et al., 2014).

In this research, a new methodology to estimate this risk based on the characteristics of vehicles, floods, bridges and vehicular traffic was developed. This methodology was generated from a novel conceptual structure and mathematical development and allows to determine the risk by the statistical integral of the instability hazard and the vehicles' vulnerability. In urban areas and stream crossings, the hazard is determined by a stability criterion of partially submerged cars, the geometric characteristics of the vehicles and the hydrodynamic characteristics of the floods (depths and velocities) and their probability of occurrence, while vulnerability is calculated by combining the susceptibility and exposure of cars.

In bridges, the hazard is obtained by analysing available discharge data and the vulnerability by examining the structural condition of the bridge, the characteristics of the watershed and watercourse upstream and downstream of the structure, the stability of the channel and the potential accumulation of debris.

The developed methodology was implemented to determine the risk in the following case studies, which are located in Spanish territory: (i) in the urban areas corresponding to the towns of Alfafar and Massanassa; (ii) in the stream crossings located in the municipality of Godelleta; and (iii) in 12 river bridges located. The results obtained could be indicating that the proposed method takes into account the most important elements to be considered when establishing this type of risk.

The developed methodology provides a detailed vision of the vehicle instability risk due to flooding in a given area. Consequently, implementing this methodology can help to reduce negative effects before and during flooding events, which is extremely helpful for those organizations in charge of urban planning and civil protection to design and take actions that cushion the negative effects of flooding. 



\section{RESUMEN}

Las inundaciones pueden llegar a desestabilizar los vehículos y estos, a su vez, pueden exacerbar los efectos negativos de las inundaciones cuando son arrastrados por el flujo, generando no solamente pérdidas económicas sino también de vidas humanas. En las ciudades, la mayor parte de las muertes durante las inundaciones ocurre al interior de los vehículos debido a que los conductores intentan cruzar con sus vehículos por zonas inundadas (Jonkzman and Kelman 2005; Drobot et al. 2007; Kellar and Schmidlin 2012). En países desarrollados, un alto porcentaje de estas muertes ocurre durante inundaciones relámpago cuando los conductores intentan cruzar por zonas inundadas en lugar de evitarlas (Fitzgerald et al. 2010; Kellar y Schmidlin 2012). Debido a esto, en áreas sujetas a inundaciones relámpago, casi la mitad de las víctimas son pasajeros atrapados en sus propios vehículos (Versini et al. 2010a)

Entre las partes de las vías que resultan afectadas por las crecidas de los ríos se encuentran los puentes, las cuales son obras de infraestructura muy importantes. Un alto porcentaje de los fallos de los puentes a nivel mundial se presenta como consecuencia de las crecidas de los ríos, lo cual tiene un impacto altamente negativo en los vehículos y los sistemas de transporte.

Debido a esto, con el fin de realizar una adecuada gestión de las inundaciones es necesario determinar el riesgo de inestabilidad al que están sometidos los vehículos en una zona inundable. Sin embargo, a pesar del impacto negativo de las inundaciones, hasta la fecha se dispone de pocos estudios que permitan determinar los efectos negativos que las condiciones climáticas generan sobre los sistemas de transporte (Molarius et al., 2014).

En la presente investigación se desarrolló una nueva metodología para calcular este riesgo a partir de las características de las crecidas, los puentes, los vehículos, y el tráfico vehicular. Esta metodología fue generada a partir de una estructura conceptual y un desarrollo matemático novedosos y permite determinar el riesgo a través de la integral estadística de la amenaza de inestabilidad y la vulnerabilidad de los coches. En áreas urbanas y en las intersecciones entre las corrientes de agua y las vías, la amenaza se establece a través de una función de estabilidad de autos parcialmente sumergidos, las características geométricas de los vehículos y las características hidrodinámicas de las crecidas (calados y velocidades) y su probabilidad de ocurrencia, mientras que la vulnerabilidad se calcula por medio de la combinación de la susceptibilidad y la exposición de los coches.

En puentes, la peligrosidad se obtiene a través del análisis de los datos de caudal disponibles y la vulnerabilidad mediante el análisis del estado estructural del puente, las características de la cuenca y del cauce aguas arriba y aguas abajo de la estructura, la estabilidad del canal y la potencial acumulación de acarreos.

La metodología desarrollada se implementó para determinar el riesgo en los siguientes casos de estudio, los cuales están localizados en territorio español: (i) en las áreas urbanas correspondientes a los municipios de Alfafar y Massanassa, (ii) en los sitios de intersección entre vías y ríos localizados en el municipio de Godelleta; y (iii) en 12 puentes fluviales. Los resultados obtenidos podrían estar indicando que el método propuesto tiene en cuenta los elementos más importantes que deben considerarse al establecer este tipo de riesgo.

La metodología desarrollada permite obtener un panorama detallado del riesgo de desestabilización de los vehículos debido a inundaciones en una zona determinada. En 
consecuencia, la implementación de esta metodología puede ayudar a disminuir los efectos negativos antes y durante este tipo de eventos, resultando de gran ayuda para las entidades encargadas de la planificación urbana y de la protección civil con el fin de diseñar e implementar acciones que permitan disminuir los efectos negativos de las inundaciones. 


\section{RESUM}

Les inundacions poden desestabilitzar els vehicles i aquests, al mateix temps, poden exacerbar els efectes negatius de les inundacions quan són arrossegats pel flux, generant no solament pèrdues econòmiques sinó també de vides humanes. A les ciutats, la major part de les morts durant les inundacions ocorre a l'interior dels vehicles pel fet que els conductors intenten creuar amb els seus vehicles per zones inundades (Jonkzman and Kelman 2005; Drobot et al. 2007; Kellar and Schmidlin 2012). En països desenvolupats, un alt percentatge d'aquestes morts ocorre durant inundacions llampec quan els conductors intenten creuar per zones inundades en lloc d'evitar-les (Fitzgerald et al. 2010; Kellar i Schmidlin 2012). A causa d'això, en àrees subjectes a inundacions llampec, quasi la meitat de les víctimes són passatgers atrapats en els seus propis vehicles (Versini et al. 2010a)

Entre les parts de les vies que resulten afectades per les crescudes dels rius es troben els ponts, les quals són obres d'infraestructura molt importants. Un alt percentatge de les fallades dels ponts a nivell mundial es presenta com a conseqüència de les crescudes dels rius, la qual cosa té un impacte altament negatiu en els vehicles i els sistemes de transport.

A causa d'això, amb la finalitat de realitzar una adequada gestió de les inundacions és necessari determinar el risc d'inestabilitat al qual estan sotmesos els vehicles en una zona inundable. No obstant això, malgrat l'impacte negatiu de les inundacions, fins a la data es disposa de pocs estudis que permeten determinar els efectes negatius que les condicions climàtiques generen sobre els sistemes de transport (Molarius et al., 2014).

En la present investigació es va desenvolupar una nova metodologia per a calcular aquest risc a partir de les característiques de les crescudes, els ponts, els vehicles, i el trànsit vehicular. Aquesta metodologia va ser generada a partir d'una estructura conceptual i un desenvolupament matemàtic nous i permet determinar el risc a través de la integral estadística de l'amenaça d'inestabilitat i la vulnerabilitat dels cotxes. En àrees urbanes i en les interseccions entre els corrents d'aigua i les vies, l'amenaça s'estableix a través d'una funció d'estabilitat de cotxes parcialment submergits, les característiques geomètriques dels vehicles i les característiques hidrodinàmiques de les crescudes (calats i velocitats) i la seua probabilitat d'ocurrència, mentre que la vulnerabilitat es calcula per mitjà de la combinació de la susceptibilitat i l'exposició dels cotxes.

En ponts, la perillositat s'obté a través de l'anàlisi de les dades de cabal disponibles i la vulnerabilitat mitjançant l'anàlisi de l'estat estructural del pont, les característiques de la conca i del llit aigües amunt i aigües avall de l'estructura, l'estabilitat del canal i la potencial acumulació d'enderrocs.

La metodologia desenvolupada es va implementar per a determinar el risc en els següents casos d'estudi, els quals estan localitzats en territori espanyol: (i) en les àrees urbanes corresponents als municipis d'Alfafar i Massanassa, (ii) en els llocs d'intersecció entre vies i rius localitzats en el municipi de Godelleta; i (iii) en

12 ponts fluvials. Els resultats obtinguts podrien estar indicant que el mètode proposat té en compte els elements més importants que han de considerar-se en establir aquest tipus de risc.

La metodologia desenvolupada permet obtindre un panorama detallat del risc de desestabilització dels vehicles a causa d'inundacions en una zona determinada. En 
conseqüència, la implementació d'aquesta metodologia pot ajudar a disminuir els efectes negatius abans i durant aquesta mena d'esdeveniments, resultant de gran ajuda per a les entitats encarregades de la planificació urbana i de la protecció civil amb la finalitat de dissenyar i implementar accions que permeten disminuir els efectes negatius de les inundacions. 


\section{INTRODUCTION}

\subsection{General Introduction}

Floods are a natural phenomenon with major negative impacts on society because they cause substantial indirect and direct losses that affect people's lives and health, deteriorate existing infrastructures and interrupt different public services and productive activities (Yin et al., 2016). Those elements and activities that floods affect include roads, vehicles, and transport systems in general. The impact on these systems leads to a cascading effect with possible local and/or regional repercussions (Suárez et al., 2005).

Moreover, the effects of floods on cars and transport systems may worsen due to roads themselves because a road network can modify the natural topography and create a new drainage network, which can change the hydrological response of basins (Jones et al., 2000; Wemple et al., 2001).

Floods are the main cause of disruption of public and private transport systems due to the blockage of roads and the risk they generate for vehicles being driven or parked on floodplains (Pregnolato et al., 2017, Teo et al. 2012a; Versini et al. 2010a). Vehicles can be washed away by overflowing water bodies, effectively becoming debris that can cause additional damage by impacting buildings and infrastructure and by clogging hydraulic structures (Teo et al. 2012b; Kalantari et al. 2014; Arrighi et al. 2015; Pregnolato et al. 2017).

Vehicles are swept along during floods much more frequently than it seems, even in large numbers in some cases. In 1989, a flood that took place in the city of Nagasaki, Japan, damaged 20,000 cars and 299 people died, of whom roughtly 20 died when their vehicles were dragged away by overflowing flood water (Oshikawa and Komatsu, 2014). In August of 2004, a flash flood affected the village of Boscastle in the United Kingdom, causing enormous damage and sweeping away more than 100 vehicles, some of which blocked a bridge causing its collapse while driving others to the sea (Teo et al. 2012a; Teo et al. 2012b). In May 2018 in Barranquilla (Colombia), the torrents of water brought by a precipitation episode exceeding $80 \mathrm{~mm}$ swept away more than 40 cars (El Tiempo, 2018). In September 2019, rainfall exceeding $400 \mathrm{~mm}$ in 48 hours fell in SE Spain. Seven people were killed, of whom four were trapped in their cars and died (Levante, 2019). In Brazil, extremely heavy rainfall in January 2020 and at least 53 people died, and several people did so inside their vehicles (Fhola de S. Paulo, 2020).

Several studies have shown that the main cause of death in cities during flood events corresponds to cars being swept away when they are driven by flooded roads (Jonkman and Kelman 2005; Drobot et al. 2007; Fitzgerald et al. 2010; Kellar and Schmidlin 2012). In developed countries a high percentage of these deaths occurs during flash floods when drivers try to cross overflowing water bodies instead of avoiding them (Fitzgerald et al. 2010; Kellar and Schmidlin 2012). Hence, in areas subject to flash floods almost half of the victims are passengers trapped inside their own vehicles (Versini et al. 2010a). In the USA, 45.4\% of people who died during flooding had been inside vehicles (Jonkman \& Kelman, 2005). In Australia, $48.5 \%$ of deaths in floods are related to the use of motorized vehicles (Fitzgerald et al., 2010). In Europe, approximately $13 \%$ of fatalities during floods occur inside vehicles (Jonkman and Kelman, 2005). Every year in Texas (USA), an average of 15 drivers drown when they drive their vehicles on flooded underground roads or through tunnels (Maples \& Tiefenbacher, 2009). 
Among the parts of the roads that are affected by the rivers floods are the bridges, which are very important infrastructure works. The failure of these structures has highly negative tangible impacts, both direct and indirect, and intangible impacts such as loss of human life and significant social and environmental problems.

A high percentage of bridge failures worldwide occur as a result of river floods. For example, according to Wardhana and Hadipriono (2003), of the 503 bridges that collapsed in the United States between 1989 and 2000, approximately 53\% failed due to river floods; most of these failures occurred within the service life of the bridges, whose ages ranged from 1 to 157 years, averaging 52.5 years. Owing to the failure of these structures 76 people died and 161 others were injured.

Colombia has a similar percentage of bridge failures due to floods: of the 63 failures reported between 1986 and 2001, 47\% were caused by floods, scour and avalanches (Muñoz, 2002). In Taiwan several bridges have failed in recent years due to the effects of floods (Ko et al., 2014). In addition, climate change is expected to increase the probability of bridge failure due to erosion caused by floods (Khelifa et al, 2013).

Among the impacts generated by bridge failures is the traffic disruption, which can last a considerable time if the damage to the infrastructure has been severe. Normally, this traffic disruption affects the performance of many activities, generating a chain reaction that has important social and economic consequences.

Apart from fatalities, damaged infrastructure and interrupted traffic, rescuing people trapped in their vehicles in flooded areas demands costly investments in money and time terms (Smith et al. 2017). Moreover, as a result of climate change and growing urban development, such threats are expected to continue in the future (Dawson et al., 2016; Xia et al., 2011). Therefore, for an adequate land management it is necessary to identify safe areas and the risk to which the different vehicle types and bridges are exposed during floods.

However, despite the negative impact of floods, and the fact that the integral management of such events requires assessing the risk posed for vehicles, very few studies have centred on determining the negative effects of floods on transport systems (Suarez et al., 2005; Molarius et al., 2014, Mitsakis et al., 2014). Very few studies have attempted to assess the stability of partially submerged vehicles or to determine the risk to which vehicles are subjected or to establish the risk of bridge failure due to flooding.

Due to this, in the present investigation a new methodology was developed to estimate the impact that river floods can have on a road network, trying to cover several of the most affected elements when this type of event occurs. Three different scenarios were considered:

(i) The risk of vehicle instability in the floodplains was determined. The proposed methodology was applied in a case study in which an urban area was considered.

(ii) The risk of instability of vehicles in stream crossings, most of which are located in rural areas, was established. The procedure developed was applied to stream crossings in a Spanish municipality.

(iii) The risk of bridge failure due to flooding was evaluated. The proposed methodology was implemented in 12 Spanish bridges of different characteristics. 
In these three scenarios, procedures were developed that have a common methodology, which is based on the integration of the flooding hazard and the vulnerability of the exposed elements. According to the literature review carried out, currently there is no methodology available that allows estimating risk with the approach proposed here or trying to cover as many scenarios as those studied here.

\subsection{Objectives}

The general objective of this research is to develop a methodology to estimate at the regional level the risk of vehicles and bridges instability due to flooding.

The specific objectives of the research are the following:

- Analyse the vehicle stability models during floods and select the most suitable for risk determination.

- Develop a methodology to assess the risk of vehicle instability due to urban flooding

- Establish a methodology for determining the risk of vehicle instability in stream crossings.

- Define a methodology to determine the risk of bridge failure due to flooding.

\subsection{Flood risk}

Risk is defined as the combination of the probability of a flood occurring and its possible negative consequences for human health, environment, cultural heritage, economic activity and infrastructure (Ministry of the Presidency of Spain, 2010). These negatives consequences are understood as the vulnerability of the receptors to such an event. Figure 1.1 presents a diagram of the process that must be implemented to obtain the risk. According to this scheme, to calculate the risk it is necessary to previously know the hazard, which is characterized by the frequency of occurrence of the flood and by indicators of its magnitude or intensity, and the vulnerability. This vulnerability is a function of exposure, which indicates the potential receptors of the flood, and susceptibility, which indicates the level of damage the receptors may suffer.

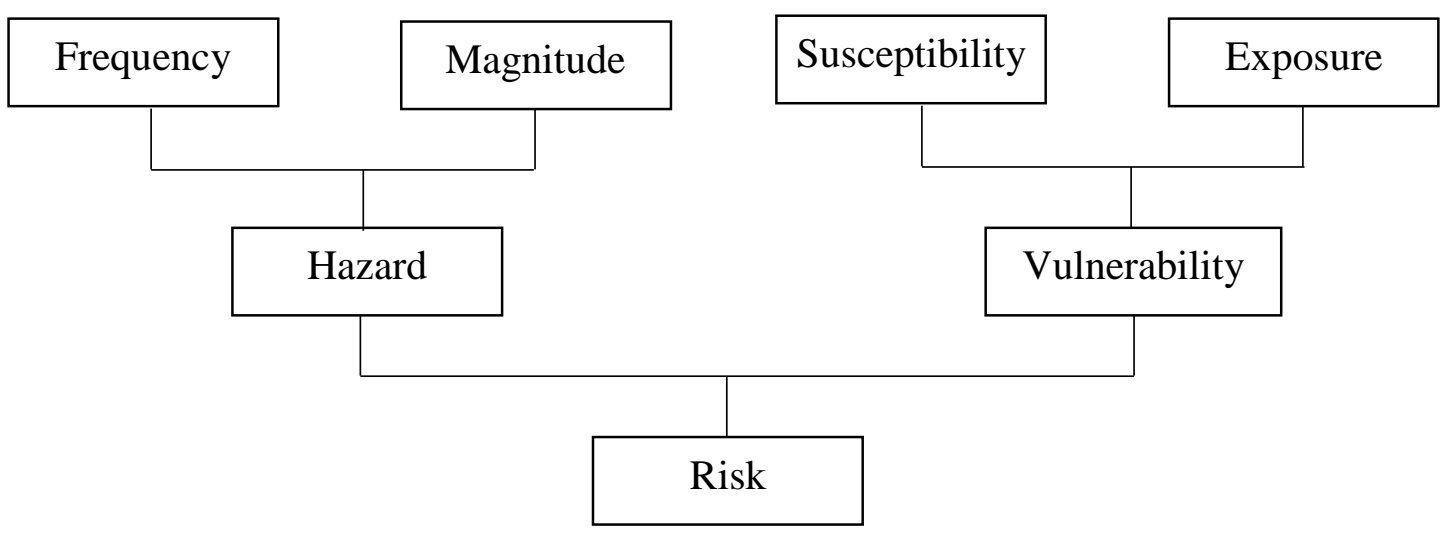

Figure 1.1 Diagram illustrating the process that must be implemented to calculate the risk 


\subsubsection{Flood hazard}

Hazard is defined as the probability of occurrence of a potentially damaging flood event over a certain period of time and at a given site. Floods, which are classified as natural hazards, are physically characterized by indicators of their magnitude or intensity, such as depth, flow velocity, and duration. The conversion of discharges to these variables is normally carried out through hydrodynamic models, which range from one-dimensional stationary models to twodimensional non-stationary models. Usually, the main channel of the river is studied using onedimensional models, which do not require too much information and are not so expensive in computational terms, and the floodplain is modelled two-dimensionally.

The probability of occurrence of floods is normally expressed by the frequency of occurrence expressed as the return period or by the probability of non-exceedance. This probability is normally calculated through statistical methods, which are based on recorded data.

\subsubsection{Vulnerability}

Vulnerability represents the characteristics of a system that describe its potential to be damaged (Samuels et al., 2009; UNISDR, 2009). It is a function of the degree of exposure, which indicates the potential receptors to the flood event, and the susceptibility, which indicates the level of damage that these receptors may experience. According to Schanze (2006), the damage generated by floods depends on the vulnerability of the exposed elements. The more elements contains a system, the more vulnerable to flooding it will be. Likewise, the damages will be more extensive as these elements at risk are more susceptible and more exposed (Scheuer et al., 2011).

Susceptibility indicates the propensity of the exposed elements to damage (Samuels et al. 2009), therefore it depends on the type of flood event and the constitution of the exposed elements (Schanze, 2006). Susceptibility represents a measure of the potential negative consequences of receptors according to their characteristics or social value, such as monetary value, human lives, etc.

Susceptibility is usually expressed through damage or loss functions. The most used are the depth - damage functions, which relate the depth of the flood with the damage that could be generated in the elements at risk. In these functions, as the depth of the flood increases, the damage generated in the exposed elements increases.

Exposure is a measure of potential receptors of the hazard and can be expressed in different units, such as the number of potentially affected people or property. Generally, the quantification of the exposed elements is carried out using geographic information systems, which allow various types of analysis, including quantitative methods.

\subsubsection{Calculation of risk}

According to UNISDR (2009), risk $(R)$ can be calculated by multiplying the probability of occurrence $(P)$ of an event by its consequences $(C)$, as presented in Equation 1.1:

$$
R=P * C
$$


By implementing equation 1.1 and plotting the probabilities of occurrence of flood events against their corresponding consequences or damages, a graph similar to that presented in Figure 1.2 is obtained.

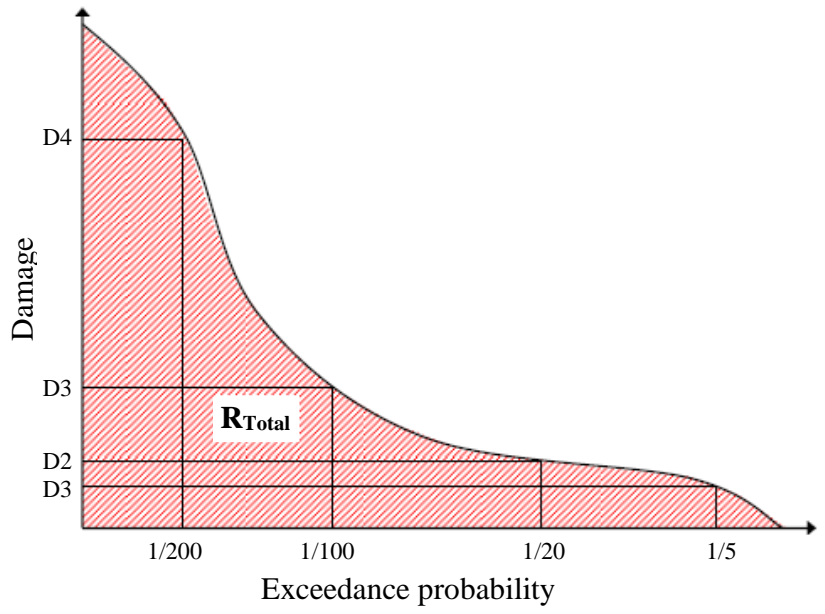

Figure 1.2 Damage - probability curve

Source: Meyer et al. 2009

The area under the curve obtained by joining the calculated consequences for each probability corresponds to the total damage, which can be represented through the following expression presented by Hashimoto et al. (1982):

$$
R=\int_{0}^{1} V(y) d F_{y}=\int_{0}^{\infty} V(y) f_{y}(y) d y
$$

Where Risk $(R)$ indicates the expected annual damage, $V$ is the vulnerability expressed as the probability of failure when the event of magnitude $y$ occurs, $F y$ is the cumulative distribution function of $y$ and $f y$ is the probability density function of the magnitude $y$.

\subsection{Document structure}

This document is made up of six chapters, in which the development and implementation of the proposed methodology is described in detail. The first chapter corresponds to the introduction and includes the motivation to carry out the research, its objectives and the description of the components and the calculation of the risk.

Chapter two discusses the stability models of partially submerged vehicles developed in recent years that can be applied to one or more types of vehicles according to their authors. The main strengths and weaknesses of these models are presented and the most robust of them is selected.

Chapter three describes the established methodology to determine the risk of vehicle instability in urban areas due to flooding. It is made a detailed description of the process that must be followed to estimate the hazard, the vulnerability and the risk of vehicles, and of the implementation of the methodology in a case study. 
Chapter four presents the developed methodology to estimate the risk of vehicle instability at stream crossings. The procedure that allows obtaining each of the risk components and the application of the methodology in a case study are described.

Chapter five presents the developed methodology to determine the risk of bridge failure due to flooding by analysing the integrity of the structure and the hydrological, hydraulic and morphological characteristics of the water current and watershed.

Chapter six presents the main conclusions of the research carried out and proposes future lines of research that will allow further progress in determining the risk of transport systems due to river overflows. 


\section{REVIEW AND ANALYSIS OF VEHICLE STABILITY MODELS DURING FLOODS}

\subsection{Introduction}

Flood water can affect vehicles significantly, which in turn can increase the negative effects of floods as vehicles are washed away by the flow and become a form of debris. (Teo et al. 2012a; Versini et al. 2010a). In cities, most fatalities during floods occur inside vehicles (Fitzgerald et al. 2010; Kellar and Schmidlin 2012). Additionally, as a result of urban growth and changes in climate and meteorological conditions, the probability of urban floods continue presenting has increased, so the risk of vehicles become unstable during these events is growing (Xia et al., 2011; Shu et al., 2011).

Consequently, it is necessary to establish thresholds for vehicle stability during this type of events to provide information necessary for flood risk management. However, despite the danger caused by vehicles swept away and the fact that once vehicles have been washed away they can aggravate flood impacts, very few studies have been carried out on this topic so far (Suárez et al. 2005; Teo et al. 2012a; Arrighi et al. 2015).

Most of the available studies were conducted in laboratory flumes during the 60's and 70's while some theoretical analyses were done in the 90's. However, given the significant changes undergone by vehicles over the last decades, it is considered that these studies are not representative of current conditions anymore (Arrighi et al. 2015; Teo et al. 2012a). A review of the state of the art was presented by Martínez - Gomariz et al. (2016a). This chapter develops an in-depth analysis of some of the methodologies presented in that study and includes the methodologies developed over the last years.

This chapter discusses the existing models developed in recent years to establish stability thresholds that can be applied to one or more types of vehicles according to their authors. In order to do this, a description of these stability models is made first, grouping them according to how they consider vehicle watertightness. Subsequently, the stability thresholds proposed by these models are inter-compared, based on the type of cars for which they were developed. Finally, the ranges in which these stability thresholds fluctuate are compared with the pairs of velocity and depth data measured in laboratory for which the studied cars became unstable.

\subsection{Description of the studied stability models}

On a partially submerged vehicle, the forces of floating $F_{B}$, lift $F_{L}$, own weight $\mathrm{W}$, drag $F_{D}$ and friction $F_{R}$ act (Martínez-Gomariz et al., 2017). The action of all these forces gives way to three hydrodynamic mechanisms coming into play, which can destabilize a vehicle: floating, sliding and toppling. Loss of floating stability occurs when forces floating $F_{B}$ and lift $F_{L}$ exceed the vehicle's weight (W), causing for most cases the rear wheels to lose traction, due to weight distribution in modern vehicles, making the vehicle rotate on its front wheels and in many cases be washed away by the flow. This type of instability occurs mainly when the flow moves at a slow velocity and high depths of water are found. Loss of sliding stability occurs when drag force $F_{D}$ generated by flow exceeds friction force $F_{R}$, which depends on the friction coefficient between the vehicle's tire rims and the wet surface. An interaction takes place between the floating and sliding mechanisms because both forces lift $F_{L}$ and floating $F_{B}$ lower normal force $F_{N}$ which, in turn, lowers friction force $F_{R}$. 
Destabilization owing to the vehicle toppling seems to occur only when the vehicles have already been washed away by the flow or have floated and found irregular land (Shand et al. 2011). This mechanism has been poorly studied to date. None of the available stability models to date has considered this type of instability.

In recent years, some research has been conducted with the objective of establishing a stability threshold for modern vehicles through the study of the interaction between these vehicles and the flow. This threshold is usually defined through expressions that relate water depth and flow velocity. However, many of these studies differ in the way they approach the problem and in the driving factors considered in their analysis. As a result, they have produced different models for the determination of this stability threshold.

According to some authors (Teo et al. 2012a,b), assuming that vehicles are completely watertight during floods is a highly idealized condition, which is why they consider the entry of water into vehicles when trying to determine the stability threshold. However, most authors consider that, due to improvements in modern vehicles in aspects such as sealing against dust, it is legitimate to assume that vehicles are watertight during flood events. Some of them determine the stability threshold using the total energy of the flow (Ausroads 2008; Kramer et al. 2016) while others use the product of flow velocity and depth. Among the latter, some models establish a maximum limit for depth and flow velocity (DIPNR 2005; Shand et al. 2011; Smith et al. 2014) and others a maximum limit only for depth (Moore and Power 2002; Martínez-Gomariz et al. 2017). Finally, some authors have developed models that enable the calculation of vehicle stability either considering or disregarding its watertightness; i.e., one of these models establishes the stability threshold by registering the combinations of flow velocity and depth that generate stability loss (Toda et al. 2013), another compares the forces acting on the vehicle (Oshikawa and Komatsu 2014) and the third uses the Froude number and a mobility parameter (Arrighi et al 2015).

The different models available for evaluating stability of vehicles exposed to flooding are described in more detail here below. A synthesis of the main characteristics of these stability models is presented in Table 2.1.

\subsubsection{Stability models that consider non-watertightness of vehicles during floods}

In order to understand the impact of water level and flow velocity in the hydrodynamic processes that cause stability loss of a vehicle during a flood event, Teo et al. (2012a) and Teo et al. (2012b) presented in similar papers a series of experiments in a flume using physical models of three different vehicle types: a Mini Cooper, a BMW M5 and a Mitsubishi Pajero. They used scales 1:43 and 1:18, satisfying the principle of geometric similarity. Additionally, these authors assumed the vehicles were not completely watertight. These experimental data were also reported by Xia et al. (2011).

Teo et al. (2012a) and Teo et al. (2012b) extrapolated their results to the prototypes and established the stability threshold from the combinations of water depth and flow velocity that cause the movement of the vehicles. On the basis of the obtained results, a graph was developed by relating depth with flow velocity, this graph enabled the definition of three zones: a stable zone where the interaction of flow velocities and depths does not affect vehicle stability, a transition zone and an unstable zone in which flow velocities and depths would cause the vehicles to move by sliding (Figure 2.1a). 
However, according to Froude number similarity, the weights of the different scale physical models were not correctly scaled. Consequently, the validation carried out for the 1:18 scale was not sufficiently accurate. Additionally, they considered water came inside the vehicle from the very beginning of the experiment whereas it appears the entry of water into the prototypes is likely to occur not as fast as it was assumed. Owing to all this, the results presented by this model should be used with caution.

\subsubsection{Stability models that consider vehicle watertightness during floods}

From the analysis of the experimental results reported by Bonham and Hattersley (1967), Gordon and Stone (1973) and Keller and Mitsch (1993), Moore and Power (2002) defined the threshold of instability through a linear relationship between flow velocity and depth for subcritical regime and through the multiplication of these two parameters for supercritical regime, assigning to this product a value of 0.6 (Figure $2.1 \mathrm{~b}$ ). They established the separation between these relationships at $1.81 \mathrm{~m} / \mathrm{s}$. It should be noted that this stability model was based on experimental tests carried out with vehicles having very different characteristics from current ones, so the results may not be entirely valid today.

The Department of Infrastructure, Planning and Natural Resources of the New South Wales Government (DIPNR 2005) considers that vehicle instability is initially generated by buoyancy and establishes a stability threshold through a linear relationship between flow depth and velocity. This threshold includes maximum values of $2.0 \mathrm{~m} / \mathrm{s}$ for the velocity and $0.3 \mathrm{~m}$ for the depth (Figure 2.1b).

Mens et al. (2008) obtained the stability thresholds for a standard car, a van, an ambulance and a fire truck applying the stability model proposed by Keller and Mitsch (1993), as shown in Figure 2.1b. However, as already noted, the characteristics of vehicles have changed significantly in recent years, so the model applied could not be valid at present.

Based on the analysis of the data reported by Bonham and Hattersley (1967), Gordon and Stone (1973) and Keller and Mitsch (1993), Australian Rainfall and Runoff -AR\&R- (Shand et al. 2011) proposed provisional stability criteria for vehicles at rest (Figure 2.1b). According to their dimensions, weight and free distance to the ground, the cars were classified into large 4WD, large passenger and small passengers (Sections 2.3 and 2.4 use this same classification) and it was considered that the stability limit for each of these types of vehicle is reached when the product of flow velocity with depth is equal to $0.3,0.45$ and 0.6 , respectively. According to buoyancy limits, maximum depths of $0.5 \mathrm{~m}$ were defined for large $4 \mathrm{WD}$ vehicles, $0.4 \mathrm{~m}$ for large passenger vehicles and $0.3 \mathrm{~m}$ for small passenger vehicles. A maximum flow velocity of $3.0 \mathrm{~m} / \mathrm{s}$ was established for all vehicles to ensure human safety when leaving the vehicles, following the recommendation reported by Cox et al. (2010). According to the authors, these criteria have a provisional character and must, therefore, be updated.

From results reported in literature, Smith et al. (2014) proposed a stability threshold for small vehicles and another for all other types of vehicle, considering in both cases a maximum limit of flow velocity of $2.0 \mathrm{~m} / \mathrm{s}$ (Figure $2.1 \mathrm{~b}$ ). The other criteria for both small and other vehicles coincide with the ones defined by the AR\&R in 2011 (Shand et al. 2011) for small vehicles and large 4WD vehicles, respectively. 
Kramer et al. (2016) conducted several laboratory tests using a 1: 9.8 scale physical model of a VW Golf III and a 1:13.1 scale physical model of an emergency rescue vehicle. The results indicated that the different combinations of flow velocity and depth that define the stability threshold of the analysed vehicles describe a curve similar in shape to the curve of constant total energy head. These authors established that the safety criteria for the transit of vehicles on flooded roads must consider technical restrictions of each vehicle, such as the height of the air inlets or the tightness of the electrical devices, in addition to stability aspects. Consequently, a stability threshold equal to the total energy of the water was defined, giving it a constant value equivalent to the minimum wading depth, according to the vehicle under study: for emergency rescue vehicles this value was established at $0.6 \mathrm{~m}$ and for passenger vehicles at $0.3 \mathrm{~m}$. This last criterion coincides with that proposed by Ausroads in 2008 (Figure 2.1b).

Concerning the instability drivers, Kramer et al. (2016) concluded that in floods in which the Froude number of the flow is less than 0.5 , stability is controlled by the flotation forces and does not seem to depend on the orientation of the vehicle with respect to the flow. In contrast, when Froude numbers are greater than 0.5, the sliding instability mechanism becomes more dominant and the incidence angle of the flow has an important effect.

Finally, through tests carried out with a prototype of the VW Golf III car, Kramer et al. (2016) concluded that it is reasonable to assume watertightness conditions in order to define safety criteria for vehicles in urban environments.

Smith et al. (2017) conducted measurements on a 2006 Toyota Yaris Sedan and a 1998 Nissan Patrol GRII on a full prototype scale in order to determine the force required to overcome the friction force when the vehicles were submerged at different depths of water at rest. Additionally, they conducted tests on a 1:18 scale physical model of a 2005 Toyota Yaris Hatch with the objective of determining the equivalent hydrodynamic force required to reproduce the instability conditions of the prototype vehicle. The test results showed average values of 0.76 for the friction coefficient between the floor and the tyres and values fluctuating between 1.2 and 2.0 for the drag coefficient, which is used to calculate the drag force. Stability thresholds were defined as the product of flow velocity and depth, finding values close to 0.5 for the Toyota Yaris and higher than 1.0 for the Nissan Patrol. However, considering that conditions in real world can differ widely from the controlled conditions in the laboratory and that several simplifications were made in the tests performed, Smith et al. concluded that the stability thresholds proposed by AR\&R (Shand et al. 2011) are appropriate (Figure 2.1b).

Martínez-Gomariz et al. (2017) proposed a model to determine the stability of any vehicle exposed to flooding based on the analysis of the results of experimental tests. Measurements were made with 12 car physical models using three different scales (1:14, 1:18 and 1:24). From the results, these authors defined a stability function that allowed them to establish a constant value of the product of flow velocity and depth. This function was found on the basis of the depth from which the vehicle starts to float and a stability coefficient which is calculated from the friction coefficient between the tyres and the road and the following characteristics of the vehicle: weight, free distance to the ground and plan area (Figure 2.1b).

Through the implementation of the obtained stability function by Martínez-Gomariz et al. (2017) and using friction coefficient values of 0.25 and 0.75 , the model enables to obtain a graph showing depth versus flow velocity for each vehicle. This graph shows a stable zone, a transition zone and a zone in which vehicles would reach instability conditions. However, it should be noted that in all tests performed, the friction coefficient fluctuated between 0.52 and 
0.62 , while for the calculation of the stability thresholds the values adopted were of 0.25 and 0.75 , which are very far from the experimental range.

\subsubsection{Stability models that consider watertightness and non-watertightness of vehicles during floods}

Oshikawa and Komatsu (2014) conducted experimental tests with 1:24 scale physical models of a Nissan March compact car and a 4WD Toyota Land Cruiser. From the results analysis the stability threshold was determined as the ratio between the drag force and the friction one. A value of this ratio greater than 1.0 indicates that the vehicle would be washed away by the water flow.

Values of drag and lift coefficients were experimentally determined and used to calculate the corresponding forces exerted by the flow on the vehicle. The drag coefficients fluctuated between 0.8 and 5.1 for the compact car, and between 2.1 and 3.6 for the 4WD car. Lift coefficients varied between -0.28 and 0 for the compact vehicle and between -0.52 and -0.17 for the $4 \mathrm{WD}$ vehicle. In the cases where water can enter the vehicle, there will be a decrease in the flotation force due to the vehicle porosity, which was defined with a minimum value of 0.0 when the vehicle was well-closed and with a maximum value of 0.5 that corresponded to the cases where the dead weight of the vehicle and the buoyancy were balanced. Therefore, it is possible to define a safe zone below the obtained stability threshold with a friction coefficient of 0.4 and a porosity of 0.0 , and a danger zone above the result for a friction coefficient of 0.6 and a porosity of 0.5 (Oshikawa and Komatsu 2014) (Figure 2.1c).

Using a similar approach to that of Oshikawa and Komatsu (2014), Toda et al. (2013) performed laboratory tests using physical models at scale 1:10 of a sedan-style vehicle and 1:18 of a minivan. These authors obtained friction coefficients equal to 0.26 for the sedan vehicle and 0.57 for the minivan with the car oriented in the flow direction and the handbrake on. With the car oriented transversely to the flow and with the handbrake off, the coefficients of friction were equal to 0.565 for the sedan vehicle and 0.65 for the minivan. Porosity values were established as $0.2,0.3$ and 0.5 . It was concluded that vehicles are likely to start moving with depths greater than $0.5 \mathrm{~m}$ and velocities greater than $2.0 \mathrm{~m} / \mathrm{s}$.

According to Arrighi et al. (2015), vehicle stability can be determined from the Froude number and a mobility parameter. This parameter is defined for water depths greater than the height of the chassis and considers the shape and the submerged relative weight of the vehicle. Arrighi et al. (2016a) improve the estimation of the mobility parameter when considering the incidence angle of the flow with the vehicle. The mobility parameter was calculated for experimental data reported by Xia et al. (2011), Shu et al. (2011) and Xia et al. (2014). The results were plotted against the corresponding Froude numbers, obtaining a stability threshold which determines a safe zone and a dangerous zone (Figure 2.1c). It should be noted that this model allows considering the entry of water into the vehicle during the flooding, because it allows modifying the density of the car, which is required to calculate the mobility parameter. Also, it is important to note that a certain degree of uncertainty is associated to the stability threshold, because Arrighi et al. used the data reported by Xia et al. (2011), which present the inaccuracies already discussed in Subsection 2.2.1. 
Chapter 2, Review and analysis of vehicle stability models during floods

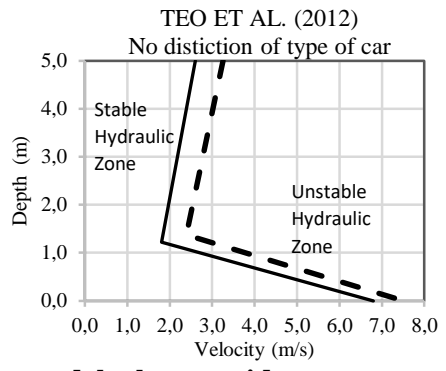

a.- Stability models that consider non-watertightness of vehicles
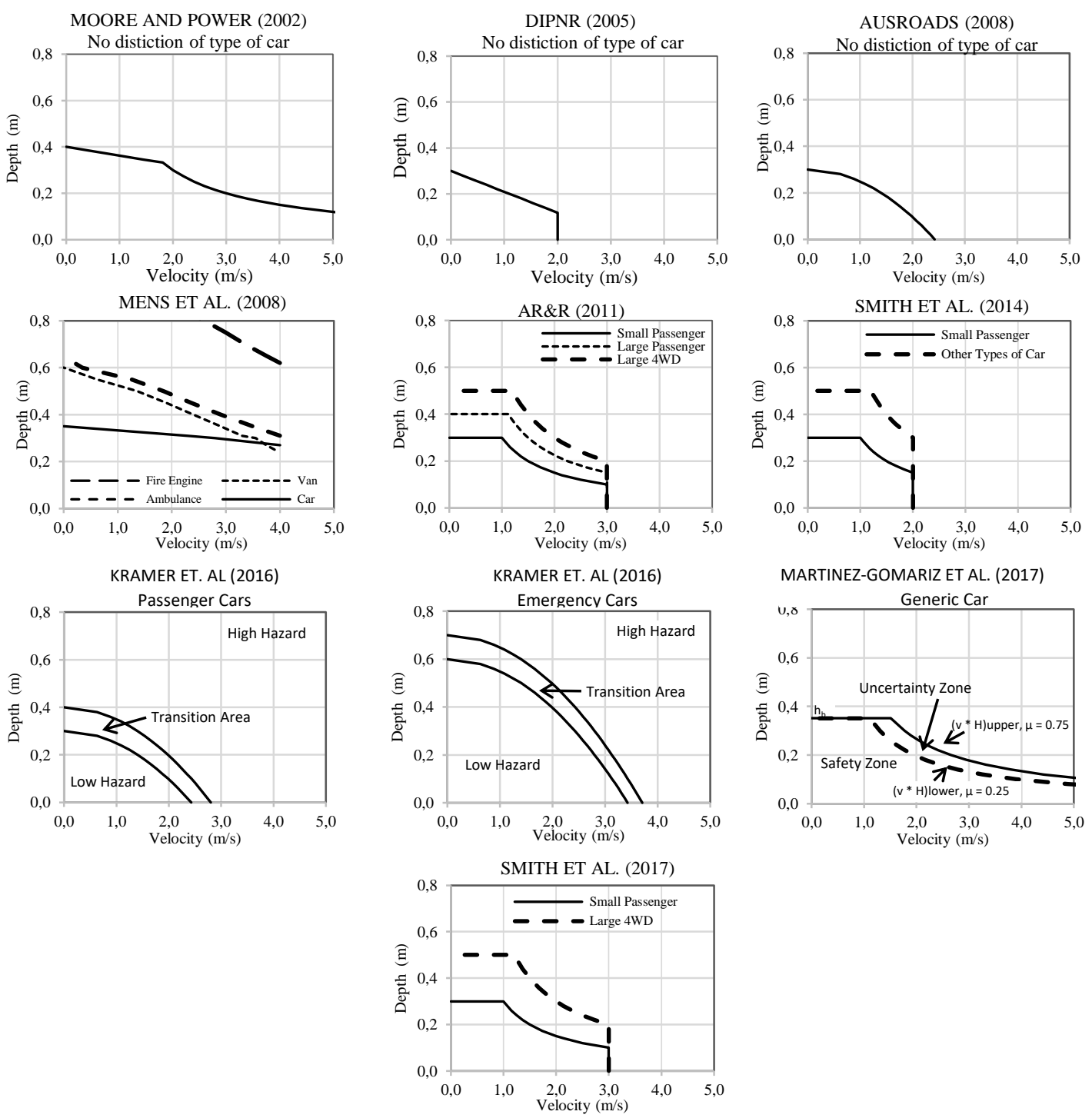

b.- Stability models that consider watertightness of vehicles
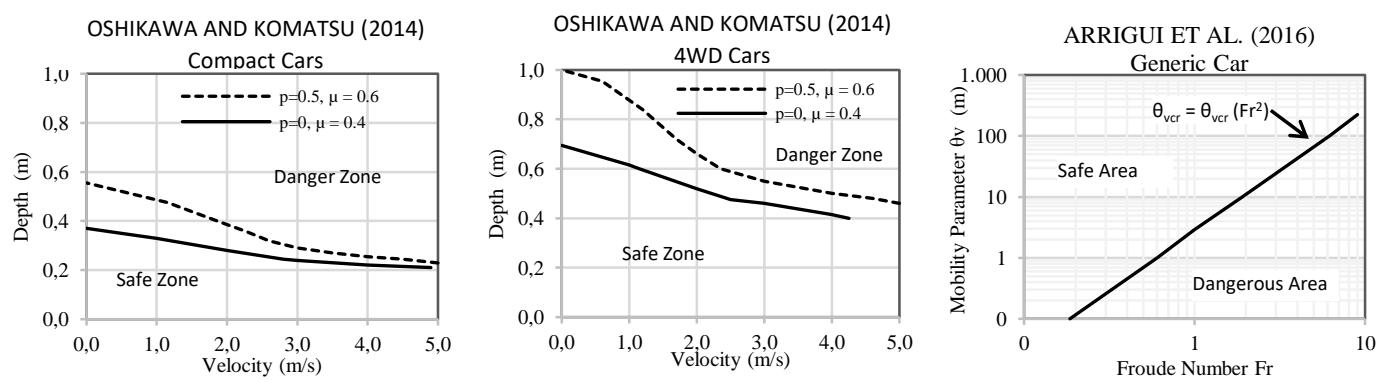

c.- Stability models that consider watertightness and non - watertightness of vehicles

Different scales have been used in panels $\mathrm{a}, \mathrm{b}$ and $\mathrm{c}$ for better visibility

Figure 2.1 Stability thresholds for vehicles in flood events 


\subsection{Comparison of vehicle stability thresholds}

\subsubsection{Assuming vehicle watertightness}

Figure 2.2 compares the results obtained by applying the stability models that consider vehicle watertightness to three different types of cars according to the classification proposed by the AR\&R (Shand et al. 2011): large 4WD, large passengers and small passengers. Although the stability models of DIPNR (2005), Ausroads (2008) and Kramer et al. (2016) were proposed for any type of vehicle, they are only shown in the graph for small passenger vehicles, because, in reality, the vehicles they used fell within this category.

For the implementation of the stability models of Arrighi et al. (2016a) and Martínez-Gomariz et al. (2017), the following vehicles were used: (i) large 4WD cars: Mercedes G55 AMG and Audi Q7; (ii) large passenger cars: Mercedes GLA and Ford Focus; (iii) small passenger cars: Mini Cooper and Toyota Yaris.
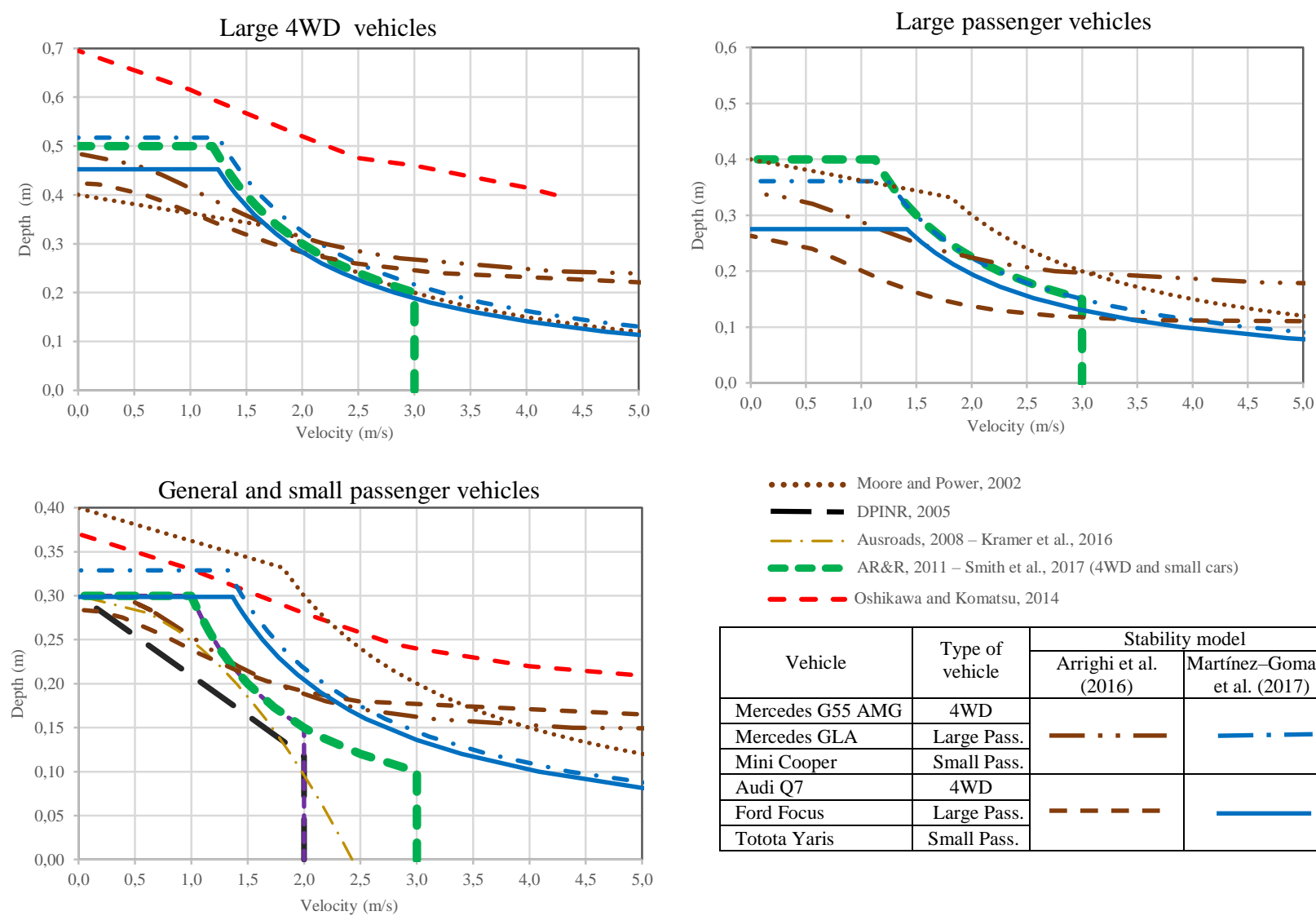

- - Oshikawa and Komatsu, 2014

\begin{tabular}{|l|c|c|c|}
\hline \multirow{2}{*}{ Vehicle } & \multirow{2}{*}{$\begin{array}{c}\text { Type of } \\
\text { vehicle }\end{array}$} & $\begin{array}{c}\text { Arrighi et al. } \\
\text { (2016) }\end{array}$ & $\begin{array}{c}\text { Martínez-Gomariz } \\
\text { et al. (2017) }\end{array}$ \\
\hline Mercedes G55 AMG & 4WD & & \\
\hline Mercedes GLA & Large Pass. & & - \\
\hline Mini Cooper & Small Pass. & & - \\
\hline Audi Q7 & 4WD & & \\
\hline Ford Focus & Large Pass. & & \\
\hline Totota Yaris & Small Pass. & & \\
\hline
\end{tabular}

Figure 2.2 Comparison of vehicle stability thresholds during floods proposed by stability models that consider car watertightness

The analysis of Figure 2.2 allows identifying how the studied stability models generate a wide range of stability thresholds, which are based on the decision criteria established in each case. For example, in the case of 4WD vehicles, with a flow velocity of $3.5 \mathrm{~m} / \mathrm{s}$, it can be observed that the stability models proposed by AR\&R (2011) and Smith et al. (2017) consider it is not safe to drive with any depth, while the models proposed by Moore and Power (2012) and Martínez-Gomariz et al. (2017) consider safe to drive with depths approximately equal to or less than 0.18 meters and Oshikawa and Komatsu (2014) establish this depth limit at 
approximately 0.45 meters. Variations of similar order of magnitude are observed for large and small passenger vehicles.

There are also differences in the shape of the safety thresholds provided by the different stability models, presenting different decreases in depth as flow velocity increases (Figure 2.2). Concerning high velocities, on the one hand, Arrighi et al. (2016a) do not establish a limit to flow velocity for the circulation of vehicles with depths lower than the chassis height. On the other hand, the stability models proposed by Martínez-Gomariz et al. (2017) and Moore and Power (2002) admit limits to flow velocity for low flow depths. The remaining models establish maximum velocities values between $3.0 \mathrm{~m} / \mathrm{s}$ and $5.0 \mathrm{~m} / \mathrm{s}$ to define the stability threshold.

From Figure 2.2, it can be underlined that the stability thresholds proposed by Moore and Power (2002) for velocities greater than $1.81 \mathrm{~m} / \mathrm{s}$, AR\&R (2011), Martínez-Gomariz et al. (2017) and Smith et al. (2017) for large 4WD vehicles are equal or quite similar to each other. The same similarity is observed among the stability models proposed by DIPNR (2005), Ausroads (2008) and Kramer et al. (2016), but for a different range of values.

\subsubsection{Assuming vehicle non-watertightness}

Figure 2.3 compares the results obtained when implementing the stability models that consider non-watertightness of the vehicles. Considering that the model proposed by Teo et al. (2012) establishes an instantaneous water entry into the vehicle, and in order to obtain comparable figures, this graph presents the values proposed by Oshikawa and Komatsu (2014) for an 4WD vehicle with porosity equal to 0.5 and the results obtained by Arrighi et al. (2016a) to a Mercedes G55 AMG car, which corresponds to a large 4WD vehicle. In the latter case, three scenarios were considered with different amounts of water entering the vehicle, increasing the weight of the car by 250,300 and $400 \%$. The increase in weight equal to $250 \%$ is approximately the same as the average increase considered in the experimental data of the 4WD car used by Teo et al. (2012).

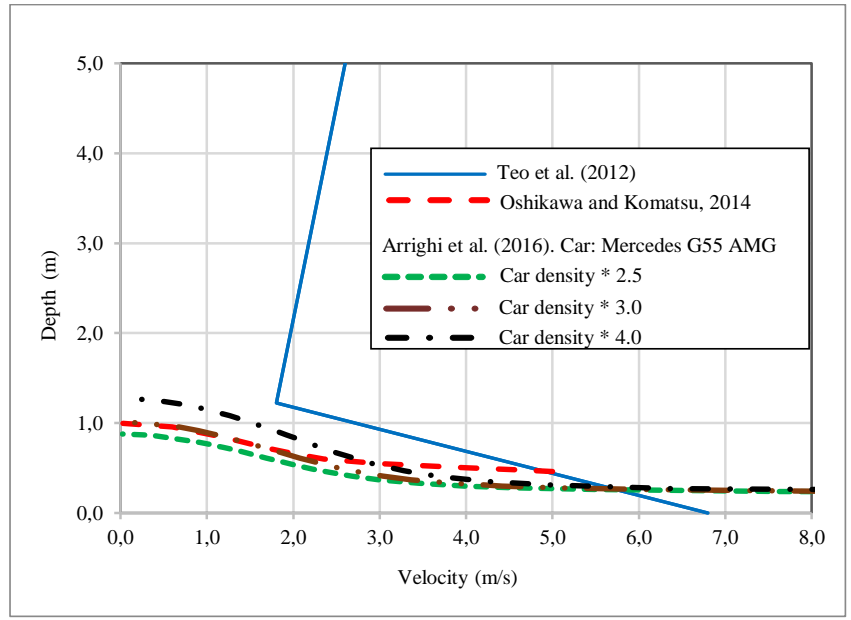

Note: The stability model of Arrighi et al. (2016a) was applied for a Mercedes G55 AMG car considering that the water volume getting inside the vehicle increases its density by a 250, 300 and $400 \%$

Figure 2.3 Comparison of vehicle stability thresholds during floods proposed by models that consider large 4WD vehicles and car non-watertightness 
The information shown in Figure 2.3 makes it possible to conclude that for low velocities the stability model proposed by Teo et al. (2012) establishes a stability threshold through the combination of flow velocities and depths that are considered unsafe or exceed several times the limit values proposed by the other stability models. In general, the stability thresholds proposed by Arrighi et al. (2016a) for a weight increase of 300\% and Oshikawa and Komatsu (2014) are quite similar to each other. For high velocities, Teo et al. (2012) consider that speeds higher than $6.8 \mathrm{~m} / \mathrm{s}$ are unsafe with any depth, while Arrighi et al. (2016a) do not set limits for low depths. The model proposed by Oshikawa and Komatsu (2014) only consider flow velocities lower than 5.0.

\subsection{Comparison of vehicle stability thresholds with experimental data}

The goal of this sub-section is to compare experimentally obtained data of depth and flow velocity in which the vehicles studied under watertight conditions lost their stability with the ranges of values in which the thresholds of the previous stability models fluctuate for the three types of vehicles defined by the AR\&R in 2011 (Figure 2.4). In the determination of these ranges, the stability model of Moore and Power (2002) was not considered because they used experimental and analytical data for old cars, which had different characteristics from modern ones.

\subsubsection{Experimental data}

The results for experimental data are condensed in Figure 2.4 as dots. In general, it is observed in all cases that, as expected, the depths found experimentally show a tendency to decrease as flow velocity increases. However, this tendency seems to differ between data obtained in different laboratory tests, since the decrease in depths related to the increase in velocities is bigger in some measurements than in others. For example, in the data measured for large vehicles 4WD by Smith et al. in 2017, there is a much more pronounced decrease in the depths causing vehicle destabilization than the decrease observed in the data recorded by Shu et al. in 2011. In other cases, the depths descend rapidly until a certain velocity is reached and from that point onwards, this decrease is less pronounced (measurements made by Martínez-Gomariz et al. in 2016 for large passenger vehicles), which contrasts with other measurements in which the decrease in depths seems to have a more uniform tendency for the range of studied velocities (for example, measurements made by Shu et al in 2011 for large passenger vehicles).

Figure 2.4 also shows that experimental data have a relatively high sample dispersion. For example, Martínez-Gomariz et al. (2017) found that the Mercedes GLA reached conditions of instability with a flow velocity of $1.98 \mathrm{~m} / \mathrm{s}$ and a depth of $0.30 \mathrm{~m}$, while in the study carried out by Shu et al. (2011) it was found that the Ford Focus vehicle, which can be classified in the same category that the Mercedes GLA but it should be less stable, lost its stability at the same depth when the velocity reached a value of $4.0 \mathrm{~m} / \mathrm{s}$, that is, at twice the velocity found for the Mercedes GLA.

The sample dispersion found in the trends followed by the consulted experimental data could be due, in part, to the differences in the flow conditions of the flumes and the quality and scales of the physical models used in the tests carried out. The used flumes width varied between 0.6 and $1.2 \mathrm{~m}$, which implies that the sidewalls could have exerted an effect not considered in the results in the case of the narrower ones. This is due to the fact that, when cars were oriented in the normal direction to the flow, the walls could have been too close to the front and rear car ends, affecting their behaviour. Additionally, the flume bottoms were constituted by different 
materials among which are acrylic, bakelite, cement and plastic; due to this, the friction coefficient between the car wheels and the bottom of the flumes fluctuated in relatively wide range (Table 2.1), which generates variations in the stability thresholds.

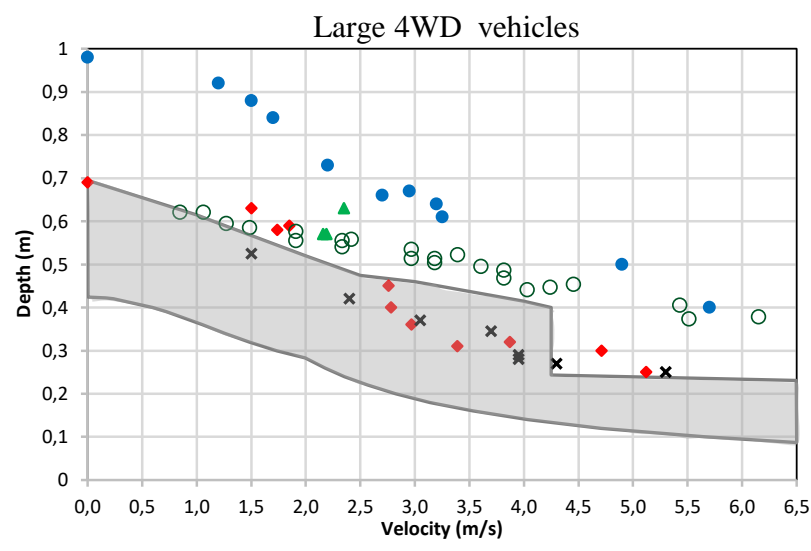

\begin{tabular}{|c|c|c|c|}
\hline \multicolumn{4}{|c|}{ Experimental Data } \\
\hline \multirow[b]{2}{*}{ Author } & \multicolumn{3}{|c|}{ Type of vehicle } \\
\hline & Large 4WD & Large passenger & $\begin{array}{c}\text { Small } \\
\text { passenger }\end{array}$ \\
\hline Shu et al. (2011) & O Volvo XC90 & $\begin{array}{l}\text { O Ford Transit } \\
\text { O Ford Focus }\end{array}$ & \\
\hline Toda et al. (2013) & $\Delta$ Minivan & $\Delta$ Sedan & \\
\hline Xia et al. (2013) & * Audi Q7 & * Honda Accord & \\
\hline $\begin{array}{l}\text { Martínez-Gomariz et } \\
\text { al. (2017) }\end{array}$ & $\diamond$ Mercedes G55 AMG & $\diamond$ Mercedes GLA & Mini Cooper \\
\hline Kramer et al. (2016) & & & * VW Golf III \\
\hline Smith et al. (2017) & - Nissan Pat. GRII & & - Toyota Yaris \\
\hline
\end{tabular}

Range in which the proposed stability thresholds fluctuate
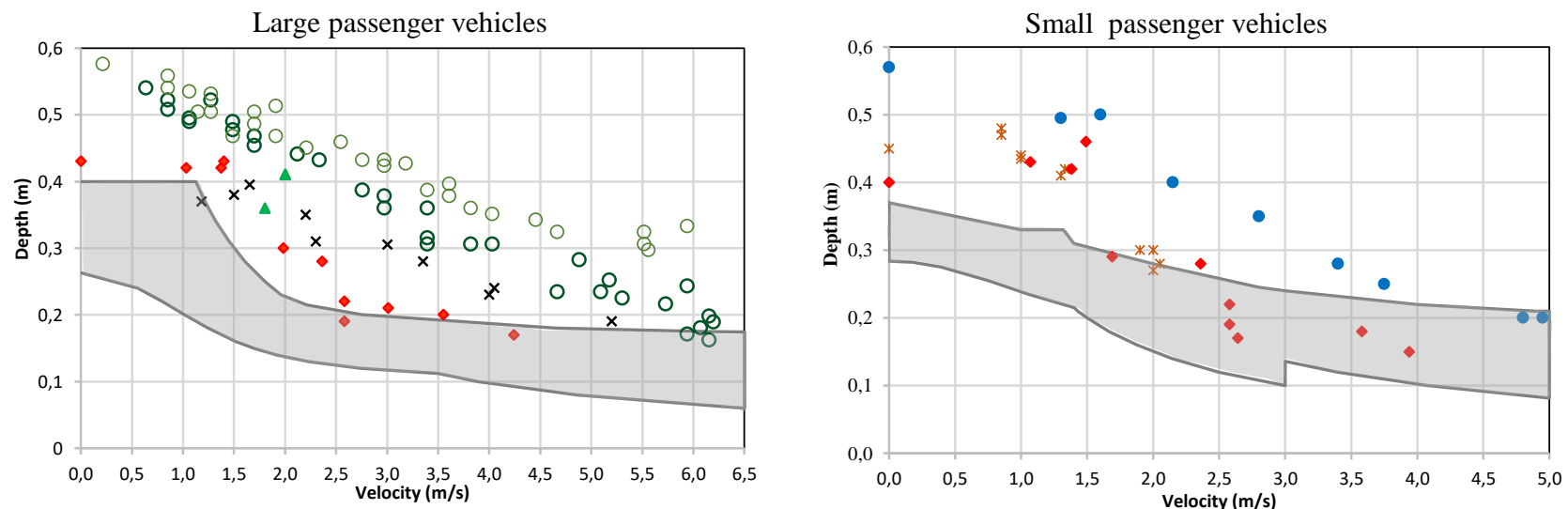

Figure 2.4 Comparison of proposed stability thresholds for vehicles under watertight conditions during floods with experimental data

On the other hand, scale models of different qualities have been used, such as: commercial plastic models, model produced by powder-based laser sintering, radio control models and diecast models. Not all of these models made an appropriate scaling of the geometric characteristics and the weight of the prototype vehicles, which could be one of the causes of the dispersion presented by the experimental results. In addition, the scales of the physical models used fluctuated between 1:9.8 and 1:24 (Table 2.1), which represents a relatively wide range and could generate important differences in the uncompensated scale effects that occur when working with this type of models.

In all cases, the depths measured in the laboratory that generated vehicle stability loss were greater than the free height between the floor and the chassis. This could suggest that, as considered by the stability model proposed by Arrighi et al. (2016a), water depths lower than chassis height would not destabilize the vehicles within the studied velocity range, which corresponds approximately to the expected range in real situations.

\subsubsection{Comparison between experimental data and stability models}

For low flow velocities most of the stability models (grey area) seem to be too conservative, as the proposed thresholds are relatively far from the experimental measurements (Figure 2.4). 
For medium and high velocities, some of the experimental results start to fall within the range of the proposed stability thresholds, especially for small cars. This situation could suggest that some of the studied stability models, such as those of Oshikawa and Komatsu (2014) and Moore and Power (2012) for large and small passenger cars (as can be seen in previous Figure 2.3), propose combinations of flow velocity and depth that would not guarantee vehicle stability during flood events. For high velocities some of the stability models seem too conservative. For example, for reasons of passenger safety when leaving vehicles, the model of the AR\&R (2011) considers it unsafe to circulate at any depth when the velocities are higher than $3.0 \mathrm{~m} / \mathrm{s}$ (Not represented in Figure 2.4) and the model of Martínez-Gomariz et al. (2017) admits stable depths that can be considered too low when compared with the experimental ones.

On the other hand, the stability models proposed by DIPNR (2005), Austroads (2008) and Kramer et al. (2016) (Figure 2.1b) seem to be somewhat conservative for large passenger cars and very conservative for 4WD vehicles, since the data found experimentally (Figure 2.4) are quite different from the stability thresholds proposed by these models. In the case of the stability model proposed by Kramer et al. (2016), this could be due to the fact that the stability threshold was determined from the analysis of experimental results obtained for one single small passenger vehicle.

\subsection{Final Remarks}

The available stability models have made simplifications that could affect the results achieved. Some of the main simplifications are the following:

- Only cars at rest have been considered.

- Most of the experiments have been carried out on a horizontal surface.

- The friction coefficient between the tyres and the road has not been studied in depth, especially when considering it can vary during flood events.

- The actual weight distribution of the vehicles (with greater weight in the front part due to the location of the engine) has not been considered in several of the developed studies.

- The tests have been conducted using a controlled flow. This is not representative of reallife flow conditions, which could be, for example, variable or pulsating.

- Measurements have been made in laboratory flumes, whose characteristics can vary significantly from the conditions of the actual roads.

- Most of the experimental studies have been carried out with scale physical models, implying that some forces acting on the vehicles may not have been well represented due to scale effects.

- With the exception of the study developed by Martínez-Gomariz et al. (2017), experimental tests have made measurements on very few cars, which were not always the most vulnerable ones to flooding for each vehicle category.

Some of these simplifications are too restrictive so the experimental tests performed could have produced results that are not sufficiently representative of the stability of vehicles against floods.

With regard to the theoretical approach of the studied stability models, it should be noted that the model developed by Arrighi et al. (2016a) combines several aspects that can make it one of the most robust. Among these aspects, it is worth highlighting that the equations proposed are based on a solid theoretical base and that include the use of Froude number, which is a very important and widely used parameter in many formulations. In addition, this methodology 
allows to consider simultaneously watertightness and non-watertightness conditions of the vehicles and enables the calculation of a stability threshold for any vehicle considering key factors as ground clearance and car density. Due to these reasons, in this methodology the model developed by Arrighi was chosen to determine the stability of vehicles during floods. 
Table 2.1 Studied models for the determination of vehicle stability

\begin{tabular}{|c|c|c|c|c|c|c|c|c|c|c|c|}
\hline \begin{tabular}{|c|} 
Water- \\
tightness of \\
vehicles
\end{tabular} & Author & Year & Used data & $\begin{array}{c}\text { Scale } \\
\text { physical } \\
\text { models }\end{array}$ & $\begin{array}{l}\text { Velo- } \\
\text { city } \\
(\mathbf{m} / \mathbf{s})\end{array}$ & $\begin{array}{l}\text { Depth } \\
(\mathbf{m})\end{array}$ & $\begin{array}{c}\text { Froude } \\
\text { Number }\end{array}$ & $\begin{array}{c}\text { Friction } \\
\text { Coeffic. } \\
\mu\end{array}$ & $\begin{array}{l}\text { Drag. } \\
\text { Coeffic. }\end{array}$ & $\begin{array}{c}\text { Angle of } \\
\text { flow } \\
\beta^{(1)}\end{array}$ & Stability Equation (2) \\
\hline \begin{tabular}{l|}
$\begin{array}{l}\text { Non-water- } \\
\text { tightness }\end{array}$ \\
\end{tabular} & Teo et al. & 2012 & $\begin{array}{l}\text { Measurements on Mini Cooper, BMW M5, Mitsubishi } \\
\text { Pajero }\end{array}$ & \begin{tabular}{|l|}
$1: 43$ \\
$1: 18$ \\
\end{tabular} & $\begin{array}{l}2.37- \\
7.94 \\
\end{array}$ & $\begin{array}{c}0.65- \\
4.82 \\
\end{array}$ & $\begin{array}{c}0.50- \\
3.16 \\
\end{array}$ & - & - & $90^{\circ}-180^{\circ}$ & Linear relationship between $\mathrm{H}$ and $\mathrm{V}$ \\
\hline \multirow{7}{*}{$\begin{array}{l}\text { Water- } \\
\text { tightness }\end{array}$} & $\begin{array}{l}\text { Moore and } \\
\text { Power }\end{array}$ & 2002 & $\begin{array}{l}\text { Measurements reported by Bonham and Hettersley (1967), } \\
\text { Gordon and Stone (1973) and Keller and Mitsch }(1993)^{(3)}\end{array}$ & $\begin{array}{l}1: 16 \\
1: 25 \\
\end{array}$ & $\begin{array}{c}0.48- \\
3.69 \\
\end{array}$ & $\begin{array}{c}0.025- \\
0.57\end{array}$ & - & $0.3-1.0$ & - & $0^{\circ}, 90^{\circ}$ & $\begin{array}{c}\mathrm{H} \leq(0,4-0,0376 \mathrm{~V}) \text { for } \mathrm{V} \leq 1,81 \\
\mathrm{H}^{*} \mathrm{~V} \leq 0,6 \text { for } \mathrm{V}>1,81\end{array}$ \\
\hline & \begin{tabular}{|l|} 
DIPNR \\
\end{tabular} & 2005 & Analysis of laboratory tests not specified & - & - & - & - & - & - & - & $\mathrm{V}<-11 * \mathrm{H}+3,3 \mathrm{~V} \leq 2,0$ \\
\hline & AR\&R & 2011 & $\begin{array}{l}\text { Measurements reported by Bonham and Hettersley (1967), } \\
\text { Gordon and Stone (1973) and Keller and Mitsch }(1993)^{(3)}\end{array}$ & $\begin{array}{l}1: 16 \\
1: 25\end{array}$ & $\begin{array}{c}0.48- \\
3.69\end{array}$ & $\begin{array}{c}0.025- \\
0.57\end{array}$ & - & $\begin{array}{c}0.3- \\
1.0\end{array}$ & - & $0^{\circ}, 90^{\circ}$ & $\begin{array}{lll}\text { Small cars: } H^{*} \mathrm{~V} \leq 0,3 & \mathrm{H} \leq 0,3 & \mathrm{~V} \leq 3,0 \\
\text { Large cars: } \mathrm{H}^{*} \mathrm{~V} \leq 0,45 & \mathrm{H} \leq 0,4 & \mathrm{~V} \leq 3,0 \\
\text { 4WD cars: } \mathrm{H}^{*} \mathrm{~V} \leq 0,6 & \mathrm{H} \leq 0,5 & \mathrm{~V} \leq 3,0\end{array}$ \\
\hline & Smith et al. & 2014 & $\begin{array}{l}\text { Analysis of stability thresholds reported by AR\&R in } 2011 \\
\text { for vehicles and in } 2010 \text { for people }\end{array}$ & - & - & - & - & - & - & - & $\begin{array}{lll}\text { Small cars: } \mathrm{H}^{*} \mathrm{~V} \leq 0,3 & \mathrm{H} \leq 0,3 & \mathrm{~V} \leq 2,0 \\
\text { Others cars: } \mathrm{H}^{*} \mathrm{~V} \leq 0,6 & \mathrm{H} \leq 0,5 & \mathrm{~V} \leq 2,0\end{array}$ \\
\hline & Kramer et al. & 2016 & Measurements made on a VW Golf III and a LF 10/6 & $\begin{array}{c}1: 1 \\
1: 9.8 \\
1: 13.1\end{array}$ & $0-$ & $\begin{array}{c}0- \\
0.73\end{array}$ & $0-1.5$ & 0.3 & - & $\begin{array}{l}0^{\circ}, 45^{\circ}, \\
\quad 90^{\circ}\end{array}$ & $\begin{array}{l}\text { Passengers cars: } \mathrm{H}+\mathrm{V}^{2} / 2 \mathrm{~g} \leq 0,3 \\
\text { Emergency cars: } \mathrm{H}+\mathrm{V}^{2} / 2 \mathrm{~g} \leq 0,6\end{array}$ \\
\hline & Smith et al. & 2017 & $\begin{array}{l}\text { Measurements on a Toyota Yaris } 2005 \text { and } 2006 \text { and a } \\
\text { Nissan Patrol } 1998\end{array}$ & $\begin{array}{l}1: 1 \\
1: 18 \\
\end{array}$ & $\begin{array}{c}0.80- \\
6.56\end{array}$ & $\begin{array}{c}0- \\
0.828 \\
\end{array}$ & $\begin{array}{c}0.30- \\
6.63 \\
\end{array}$ & $\begin{array}{c}0.75- \\
0.78\end{array}$ & $\begin{array}{c}0.98- \\
2.02 \\
\end{array}$ & $90^{\circ}$ & $\begin{array}{lll}\text { Small cars: } H^{*} \mathrm{~V} \leq 0,3 & \mathrm{H} \leq 0,3 & \mathrm{~V} \leq 3,0 \\
\text { 4WD cars: } \mathrm{H}^{*} \mathrm{~V} \leq 0,6 & \mathrm{H} \leq 0,5 & \mathrm{~V} \leq 3,0 \\
\end{array}$ \\
\hline & $\begin{array}{l}\text { Martínez- } \\
\text { Gomariz et } \\
\text { al. }\end{array}$ & 2017 & $\begin{array}{l}\text { Measurements made on BMW 650, Mini Cooper, BMW } \\
\text { i3, Mercedes GLA, Mercedes Class C, Range Rover } \\
\text { Evoque, Porsche Cayenne Turbo, Bentley Continental GT, } \\
\text { Volkswagen Touareg, BMW X6, Audi Q7, Mercedes G55 } \\
\text { AMG }\end{array}$ & $\begin{array}{l}1: 14 \\
1: 18 \\
1: 24\end{array}$ & $\begin{array}{r}0.89 \\
5.12\end{array}$ & $0.16-$ & - & $\begin{array}{c}0.25- \\
0.75\end{array}$ & - & \begin{tabular}{|l|} 
All \\
orientations \\
were \\
considered
\end{tabular} & $\begin{array}{c}H * V=0,0158 * \frac{G_{c} * M_{c}}{P A} * \mu+0,32 \\
H<h_{b}=\frac{M_{c}}{\rho * L * l}+G_{c}\end{array}$ \\
\hline \multirow{3}{*}{$\begin{array}{l}\text { Water- } \\
\text { tightness/ } \\
\text { Non- Water- } \\
\text { tightness }\end{array}$} & Toda et al. & 2013 & $\begin{array}{l}\text { Measurements made with a sedan-type vehicle and a } \\
\text { minivan (ambulance) }\end{array}$ & $\begin{array}{l}1: 10 \\
1: 18 \\
\end{array}$ & $\begin{array}{c}1.05- \\
2.00\end{array}$ & $\begin{array}{c}0.30- \\
1.21\end{array}$ & - & $\begin{array}{c}0.26- \\
0.65 \\
\end{array}$ & $\begin{array}{c}0.40- \\
3.50 \\
\end{array}$ & $\begin{array}{l}0^{\circ}, 45^{\circ} \\
90^{\circ}\end{array}$ & $\mathrm{V} \leq 2,0$ and $\mathrm{H} \leq 0,5$ \\
\hline & $\begin{array}{l}\text { Oshikawa } \\
\text { and Komatsu }\end{array}$ & 2014 & $\begin{array}{l}\text { Measurements made on a Nissan March and a Toyota } \\
\text { Land Cruiser }\end{array}$ & $1: 24$ & $\begin{array}{c}1.47- \\
7.35\end{array}$ & $\begin{array}{c}0.24- \\
1.08\end{array}$ & $\begin{array}{c}0.90- \\
2.77\end{array}$ & $\begin{array}{c}0.40- \\
0.60\end{array}$ & $\begin{array}{l}0.75- \\
5.1\end{array}$ & $90^{\circ}$ & Non-linear relationship between $\mathrm{H}$ and $\mathrm{V}$ \\
\hline & Arrighi et al. & 2016 & $\begin{array}{l}\text { Measurements reported by Shu et al. (2011), Xia et al. } \\
\text { (2011) and Xia et al. (2014) }\end{array}$ & $\begin{array}{l}1: 14 \\
1: 18 \\
1: 43\end{array}$ & $\begin{array}{r}0.18- \\
7.94\end{array}$ & $\begin{array}{r}0.11- \\
4.82\end{array}$ & $\begin{array}{l}0.50- \\
3.16^{(4)}\end{array}$ & $\begin{array}{c}0.25- \\
0.75\end{array}$ & - & $\begin{array}{c}0^{\circ}, 90^{\circ} \\
180^{\circ}\end{array}$ & $\begin{array}{c}0 \leq \theta_{V c r} / \theta_{V}<1 \\
\theta_{v c r}=8,2 * F r^{2}-14,1 * F r+5,4 \\
\theta_{v}=\frac{2 L}{\left(H_{v}-h_{c}\right)} * \frac{l}{l * \operatorname{Cos} \beta+L * \sin \beta} \\
*\left(\frac{\rho_{c} *\left(H_{v}-h_{c}\right)}{\rho *\left(H-h_{c}\right)}-1\right)\end{array}$ \\
\hline
\end{tabular}

(1) $\beta=$ angle of incidence of the flow with respect to the vehicle: $0^{\circ}=$ Vehicle oriented in the direction of flow and with the front facing the flow; $90^{\circ}=$ Vehicle oriented in the direction perpendicular to the flow; $180^{\circ}=$ Vehicle oriented in the direction of flow and with the rear facing the flow
(2) $\mathrm{H}=$ Depth (m)
$\mathrm{V}$ = Flow velocity $(\mathrm{m} / \mathrm{s})$
$\mathrm{Gc}=$ Ground clearance $(\mathrm{m})$
$\mathrm{Mc}=$ Weight $(\mathrm{kg})$
PA $=$ Plan Area $\left(\mathrm{m}^{2}\right)$
$\mu=$ Friction Coefficient
$\rho=$ Water density $\left(\mathrm{kg} / \mathrm{m}^{3}\right)$
$\mathrm{L}=$ Length of the vehicle $(\mathrm{m})$
1 = Width of the vehicle $(\mathrm{m})$
$\theta_{\text {vcr }}=$ Critical threshold
$\theta_{\mathrm{v}}=$ Mobility parameter
$\mathrm{Fr}=$ Froude Number
$\mathrm{Hv}=$ Height of the vehicle (m)
$\mathrm{hc}=$ Height of the planform $(\mathrm{m})$
$\rho c=$ Car density $\left(\mathrm{kg} / \mathrm{m}^{3}\right)$

(4) Only reported by Xia (2011) 



\section{ASSESSING THE RISK OF VEHICLE INSTABILITY DUE TO FLOODING}

\subsection{Introduction}

When rivers overflow, transport systems can be badly affected as traffic is interrupted, given the instability risk for those vehicles driving around or parked on floodplains (Teo et al., 2012). Most published studies about this vehicles instability risk have focused on determining the hazard or vulnerability of roads due to floods using the characteristics of basins and road networks. Some include the method of flood hazard maps proposed by Kalantari et al. (2014). This method allows the probability of flood hazards to be calculated by a multiple factor analysis, which considers topography, land use, soil texture and roadway density. Michielsen et al. (2016) proposed a methodology for identifying vulnerability caused by the flooding of a transport network based on the analysis of basin characteristics using statistical methods. Versini et al. (2010) presented a method to evaluate the susceptibility of roads being flooded using geographic information and statistical analysis methods based on general discriminant analysis principles.

Of the few studies that have attempted to really assess the flooding risk, we found the method set forward by Yin et al. (2016) to establish the risk of flash-floods on an urban roadway network. In this methodology, risk is determined through the integral of the multiplication of flood occurrence probabilities and their corresponding consequences, established with the combination of flooded road length and the time during which roads remain flooded. Pregnolato et al. (2017) developed a method to determine the impact of flooding on a transport network by means of a function relating flood depth to interrupted traffic. This study establishes the interruption risk by means of the integral of the result of each rain event probability, multiplied by the expected interruption of traffic.

This chapter presents a methodology that determines the vehicle instability risk in urban areas as a result of overflowing rivers with a formal statistical basis that allows the number of at-risk vehicles per year to be determined. Bearing this objective in mind, the mechanisms that cause a submerged vehicle to lose its stability are initially described. It then goes on to describe the methodology followed by indicating the process to be used to calculate hazard, vulnerability and the vehicle instability risk. Finally, it also presents how this methodology is implemented to determine the vehicle instability risk in the flood-prone areas of the towns of Massanassa and Alfafar, which lie south of Valencia (Spain) and very close to the Spanish Mediterranean coastline.

\subsection{Vehicle stability in flooded areas}

To calculate vehicle instability conditions, a criterion needs to be defined to establish when the depth and velocity of flows corresponding to different return periods floods generate vehicle instability, which also depends on the characteristics of each vehicle type.

As already noted in the previous chapter, some models have been recently developed to determine vehicle stability during floods based on the vehicle-flow interaction analysis 
(e.g., Teo et al., 2012; Austroads et al., 2008; etc.). A compilation and analysis of the presently available methodologies were presented by Bocanegra et al. (2020). Of these methodologies, the present study selected the model proposed by Arrighi et al. (2016) as it is considered one of the most robust methodologies of those proposed.

From the horizontal forces balance acting on car $i$ located on a plane at a slope of zero, and based on the diagram provided in Figure 3.1, Arrighi et al. (2016) defined the following mobility parameter $\theta_{v i}$ :

$$
\theta_{v_{i}}=\frac{2 L}{\left(H_{v}-h_{c}\right)} * \frac{l}{l * \operatorname{Cos} \beta+L * \sin \beta} *\left(\frac{\rho_{c} *\left(H_{v}-h_{c}\right)}{\rho *\left(H-h_{c}\right)}-1\right)
$$

where $\rho_{c}$ is the car's mean density, $\rho$ is water density, $h_{c}$ is the distance between the chassis and the ground, $\mathrm{H}$ is the undisturbed water depth, $\beta$ is the angle of flow incidence, and $\mathrm{H}_{\mathrm{v}}, \mathrm{L}$ and $\mathrm{l}$ are car height, car length and car width, respectively.

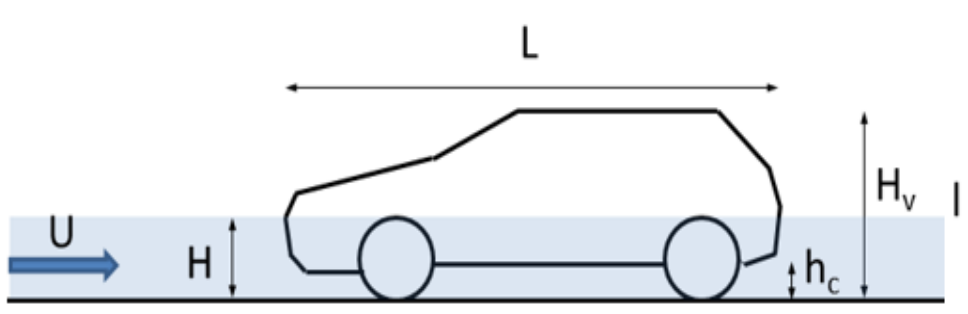

Figure 3.1 Geometry of the car used to determine mobility parameter $\theta \mathrm{v}$. Source: Arrighi et al. (2016)

Mobility parameter $\theta_{v i}$ is defined for water depths greater than the chassis and is made up of three factors: the first factor $\left(2 \mathrm{~L} /\left(\mathrm{H}_{\mathrm{v}}-\mathrm{h}_{\mathrm{c}}\right)\right)$ takes account of the car's shape; the second considers the angle of flow incidence; the third factor contemplates the submerged weight in relation to the car.

Mobility parameter $\theta_{v i}$ was calculated by Arrighi et al. (2016) with the experimental data reported by Shu et al. (2011) and Xia et al. (2011, 2014), which included several measures taken in seven car models on scales 1:14, 1:18 and 1:43 (Figure 3.2). The obtained results allowed critical mobility parameter $\theta_{v c r}$ to be obtained, which can be established by the equation below:

$$
\theta_{V c r}=8.2 F r^{2}-14.1 F r+5.4
$$

where $F r$ is the Froude number, which requires data only about water depth $H$ and velocity $U$. So a vehicle instability index, $S_{i}$, can be defined as the relation between critical mobility parameter $\theta_{v c r}$ defined in Equation 3.2 and mobility parameter $\theta_{v}$ for this vehicle defined by Equation 3.1:

$$
S_{i}=\frac{\theta_{V c r}}{\theta_{V_{i}}}
$$


The interesting point about this index is that the different vehicle stability or instability situations can be found depending on the value that it takes: if $S_{i} \geq 1$, then the vehicle will destabilize due to sliding; if $S_{i}<0$, the vehicle will float; if $0 \leq S_{i}<1$, the vehicle will remain stable.

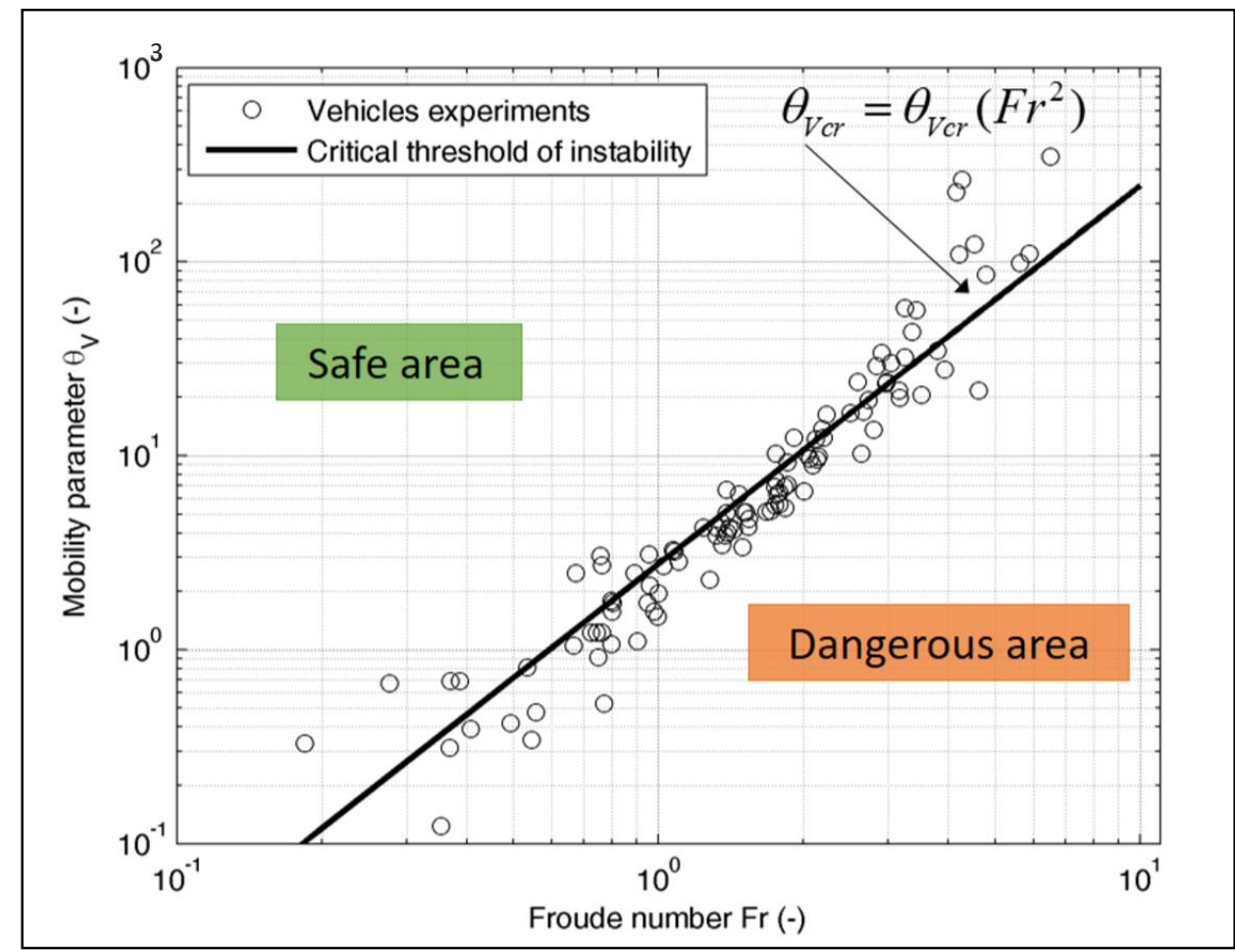

Figure 3.2 Diagram of the mobility parameter $\theta \mathrm{v}$ vs Froude number. Source: Arrighi et al.

\subsection{Methodology to estimate the vehicle instability risk using formal statistics}

The vehicle instability risk from flooding is determined by integrating the probability of the vehicle being dragged or it floating (hazard) and the types and density of vehicles located in flood-prone areas (vulnerability) at a given point of the territory (exposure). In this methodology, instability risk, $R$, at a specific point is defined as the mean number of vehicles that would destabilize annually per unit area. According to the Equation 1.2, this risk can be calculated at a given point on the territory by employing the following statistical integral adapted to this problem:

$$
R=\int_{0}^{1} V\left(s_{i}\right) d F_{s_{i}}=\int_{0}^{\infty} V\left(s_{i}\right) f_{s_{i}}\left(s_{i}\right) d s_{i}
$$

where $\mathrm{V}\left(\mathrm{s}_{i}\right)$ is vulnerability, calculated by combining the damage function and exposure to an event of magnitude $S_{i} ; F_{S i}$ is the accumulated distribution function of $S_{i} ; f_{S i}$ is the density function of probability. The following subsections describe the procedure that must be set up to calculate the risk and all its components. 


\subsubsection{Vehicle instability hazard}

To calculate the vehicle instability hazard, information is required about the flooding hazard (intensity of floods corresponding to different return periods), along with vehicles' physical characteristics. The stream intensity is usually established with maximum flow water depth and its corresponding velocity. A similar graph to that in panel A of Figure 3.3 was obtained when graphically representing the occurrence of each flood event against its intensity.

The hazard flood is normally represented on maps with its maximum water depth $h$ and its velocity $u$ for different return periods. With the information depicted on these maps, instability index $S_{i}$ is calculated for every vehicle $i$ on each point of the territory using Equation 3.3. When graphically representing the intensity of each flood event against its corresponding $S_{i}$, a similar graph to that shown in panel B of Figure 3.3 is obtained. Finally, the graphical representation of the exceedance probability of all flood events against their corresponding $S_{i}$ provides a similar figure to that seen in panel C in Figure 3.3, which depicts the vehicle instability hazard. In other words, the vehicle instability hazard can be represented on vehicle instability index $S_{i}$ maps for each return period.

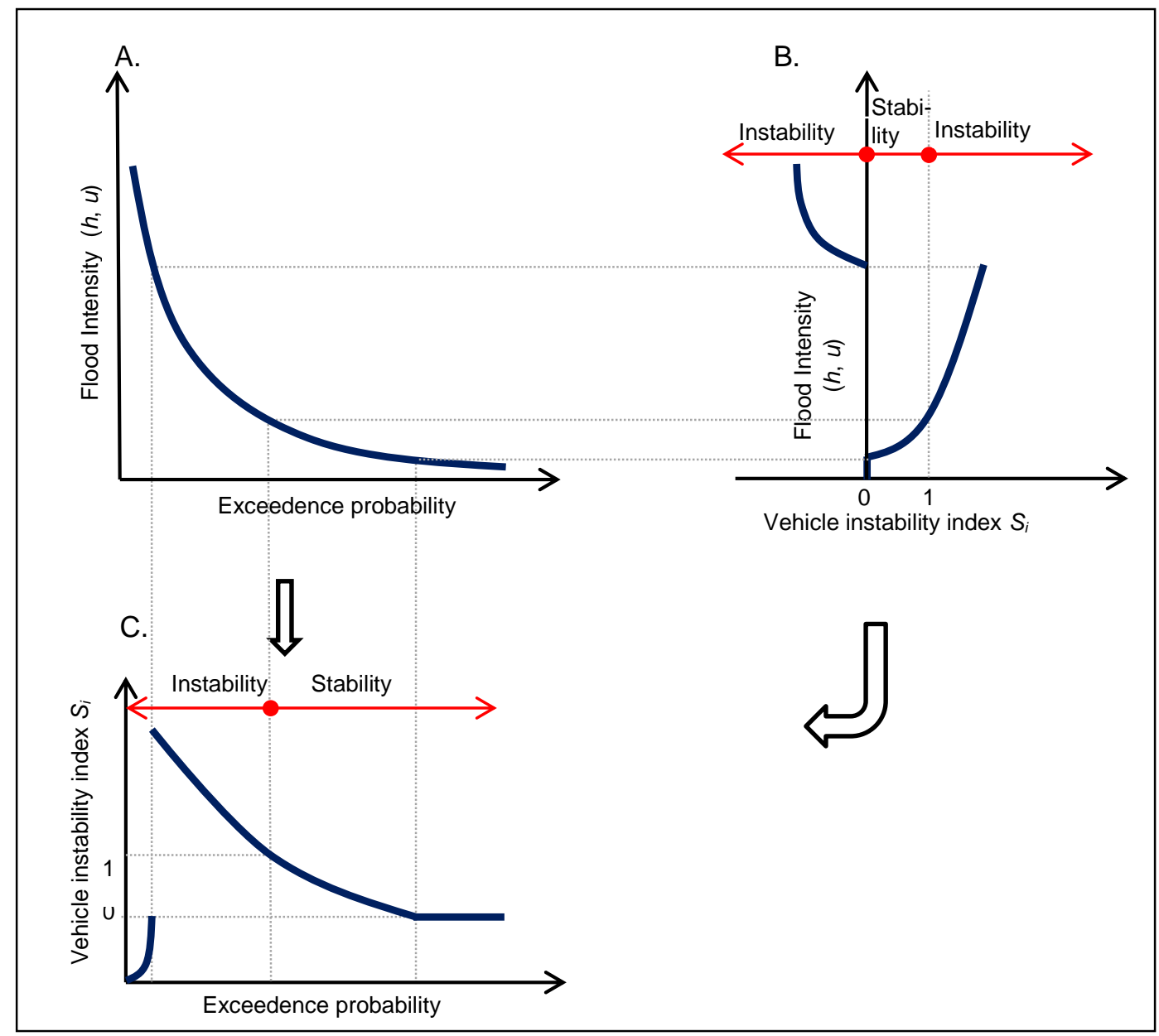

Figure 3.3 Diagram illustrating the process that must be implemented to calculate the instability hazard in one vehicle $i$ 


\subsubsection{Vulnerability}

Vulnerability represents the characteristics of a system that describes its damage potential (Messner and Meyer, 2006; Samuels et al., 2009; UNISDR, 2009), which is calculated by combining exposure and susceptibility. Exposure for one vehicle type $i$ is calculated by multiplying vehicle density $d$ at a point of interest by the proportion $g_{i}$ of this type of vehicle in a vehicles fleet in the study area. In order to calculate the flood susceptibility of one vehicle $i$ at a given point, damage function $D\left(s_{i}\right)$ must be established using vehicle instability index $S_{i}$. The present methodology assumes that damage is directly associated with vehicle stability, and in such a way that when it is unstable, i.e., when vehicle instability index $S_{i}$ calculated using Equation 3.3 takes negative values, or values equalling or exceeding 1, the damage function takes a value of 1 , which means that $100 \%$ damage has taken place. When the vehicle remains stable, i.e. when the instability index takes positive values below 1 , the damage function takes a value of 0 , which means that the vehicle is not damaged. In mathematical terms, the damage function is defined as follows:

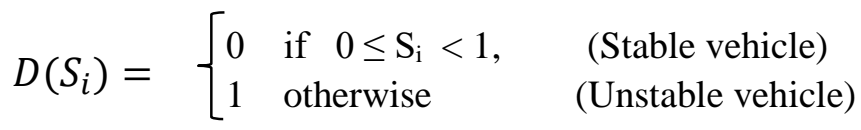

Finally, the vulnerability $V\left(S_{i}\right)$ of one vehicle $i$ at a given point of interest is calculated by this equation:

$$
V\left(s_{i}\right)=d g_{i} D\left(s_{i}\right)
$$

\subsubsection{Vehicle Instability Risk}

The instability risk is determined by Equation 3.4. When substituting Equation 3.6 in Equation 3.4, and bearing in mind the different vehicle types, the following expression is obtained:

$$
R=\sum_{i=1}^{K} d g_{i} \int_{0}^{1} D\left(s_{i}\right) d F_{S_{i}}=\sum_{i=1}^{K} d g_{i} \int_{0}^{\infty} D\left(s_{i}\right) f_{S_{i}}(s) d s
$$

where $K$ corresponds to the number of vehicle types by means of which the whole fleet is represented.

Figure 3.4 presents a diagram of the procedure that must be followed to calculate the instability risk of a vehicle type $i$ at a point on the territory. Panel A corresponds to the instability hazard, which is calculated as described in Figure 3.3. Panel B presents the damage function, which is calculated as indicated in Equation 3.5. When the instability hazard is combined with damage function $D\left(s_{i}\right)$, each probability of a flood event happening takes a certain damage function value. When graphically representing the probability of each flood event against the corresponding damage function values, a similar graph to that found in panel $\mathrm{C}$ is obtained, and the instability risk for a vehicle type $i$ at a point on the territory corresponds to the area under this curve. 


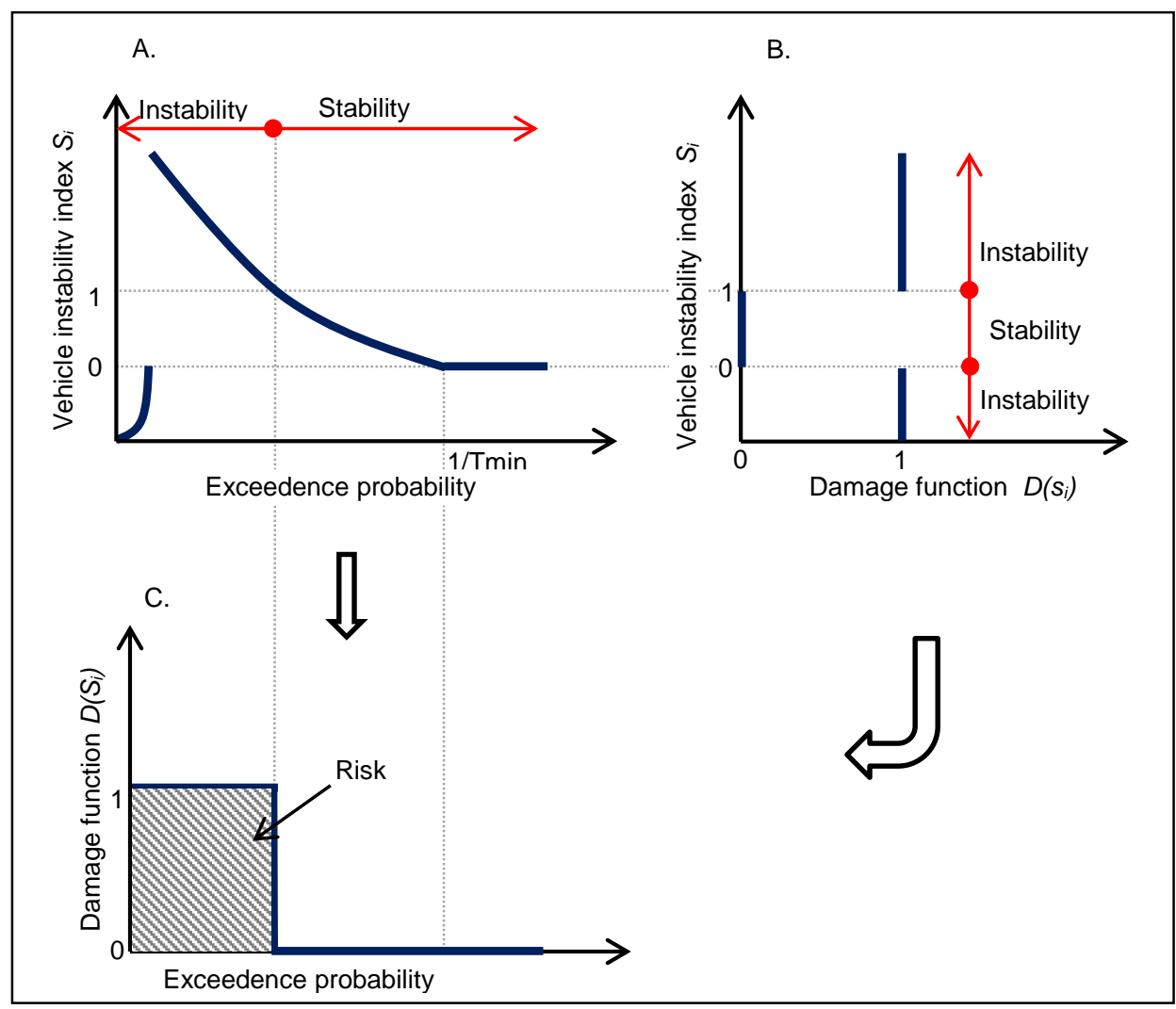

Figure 3.4 Diagram of the instability risk of a single vehicle type $i$

As previously mentioned, vehicle instability hazard is represented on vehicle instability index $S_{i}$ maps and each $S_{i}$ has a corresponding damage function $D\left(s_{i}\right)$ value. Considering this, the value of this function between two flood events with return periods $T_{j}$ and $T_{j-1}$, respectively, is obtained by defining a new function known as $D\left(S_{i, j}\right)$, which is calculated by averaging the damage function $D\left(S_{i}\right)$ values corresponding to the two superior and inferior events in terms of T. Taking into account this, the following expression is obtained when discretely solving Equation 3.7:

$$
R=\sum_{i=1}^{K} d g_{i} \sum_{j=T \text { min }}^{N} \bar{D}\left(s_{i, j}\right)\left(\frac{1}{T_{j-1}}-\frac{1}{T_{j}}\right)
$$

where $j$ corresponds to the flood hazard map for return period $T_{j}$ and $T_{\min }$ corresponds to the shortest return period from which flooding commenced.

The concept of $T_{\min }$ is introduced into Equation 3.8. Seeing that flood events with a relatively low return period have a much stronger effect on the final risk values than the less frequent events, determining the value of the return period $T_{\min }$ is particularly important because any mistakes or inaccuracies in this value might involve over- or underestimating the risk. The impact of $T_{\min }$ on the risk values is illustrated in the sensitivity analysis of the case study in the next section (Subsection 3.4.7). 


\subsection{Applying a case study}

In order to verify the procedure's applicability to a real case, to analyze the validity of the obtained results and to determine their sensitivity to $T_{\min }$, the developed methodology was implemented to establish the vehicle instability risk in the Spanish towns of Massanassa and Alfafar, which are located in the flood extent of Rambla del Poyo.

\subsubsection{Description of the study area}

La Rambla del Poyo is an intermittent watercourse located in the province of Valencia (east Spain). It flows into the coastal L'Albufera lagoon, and its water basin covers 430 $\mathrm{km}^{2}$ (Figure 3.5). This basin is classified as a Mediterranean basin with a semiarid climate, mean annual rainfall of 450-500 $\mathrm{mm}$, intense autumn and spring rainfall, and low winter and summer rainfall values. The basin's slope ranges between values over $16 \%$ in the high part and below $2 \%$ in the low part. The configuration of the network of riverbeds favours the rapid concentration of flows at the head, followed by retarded flows in the main watercourse. The ravine is characterized by flash floods with very marked hydrogram peaks and short baseline times (Salazar et al., 2012).

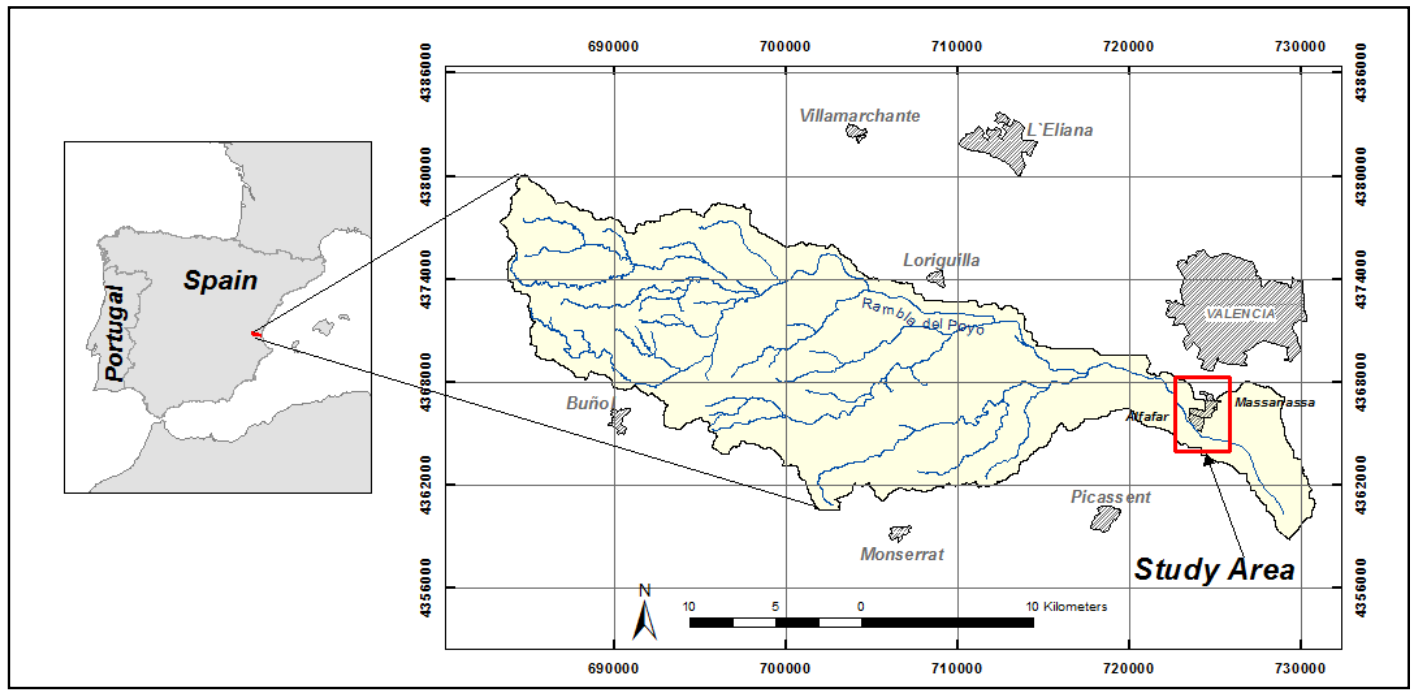

Figure 3.5 Location of the Rambla del Poyo basin and the study area

Some of the towns affected by flooding are located halfway and in low parts of the basin. They include the towns of Massanassa and Alfafar, which lie in the lower basin part where less pronounced slopes predominate. In these towns, land use is residential. Shops and services occupy ground floors, especially in the areas close to their town squares.

\subsubsection{Characterization and exposure of the vehicles in the study area}

The way the vehicles are distributed in the study area was established with the data published in 2018 by the Spanish Association of Manufacturers of Automobiles and Lorries (ANFAC, 2018): 
1. Smaller cars, with $26 \%$ of the total. This vehicle type was represented by the car model Seat Ibiza.

2. Compact vehicles, with $32 \%$ of the total. This vehicle type was represented by the car model Seat León.

3. Small SUVs, with $15 \%$ of the total. This vehicle type was represented by the car model Peugeot 2008.

4. Medium-sized SUVs and larger vehicles, with $27 \%$ of the total. This vehicle type was represented by the car model Volkswagen Tiguan.

Table 3.1 presents the main characteristics of these vehicles.

According to Francés et al. (2008), and by considering both parked vehicles and moving traffic, the vehicle density in the study area is 0.005446 vehicle $\mathrm{s} / \mathrm{m}^{2}$ of the land in urban non-built up areas, and 0.0313 vehicles $/ \mathrm{m}^{2}$ of the street in urban built up areas. The higher vehicle density in streets is explained by the fact that most of the cars in these two towns are parked in streets.

Table 3.1 Characteristics of the vehicles in the study area

\begin{tabular}{|l|c|c|c|c|}
\hline \multirow{2}{*}{ Characteristic } & \multicolumn{4}{|c|}{ Type of Vehicle i } \\
\cline { 2 - 5 } & Smaller cars & $\begin{array}{c}\text { Compact } \\
\text { Vehicles }\end{array}$ & Small SUVs & $\begin{array}{c}\text { Medium-sized } \\
\text { SUVs and larger } \\
\text { vehicles } \\
\text { Volksw. Tiguan }\end{array}$ \\
\hline Length $(\mathrm{m})$ & 3.68 & 4.18 & 4.16 & 4.43 \\
\hline Width $(\mathrm{m})$ & 1.61 & 1.74 & 1.74 & 1.81 \\
\hline Height $(\mathrm{m})$ & 1.42 & 1.44 & 1.56 & 1.67 \\
\hline $\begin{array}{l}\text { Clear distance from } \\
\text { ground }(\mathrm{m})\end{array}$ & 0.12 & 0.12 & 0.17 & 0.18 \\
\hline Density $\left(\mathrm{kg} / \mathrm{m}^{3}\right)$ & 108.00 & 125.86 & 104.41 & 115.26 \\
\hline Proportion $\mathrm{g}_{\mathrm{i}}(\%)$ & 26 & 32 & 15 & 27 \\
\hline
\end{tabular}

\subsubsection{Vehicle stability thresholds}

First, the vehicles' stability thresholds of the four vehicle types representing the vehicle fleet were determined. With the physical characteristics of these vehicles and by employing Equations 3.1, 3.2 and 3.3, the velocity from which each vehicle would lose its stability was calculated for each water depth. The obtained results are shown in Figure 3.6. The part of the graph over the threshold of each vehicle corresponds to the unstable zone; that is, the area where vehicles would destabilize. The part of the graph below the threshold corresponds to the stable zone; that is, the area where vehicles would remain stable.

The analysis of this graph indicated that the thresholds of the bigger vehicles exceeded those of the smaller vehicles; that is, for a given water depth, bigger-sized cars would 
remain stable at faster velocities than at the velocities guaranteeing smaller cars' stability. As expected, this meant that larger vehicles would be more stable during flooding.

Moreover at fast flow velocities, the water depths at which vehicles would destabilize displayed asymptotic behaviour and came close to the clear distance value between the chassis and the ground. For slow velocities, the water depths that brought about vehicle destabilization tended to move closer to the values at which the vehicle would float under conditions when water was still.

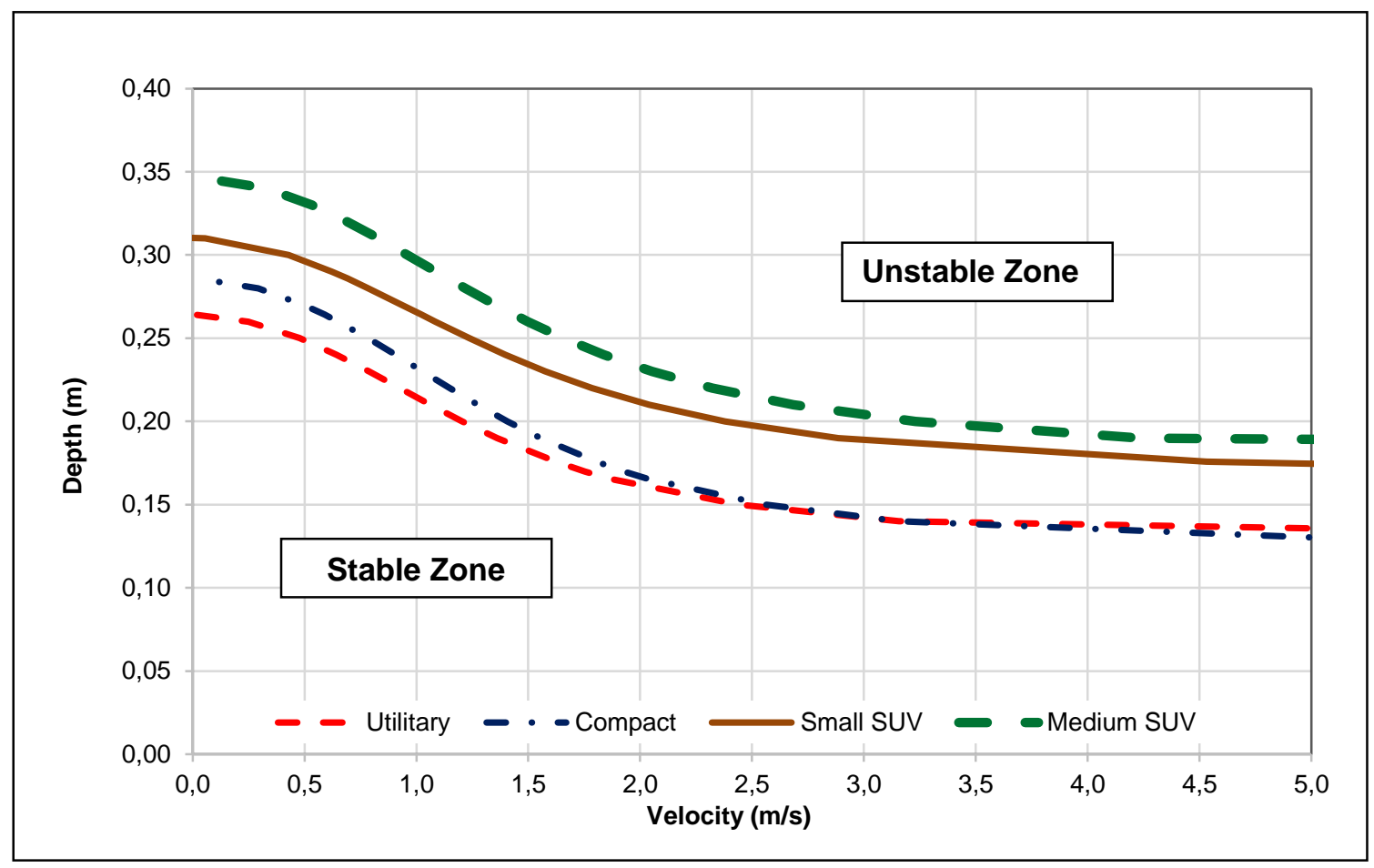

Figure 3.6 Stability thresholds for each vehicle type

\subsubsection{Vulnerability}

As previously indicated, the two vulnerability components were represented by exposure and susceptibility. Exposure was determined by the proportion of each vehicle type in fleet $g_{i}$ (Table 3.1), and by vehicle density $d$, which took different values for urbanized areas that had, and had not, been built-up (see Subsection 3.4.2). With these density values, the total number of vehicles driving around and/or parked in the flooded areas for the flood swell with a 500-year period equalled 18.205.

Susceptibility was established with the damage function, which was calculated using the vehicle instability index $S_{i}$ values (see Subsection 3.3.2). For a better spatial representation and to facilitate their interpretation, on the hazard maps obtained for each studied vehicle type, these vehicle instability indices were divided into the following five ranges according to stability: a) range 1: indices below zero, corresponding to the sectors in which vehicles would lose stability due to floating; b) range 2: indices between 0.0 and 0.5 , denoting that vehicles would probably remain stable; c) range 3: indices between 0.5 and $<1.0$, meaning that vehicles would probably remain stable, but would be about to 
destabilize owing to the sliding phenomenon; d) range 4: indices between 1.0 and 1.5, corresponding to the sectors in which vehicles would destabilize owing to sliding phenomenon; e) range 5 : indices $>1.5$, representing those sectors in which vehicles would greatly destabilize owing to sliding phenomenon.

According to Equation 3.5, damage function $D\left(S_{i}\right)$ took a value of 1 when the hazard indices had negative values (range 1), and equal to or greater than 1 (ranges 4 and 5). The damage function value equalled 0 in all the other cases (ranges 2 and 3 ).

Finally, the vulnerability for vehicle type $i$ at a point on the territory was calculated by multiplying the proportion of a vehicle type in the fleet, $g i$, by vehicle density, $d$, by the damage function value, $D(S i)$, as set out in Equation 3.6.

\subsubsection{Vehicle instability hazard}

The collected flood hazard data was provided by the Confederación Hidrográfica del Júcar (Júcar Hydrographic Confederation; CHJ, 2011), which employed the model Infoworks 2D to calculate the levels and velocities of flow in the flooded area. Flood hazard maps corresponding to floods with return periods of 10, 25, 50, 100 and 500 years were available. The floods with return periods of 10 and 25 years were found to not affect the study area. This was why a $T_{\min }$ value equalling 37.5 years was defined, which corresponded to the average of both the last return period with data available indicating that the study area had not been flooded ( 25 years) and the first return period with data available reporting that the study area had been flooded (50 years).

Figure 3.7 presents the maximum water depth maps and their velocities corresponding to the flooding with the 100-year return period. For some sectors of the study area, it shows that the flow depths for this event exceeded $3.0 \mathrm{~m}$ (panel a in Figure 3.7) and velocities went over $3.0 \mathrm{~m} / \mathrm{s}$ (panel b in Figure 3.7).

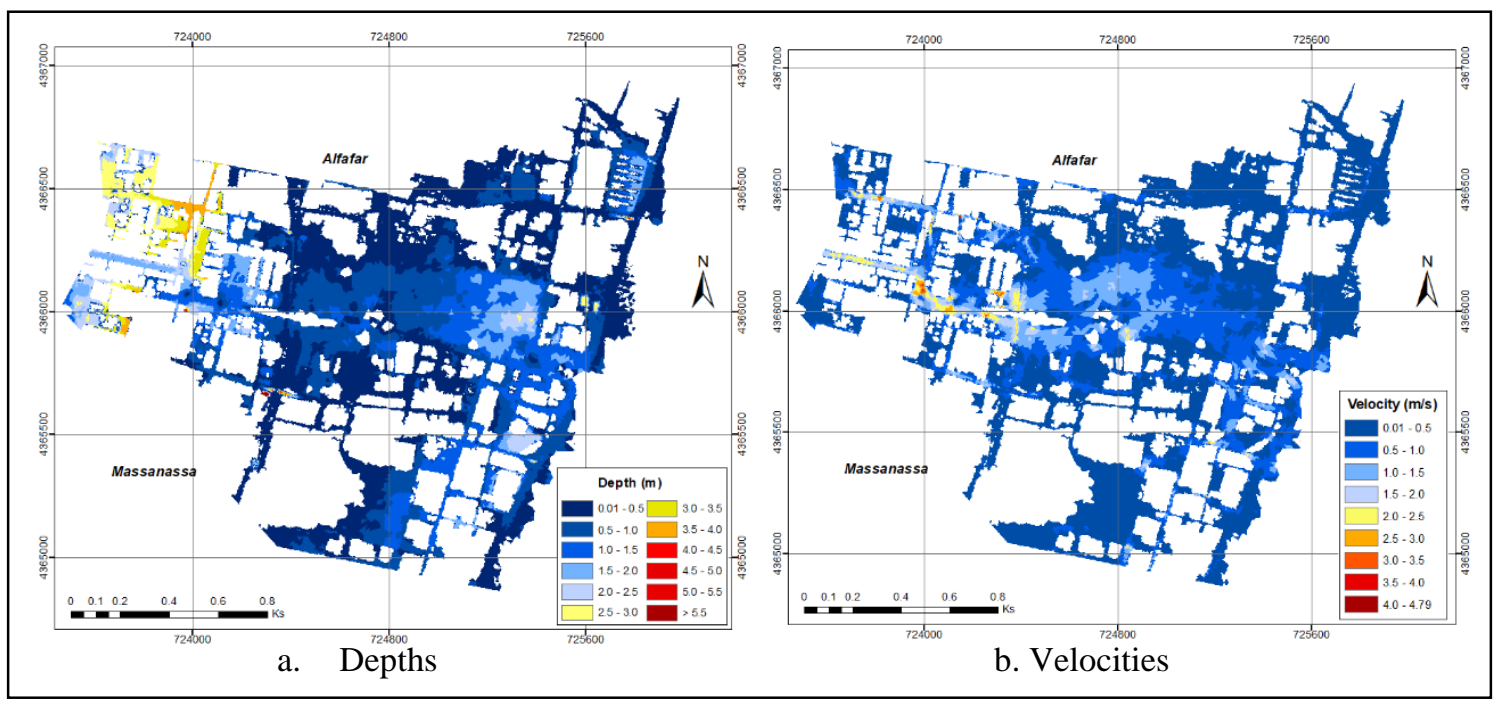

Figure 3.7 Flood hazard: maximum water depths and their corresponding flow velocities in the study area due to the Rambla del Poyo flooding with a 100-year return period Source: Confederación Hidrográfica del Júcar (2011) 
The vehicle instability hazard was calculated with the expression provided in Equation 3.3 and the procedure graphically represented in Figure 3.2. As the vehicles representing the vehicles fleet presented different characteristics, a hazard map was calculated for each vehicle type and every analysed flood. In order to determine vehicle instability index $S_{i}$, it was assumed that cars were completely water tight and lay perpendicularly to the flow, which usually represents the most unfavourable condition because the cross-sectional area exposed to the flow and, consequently, the hydrodynamic force applied to vehicles, are maximized (Smith et. al, 2017).

By way of example, Figure 3.8 presents the hazard maps of vehicle instability obtained for Seat Ibiza (represents smaller vehicles) by considering floods with return periods of 50 and 500 years. In most flooded areas, the vehicle instability index values were below 0.5 and negative values predominated. A similar behaviour was noted on the other instability hazard maps created for the other vehicle types and return periods.

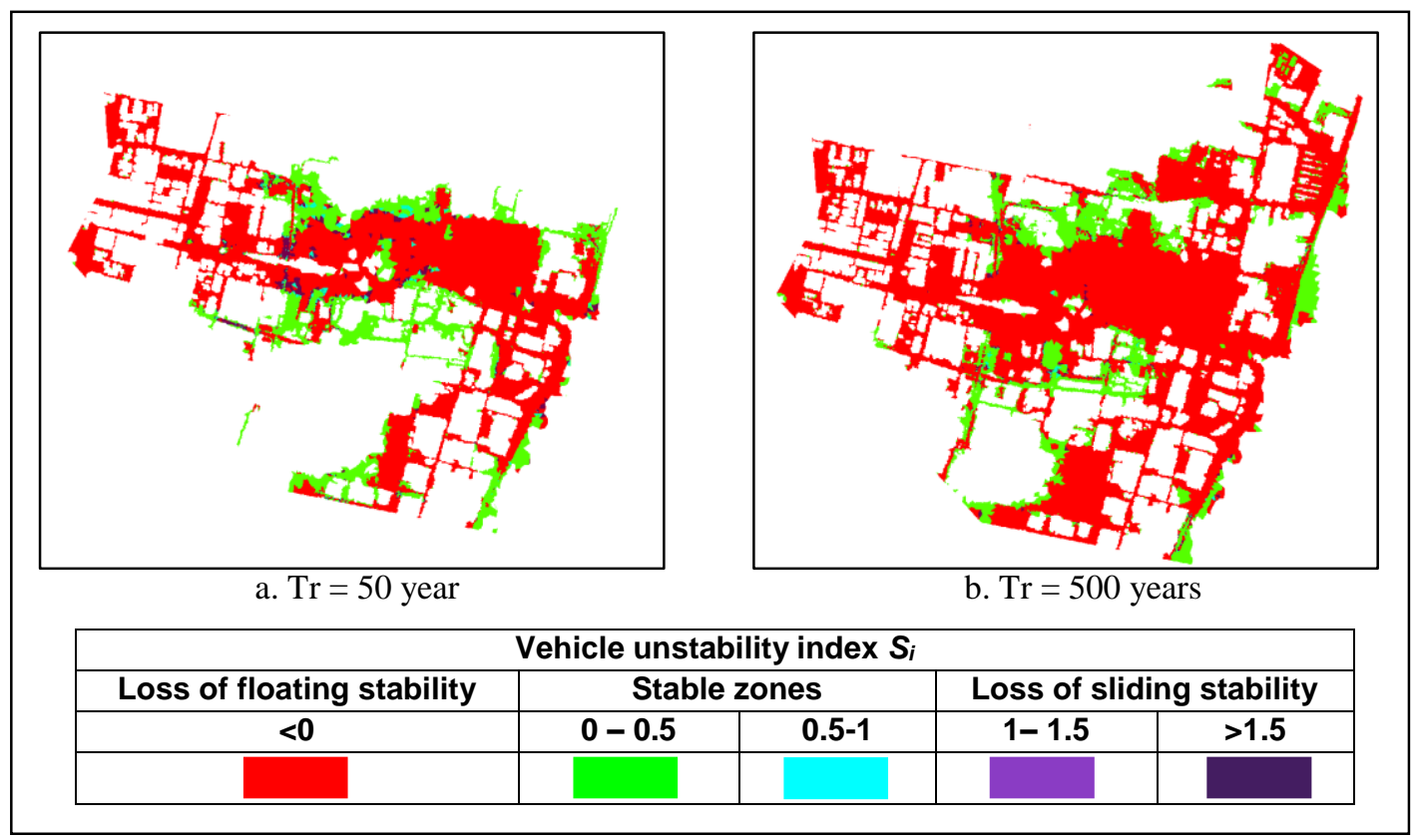

Figure 3.8 Hazard maps of vehicle instability in the study area for floods with return periods of 50 and 500 years for Seat Ibiza

The analysis performed with the results obtained for all the vehicles and return periods indicated that the Rambla del Poyo floods with return periods exceeding 50 years posed a major hazard for the vehicles being driven or parked in the built-up areas of Massanassa and Alfafar because even bigger vehicles would lose their stability in most flooded areas $\left(S_{i}<0\right.$ or $\left.S_{i} \geq 1\right)$. With medium-sized SUVs and larger vehicles, represented by Volkswagen Tiguan, both water depths and flow velocities would destabilize these vehicle types in $66 \%$ of the flooded areas due to flooding with a 50-year return period. This percentage would rise to $74 \%$ if the behaviour of smaller cars (represented by Seat Ibiza) was evaluated during the same event. When a flood with a 500-year return period was considered, the percentages of areas in which vehicles would destabilize would rise to $76 \%$ for medium-sized SUVs, and up to $80 \%$ for smaller vehicles. 
As a result of the high flow depth values shown in most of the flooded zones in the study area, loss of stability of all the studied vehicle types would be mostly attributed to the floating phenomenon $\left(S_{i}<0\right)$, while the sliding phenomenon would have less impact $\left(S_{i}\right.$ $\geq 1$ ). For instance, with smaller vehicles: as the corresponding floods would present a 500-year return period (panel b in Figure 3.8), the floating phenomenon would cause vehicle destabilization in $79 \%$ of flooded areas, whereas the sliding phenomenon would do so in only $1 \%$ of these areas. Similar behaviours to this were observed for the remaining return periods and other vehicle types.

Moreover it is worth pointing out that in percentage terms, the flooded areas that were safe for vehicles lowered as flooding frequency reduced and flooding intensity rose. For example, with smaller vehicles (Seat Ibiza), for flooding with a 50-year return period, 104 hectares (ha) would be flooded and cars would remain stable in $26 \%$ of them. However for the flooding with the 100-return period, 174 ha would be flooded and vehicles would remain stable in only $26 \%$ of them. For the flooding with a 500-year return period, 193 ha would be flooded and vehicle stability would remain in only $20 \%$.

As expected, in accordance with Figure 3.6, and given their bigger size and the longer free distance between their chassis and the ground, medium-sized SUVs (the biggest vehicle type herein included) would be the safest because they would remain stable in larger-sized flooded areas than the other vehicle types. The size of the flooded areas in which vehicles would conserve their stability would progressively reduce with vehicle size to its lowest for smaller vehicles.

\subsubsection{Vehicle instability risk}

The instability risk for each vehicle type was calculated using the expression in Equation 3.8 and the procedure depicted in Figure 3.4. The instability risk maps obtained for each employed vehicle type are shown in Figure 3.9, without considering their proportion in the vehicle fleet. The analysis of these maps indicated that as vehicle size increased, the areas with a higher instability risk (streets) diminished and, consequently, the low-risk areas increased. This result was expected because, as indicated in Section 3.4.5, the bigger the car size, the greater its stability during floods.

Figure 3.10 shows the risk map of total instability, which was obtained by summing the risk maps of each vehicle type, multiplied by their proportion in the vehicle fleet. It is noteworthy that in streets, where vehicle density exceeded the density of all the other urban areas by almost 6-fold, higher values were given for the instability risk (of the order of 8.4 cars per ha per year). These values were much higher than those for the existing risk in the other flooded areas. These relatively high-risk areas corresponded to about $8 \%$ of the whole flooded area. In an area that roughly equalled $60 \%$ of the flooded area, the risk for vehicles was relatively low with values below 1.4 cars per ha/year.

Table 3.2 shows the annual number of cars at risk of being dragged by the flood flow according to two hypotheses: (i) the vehicle fleet was represented by a single vehicle type (column 2); (ii) the vehicle fleet was represented by all four vehicle types indicated in Subsection 3.4.2 (column 3). When the data in column 2 were analysed, once again it was concluded that bigger vehicles (i.e. medium-sized SUVs) were the most stable vehicle 
type during flooding as they posed fewer at-risk vehicles for instability. The smaller vehicles (Seat Ibiza) were the least stable cars by presenting the most at-risk number of vehicles.

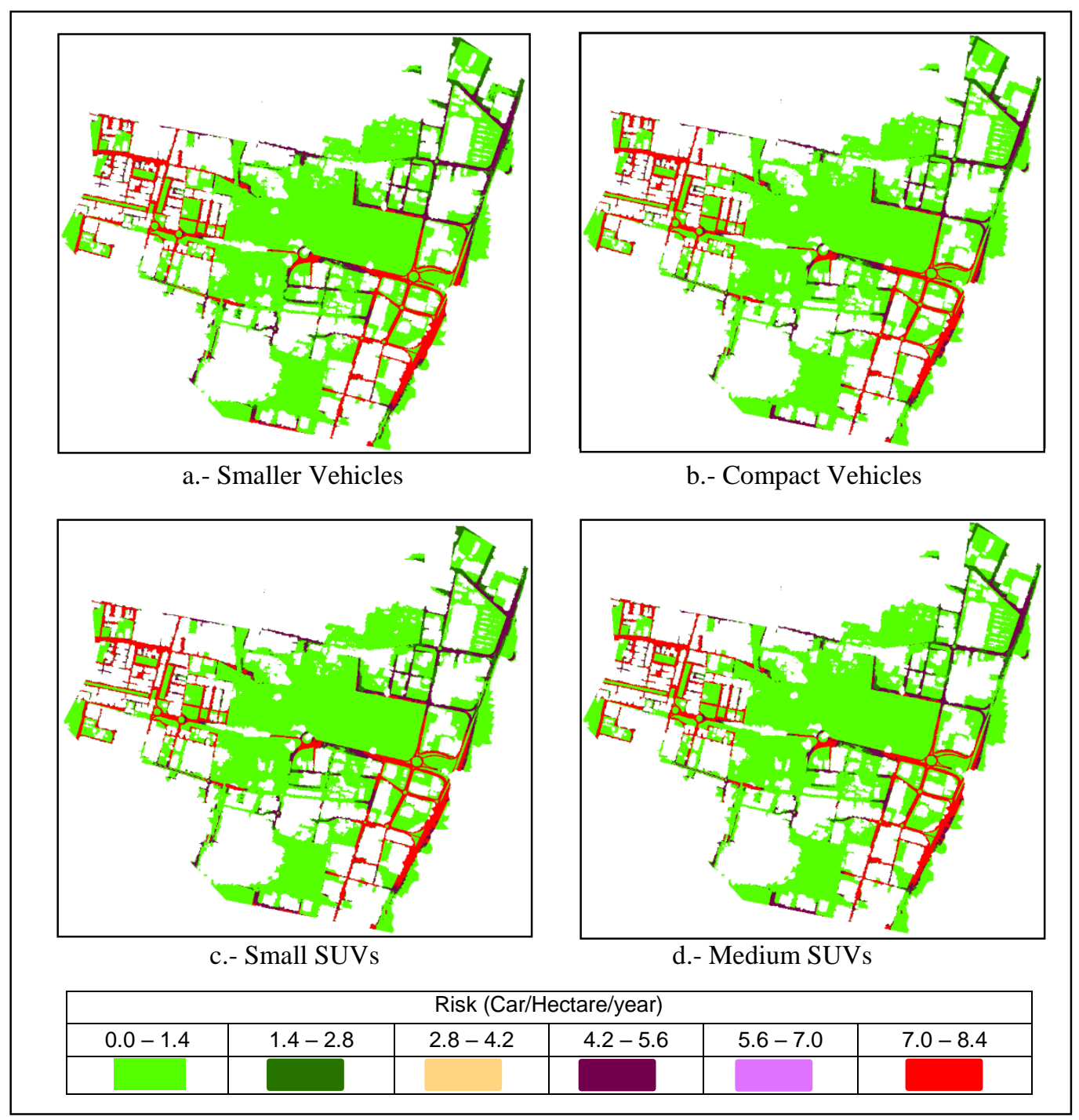

Figure 3.9 Risk map of instability for each vehicle type studied in the study area without considering their proportion in the vehicle fleet

By analysing the data in column 3, it was concluded that compact vehicles (i.e. Seat León) posed the highest risk, which correspond to roughly one third of all the at-risk vehicles. This was because, despite not being the most unstable cars, they had the highest proportion in the vehicle fleet. The smaller (least stable) vehicles presented a slightly lower risk than compact vehicles as their proportion in the vehicle fleet was also lower. The vehicles with the lowest instability risk in the study area corresponded to small SUVs because they were one of the most stable vehicle types with the lowest proportion in the vehicle fleet compared to the other studied vehicle types. For this reason, this vehicle type only represented about $15 \%$ of all the at-risk vehicles. 


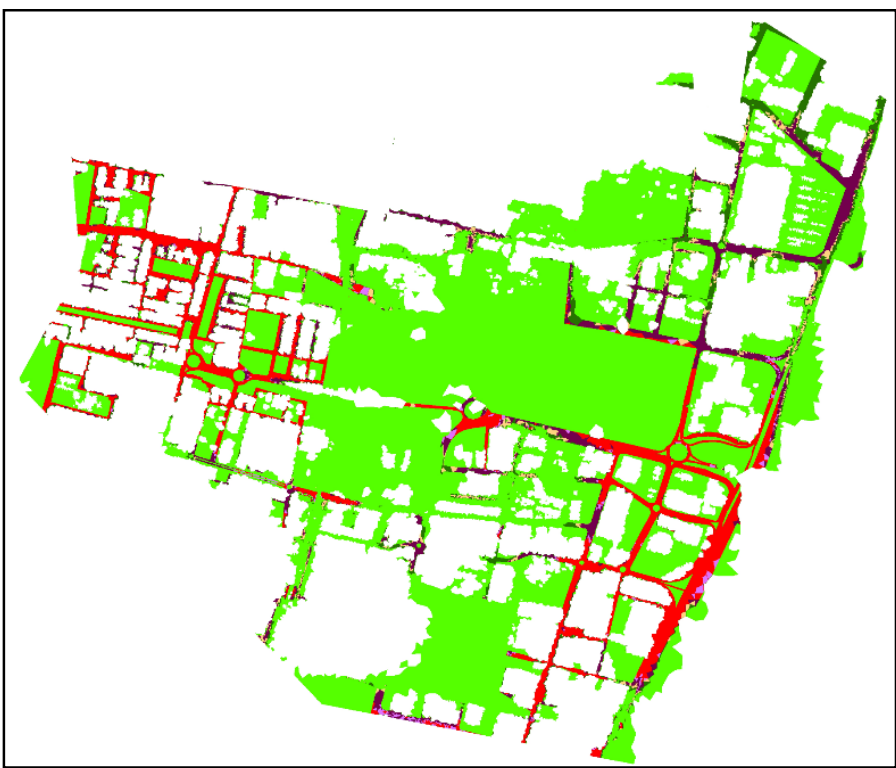

\begin{tabular}{|c|c|}
\hline \multicolumn{2}{|c|}{ Risk } \\
$($ Car/Hectare/year $)$ \\
\hline & $0.0-1.4$ \\
\hline & $1.4-2.8$ \\
\hline & $2.8-4.2$ \\
\hline & $4.2-5.6$ \\
\hline & $5.6-7.0$ \\
\hline & $7.0-8.4$ \\
\hline
\end{tabular}

Figure 3.10 Map of the instability risk for vehicles in the study area

Table 3.2 Mean annual number of at-risk vehicles for instability in the whole study area in line with the two fleet hypotheses: only one type and with the present proportion

\begin{tabular}{|l|c|c|}
\hline \multirow{2}{*}{\multicolumn{1}{|c|}{ Vehicle type }} & \multicolumn{2}{c|}{ Mean annual number of at-risk vehicles } \\
\cline { 2 - 3 } & \multicolumn{2}{|c|}{ Representation of the fleet } \\
\cline { 2 - 3 } & A single vehicle type & $\begin{array}{l}\text { The four vehicle types } \\
\text { and their proportions }\end{array}$ \\
\hline Smaller vehicles & 276.5 & 71.9 \\
\hline Compact vehicles & 269.7 & 86.3 \\
\hline Small SUVs & 252.7 & 37.9 \\
\hline $\begin{array}{l}\text { Medium-sized SUVs and } \\
\text { larger vehicles }\end{array}$ & 244.1 & 65.9 \\
\hline Total & - & 262.0 \\
\hline
\end{tabular}

\subsubsection{Sensitivity analysis to Tmin}

Bearing in mind the high uncertainty for the return period value from which the study area started being flooded (known in this methodology as $T_{\min }$ ), the sensitivity of vehicle instability risk to the values of this parameter in the study area was determined. Given that, according to available flood maps, the 25-year return period flood envelope does not reach the study area, unlike the 50-year return period flood which does, the $T_{\min }$ values adopted 30, 35, 40 and 45 years, and 37.5 years was the value employed to implement the methodology. 
Figure 3.11 offers the obtained results. The conclusion drawn from studying this graph was that a linear relation appeared between the exceedance probability of the event corresponding to $T_{\min }$ and the number of at-risk vehicles; the more the probability of the event considered to be $T_{\min }$ occurring, the more the at-risk vehicles. Furthermore, $T_{\min }$ significantly influenced vehicles' instability risk values. In relation to the value taken for the methodology implementation, the number of at-risk vehicles dropped by approximately $12 \%$ when taking a 45 -year $T_{\min }$ value, and rose by about $17 \%$ when taking a 30 -year $T_{\min }$ value.

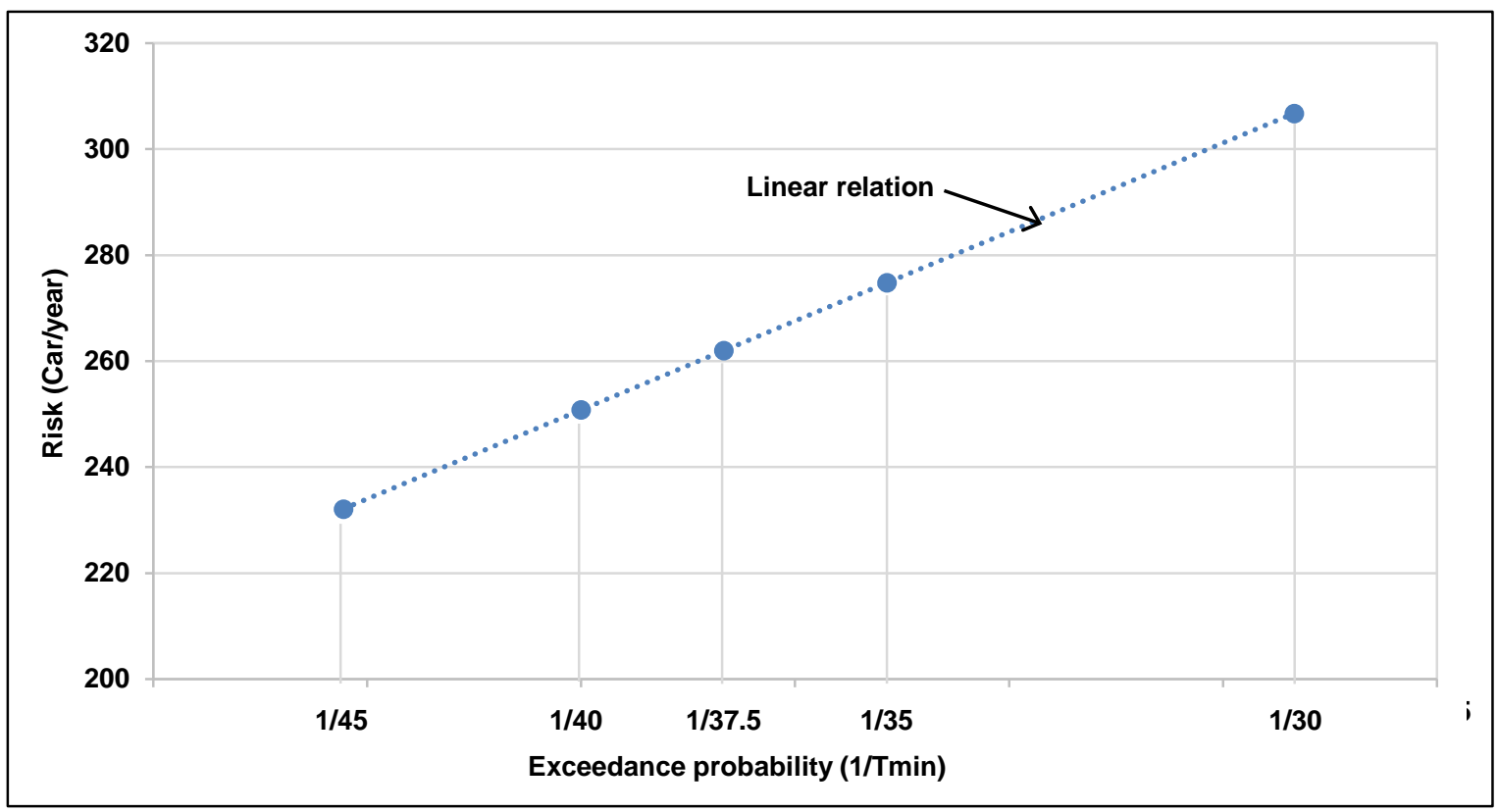

Figure 3.11 Number of cars at risk of instability in the study area when considering different Tmin values

\subsubsection{Final Remarks}

Applying the methodology to the selected case study allowed us to observe that the vehicle instability risk due to flood events in the towns of Massanassa and Alfafar is relatively high in streets given the values of about 8.4 cars per ha/year in them. Larger vehicles (e.g. medium-sized SUVs) would be the most stable vehicle type, while smallest vehicles, represented by smaller vehicles type, would be the least stable. Nonetheless, given the employed fleet proportions, the vehicle type at highest risk is compact cars, whereas the vehicle type at the lowest risk is small SUVs.

The Rambla del Poyo floods with return periods of 50 years or longer are a major hazard for the vehicles located in the study area because they would destabilize in most of the flooded area. The most damaging effect would result from the vehicle floating phenomenon owing to the vertical ascending pushing caused by flows from overflowing rivers, which would present relatively high water depth values. Loss of vehicle stability owing to the sliding phenomenon would occur in relatively small areas. 
The developed methodology provides a detailed vision of the vehicle instability risk due to flooding in a given area. The results of the described methodology allow to precisely locate not only the areas posing a higher risk for vehicles (for both vehicle type and the for entire existing vehicle fleet), but also safe zones. Consequently, the implementation of this methodology could be very useful for the entities in charge of planning the territory in order to design measures that contribute to reducing the adverse effects of floods. 


\section{DETERMINING THE VEHICLE INSTABILITY RISK IN STREAM CROSSINGS}

\subsection{Introduction}

Despite the fact that floods negatively affect vehicles, there are few studies available that attempt to determine the risk to which cars are subjected during river floods. The Word Bank Group (Rogelis Prada, 2015) presented a simple equation to calculate risks on road networks owing to floods. In this equation, risk is expressed as either number of deaths per year or economic cost per year, which is obtained with the summation of the product of the following factors: (i) hazardousness, understood as the probability of a threatening event happening; (ii) exposure, understood as the probability of vehicles being affected by the threatening event; (iii) vulnerability, which ranges between 0 and 1 , and indicates the severity of the expected damage; (iv) total potential loss, which is expressed as the number of people who died or economic costs.

Of the few studies that have centred on studying risk components specifically in stream crossings, we find that presented by Michielsen et al. (2016). By analysing physical basin characteristics by implementing statistical methods, these authors developed a methodology that could predict if stream crossings in a given area were flood-prone. Another similar study was conducted by Kalantari et al. (2019) which, based on multivariate statistical modelling, proposed a methodology to determine the probability of floods occurring in stream crossings. This methodology was also based on physical basin characteristics.

A methodology was herein developed that allows the vehicle instability risk to be estimated. This risk is posed by the growing river levels for vehicles when they cross stream crossings, which may correspond to fords, vented fords and bridges. We stress that this methodology can be used on bridges whose decks might be flooded, and whose structures would not hypothetically fail structurally during flooding.

This chapter article firstly presents a brief description of the mechanisms that lead to loss of vehicle stability. Then it describes the methodology developed to obtain the instability risk posed for those vehicles driving through a stream crossing. This risk is calculated by the discrete solution of the statistical integral of the product of hazard by vulnerability, which is a more elaborate calculation that those presented in former studies. Finally, it implements this methodology in the Godelleta municipality (Spain), where 32 stream crossings are identified.

\subsection{Methodology}

The vehicle instability risk due to floods in stream crossings $(\mathrm{R})$ corresponds to the annual mean number of vehicles whose stability would be lost when crossing these places According to Equation 3.4 the risk is determined by the statistical integral of the instability hazard and vehicles' vulnerability. The procedure that must be followed to calculate the hazard, vulnerability and, finally, the instability risk of vehicles in stream crossings, is presented below. 


\subsubsection{Vehicle instability hazard}

The flood hazard for vehicle $i$ in a stream crossing is obtained by combining the probability of a flooding event taking place with the values that the vehicle instability index, $S_{i}$, would take, as shown in Figure 3.3, panel C. The details to obtain the hazard are found in the chapter 3, section 3.3.1, for a flooding zone where there are flooding maps for different return periods. With stream crossings, it is sufficient to employ the maximum annual flow quantiles for a set of return periods and to convert this discharge into water depths and velocities by a 1D hydraulic stationary model with an adequate flow hypothesis (critical flow, uniform flow, etc.).

\subsubsection{Vulnerability}

As already noted, vulnerability depends on the degree of the elements that can be affected by flooding from being exposed, and by their susceptibility. The following subsections indicate how susceptibility and exposure should be calculated.

\subsubsection{Susceptibility}

Susceptibility indicates the degree of damage that elements exposed to flooding can suffer and is normally expressed by damage or loss functions. In this methodology, susceptibility was established through the damage function described in Section 3.3.2. A graphical representation of the way this function is defined and found in Figure 3.4, panel B.

\subsubsection{Exposure}

In the problem being solved, exposure was the number of each vehicle type i that could cross the stream crossing while water levels rose. Since the duration of the flood increases as its return period $T$ increases, the number of potentially affected vehicles type $i . N_{i}$ will depend on the return period and can be denoted as $N_{i}(T)$.

If the vehicle traffic distribution was the Poisson type, which has been applied to low and medium vehicle flows (Cal y Mayor and Cardenas, 2007), it is possible to demonstrate that the number of vehicles, $N_{i}(T)$, corresponds to the following expression:

$$
N_{i}(T)=q g_{i} \Delta t_{i}(T)
$$

where $q$ corresponds to the vehicle type $i$ traffic in the stream crossing during a flood. If no further information is available, Average Daily Traffic (ADT) can be used; $g i$ is the proportion of vehicles type $i$ in the fleet; $\Delta t_{i}(T)$ corresponds to the time interval during which flows can affect the stability of vehicles type $i$ during the flood with return period $T$.

Time interval $\Delta t_{i}(T)$ depended on the vehicle type because hazard was defined for the $S_{i}$ of the flood peak and instability could take place for smaller flows. In the case study, one calculation method will be shown in more detail. 
The relation between $\mathrm{Ni}(T)$ and return period $T$ corresponded to exposure. The graphical representation of this exposure is found in Figure 4.1, panel B.

In fact the time interval $\Delta t_{i}(T)$ during which the flood could affect exposed vehicles' stability was in accordance with drivers' behaviour. The present methodology contemplated two different drivers' behaviours: (i) drivers did not decide to stop before crossing during floods; (ii) for safety reasons, drivers decided to stop driving through the flooded area when the water depth exceeded a given value, which was called a limit water depth, and would not cross the stream crossing during the rest of the flood (the resulting value was lower than the previous one and in accordance with this limit water depth).

To calculate risk, it is necessary to express vulnerability according to hazard. So an instrumental function is required, which is called the exposure function of vehicles type $i, N_{i}\left(s_{i}\right)$, and was obtained by combining hazard and exposure, as depicted in Figure 4.1. This figure shows that, as previously indicated, a vehicle instability index $S_{i}$ corresponded to each event with a given probability (Hazard, panel A) and a number of vehicles $N_{i}$ driving through the stream crossing (Exposure, panel B). In this way, it was possible to relate the vehicle instability index $S_{i}$ to the corresponding numbers of vehicles $N_{i}$, which gave a similar graph to that found in panel $\mathrm{C}$ with the vehicles' exposure function.

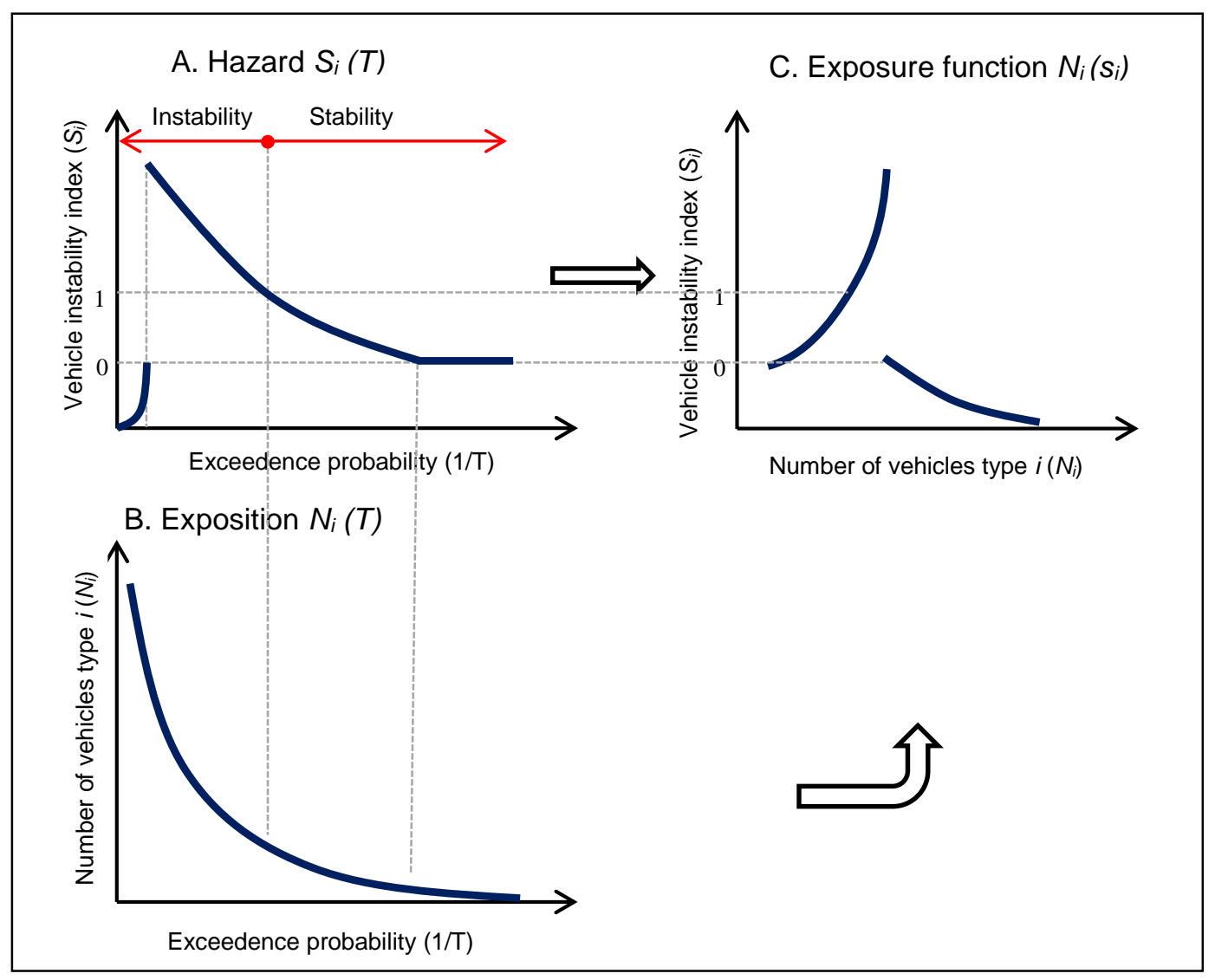

Figure 4.1 Outline of the process to follow to determine the exposure function of vehicles type $\mathrm{i}$ 
Finally, the vulnerability for vehicles type $i, \mathrm{~V}_{i}$, was obtained by combining the $D_{i}\left(s_{i}\right)$ damage and exposure $N_{i}\left(s_{i}\right)$ functions, as shown in Figure 4.2. This figure once again shows that to each vehicle instability index $S_{i}$ corresponds to a value of the damage function $D_{i}\left(s_{i}\right)$ (panel A) and a value of the exposure function $N_{i}\left(s_{i}\right)$ (panel B). When graphing the vehicle instability index against the product of its corresponding values of Damage $D_{i}\left(s_{i}\right)$ and Exposure $\mathrm{N}_{i}\left(s_{i}\right)$ function, a similar graph to that presented in panel $\mathrm{C}$ was obtained, which represents the vulnerability of the vehicles. This vulnerability was expressed as a function of the vehicle instability index $S_{i}$, which is why it was denoted as $V_{i}\left(s_{i}\right)$ and was measured in number of destabilised vehicles.

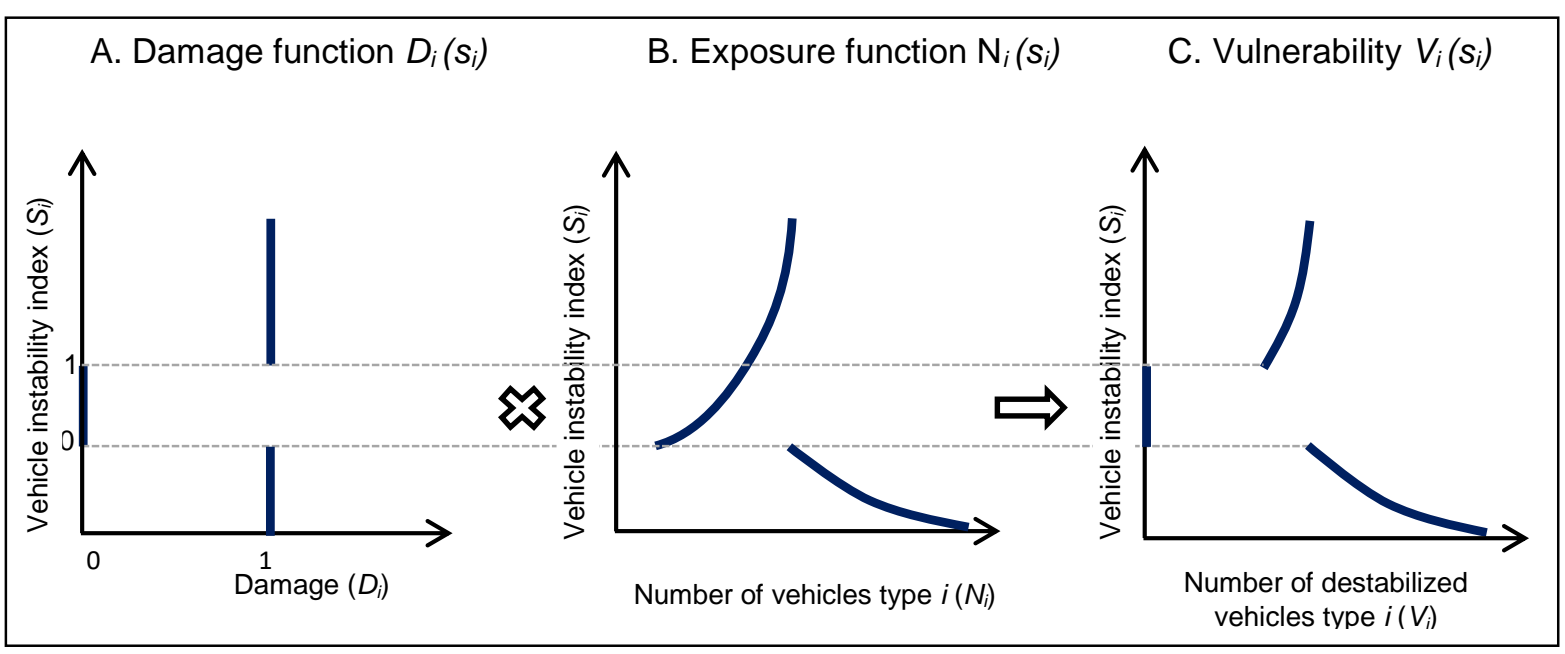

Figure 4.2 Outline of the procedure to follow to obtain vulnerability of vehicles type $i$ in the event of floods

\subsubsection{Vehicle instability risk}

The instability risk was calculated by replacing the expressions obtained for both the hazard and vulnerability of the vehicles driving through a stream crossing in Equation 3.4. Figure 4.3 outlines the procedure that must be set up to calculate the instability risk for flooding of vehicles type $i$ in stream crossings. Panel A corresponds to the instability hazard, which was obtained following the procedure described in Section 4.2.1. Panel B corresponds to vulnerability, which was obtained as set out in Section 4.2.2. When hazard was combined with vulnerability, for each flooding event with a given probability of occurring, a corresponding number of vehicles $N_{i}$ would lose their stability in stream crossings. When creating a graph to depict the probability of each event occurring with the respective number of vehicles that would lose their stability, a similar graph was obtained to that shown in panel $\mathrm{C}$. The instability risk corresponded to the area under the curve, which was formed when joining the values of those vehicles that would lose their stability during each flood event. 


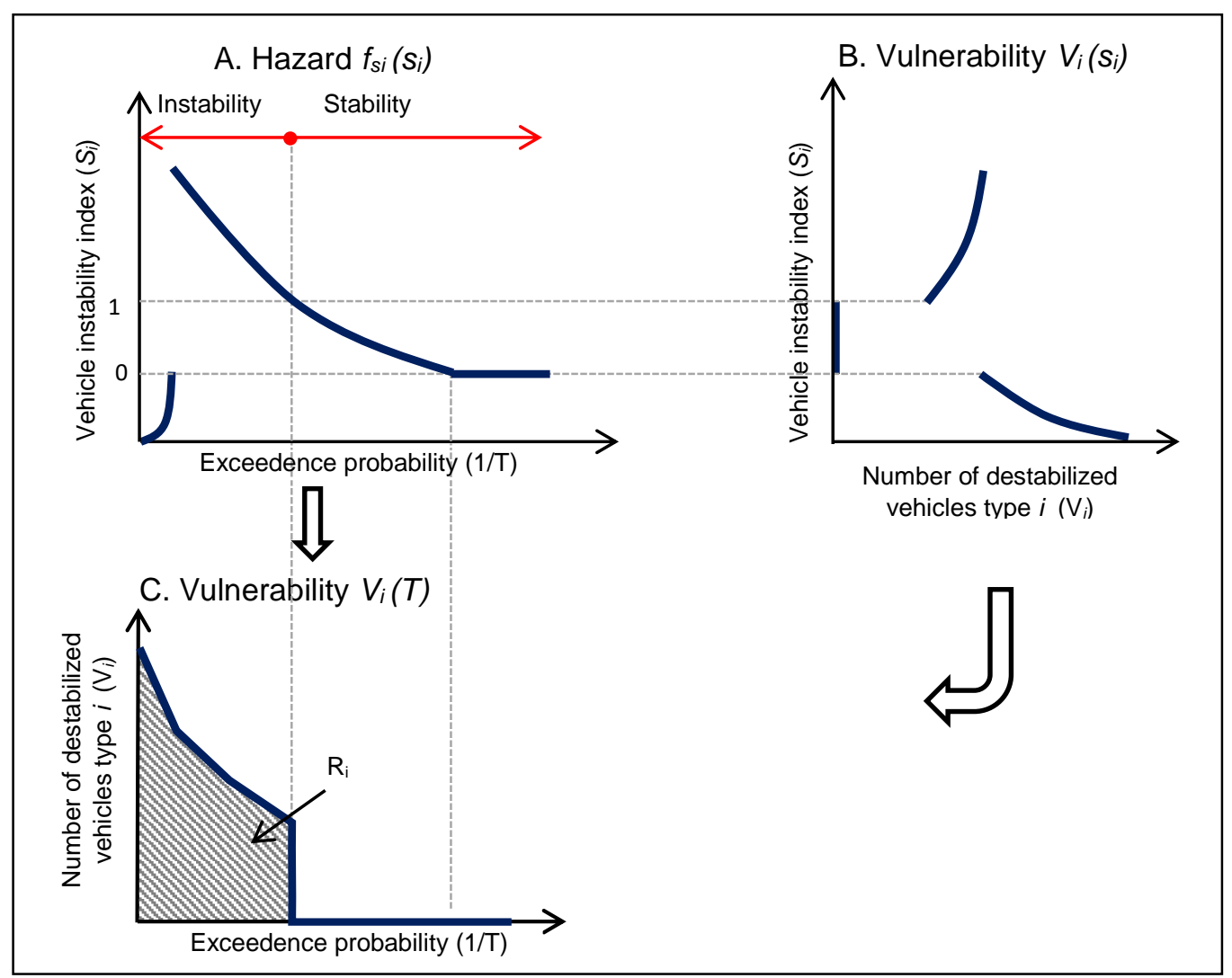

Figure 4.3 Outline of the process that must be set up to calculate the instability risk for flooding vehicles type $i$ in a stream crossing

As Equation 3.4 contemplates a vehicle type $i$, the total risk was obtained when using the summation of the partial risk obtained for each vehicle $K$ type with which the fleet was represented. So the total risk would be:

$$
R=\sum_{i=1}^{K} R_{i}=\sum_{i=1}^{K} \int_{0}^{\infty} V_{i}(s) f_{S_{i}}(s) d s
$$

In practice it is not possible to calculate and obtain the integral of Equation 4.2 as we did not work with analytical functions and had a limited $\mathrm{M}$ number of flood maps. A discrete approach could be as follows:

$$
R=\sum_{i=1}^{K}\left\{\left[\sum_{j=0}^{M-1} \frac{V_{i}\left(s_{i, j}\right)+V_{i}\left(s_{i, j+1}\right)}{2}\left(\frac{1}{T_{j}}-\frac{1}{T_{j+1}}\right)\right]+V_{i}\left(s_{i, M}\right)\left(\frac{1}{T_{M}}\right)\right\}
$$

where $\mathrm{j}$ corresponds to the number of the order of flood maps, which varied from 0 to $T_{\min }$ up to $\mathrm{M}$ for $T_{\max }$, with $\mathrm{T}_{\min }$ being the lowest return period from which vehicles would start being affected; $T_{\max }$ is the longest return period with an available flood hazard map; $V_{i}\left(S_{i, j}\right)$ corresponds to the vulnerability of vehicle type $i$ for a vehicle instability index $S_{i}$ during the flood with return period $T_{j}$. 
The last term in Equation 4.3 corresponds to the residual risk for longer return period events than $T_{\max }$, for which the same vulnerability as $T_{\max }$ was assumed.

\subsection{Application to a case study}

The developed methodology was employed to determine the vehicle instability risk for flooding in the stream crossings found in the Godelleta municipality, which lies very close to the Spanish Mediterranean coastline (Figure 4.4). This allowed the applicability of the methodology to be determined. For the case study, it permitted the influence of both drivers' behaviour and the degree of obstruction of vented fords on the results to be analysed.

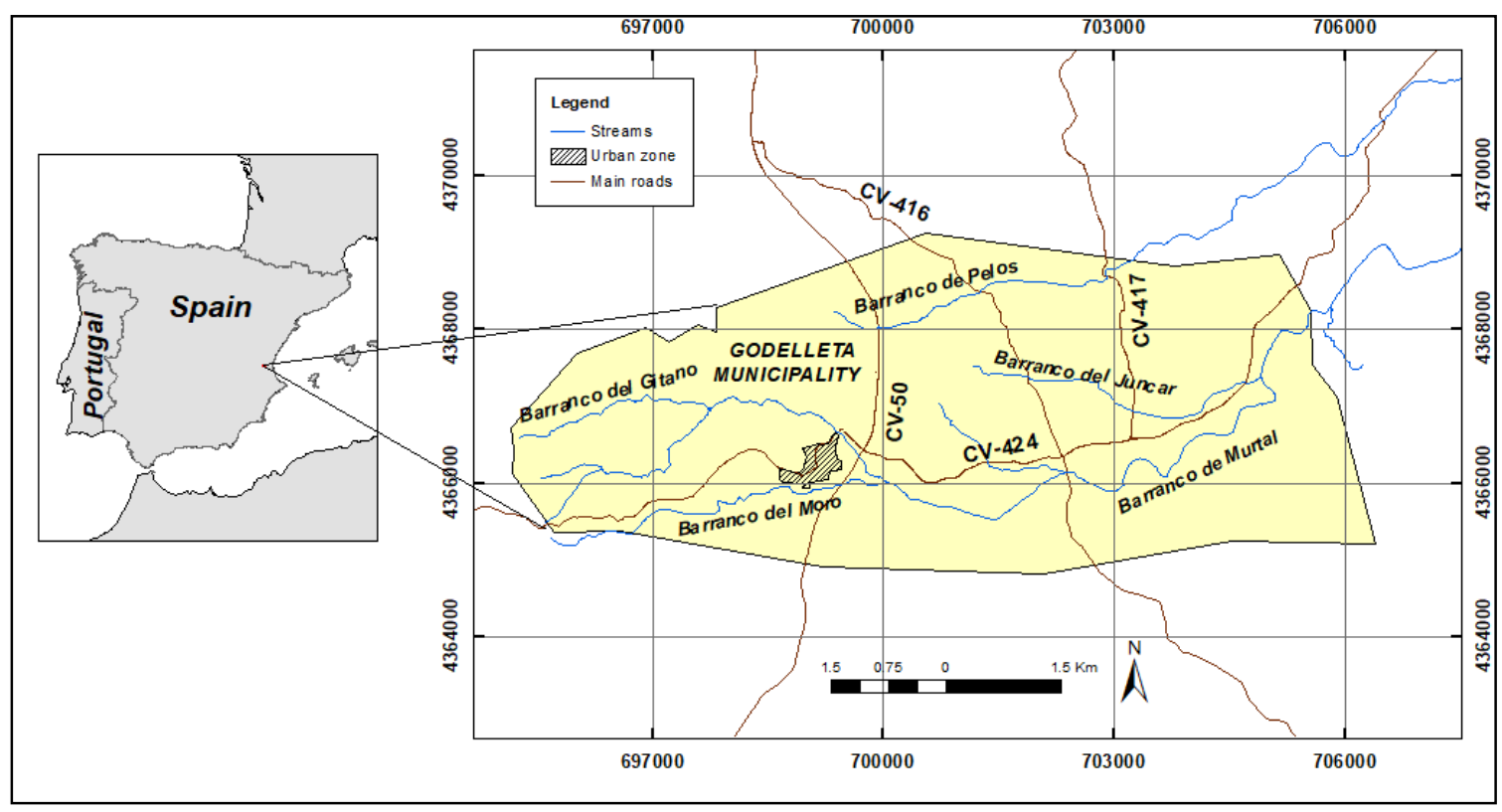

Figure 4.4 Location of the Godelleta municipality, ravines, main roads and its built-up area

\subsubsection{Characterisation of the study area}

The Godelleta municipality covers $37.5 \mathrm{~km}^{2}$, has a population of 3,441 inhabitants, is relatively flat with gentle slopes, and a mean height of 266 masl. Its climate is semiarid Mediterranean with very variable mean precipitation figures around $450 \mathrm{~mm}$, and rainfall concentrates in spring and autumn months.

The Godelleta municipality lies in the middle of the Rambla del Poyo Basin, which is an intermittent 43.5 kilometre-long current that begins to flow at a height of 1,023 masl and flows into the Albufera lagoon. The basin covers $430 \mathrm{~km}^{2}$. Its slope varies between $16 \%$ at the highest point and $2 \%$ in the lowest part, where flash flooding occasionally occurs in autumn months (Salazar, 2013). This municipality has a drainage network made up of several intermittent water currents that flow westerly-easterly of a torrential nature, with maximum flows in spring and autumn (Terrasa et al., 2018). 
This municipality's road network is relatively dense and formed by regional and local roads in good condition. Regional roads include roads CV-50, CV-416, CV-417 and CV424 (Fig. 4.4). The last three roads are B-roads (single lane for each direction) that are relatively narrow with no verges. Road CV-50 is also a B-road, but has ample verges on both sides.

The intersection between the drainage network and the road network involves 32 stream crossings. The vehicles driving through these crossings via these roads would be at risk for instability due to floods that could occur in ravines. Of these 32 stream crossings, eight correspond to fords, 18 to vented fords and six to bridges. In this paper, the risk in the stream crossings corresponding to fords and vented fords was calculated because the drainage capacity of these bridges corresponds to very little exceedance probabilities and, therefore, the risk of vehicles being dragged away is negligible. Figure 4.5 presents the location of the analysed fords and vented fords.

\subsubsection{Characterisation and exposure of the vehicles driving through the study area}

The characterisation of the vehicles found in the study area was done using the information presented in the Section 3.4.2. The vehicles selected to represent the fleet of cars circulating in the municipality of Godelleta and their characteristics are presented in Table 3.1.

The traffic data for roads CV-416, CV-417 and CV-424 were taken from the official traffic levels of the Valencian Council Offices (2018). The road traffic data for road CV50 was acquired from the information reported by the Generalitat Valenciana (2019). The ADT (number of vehicles/day), reported by these institutions for the sites of interest for this study, were as follows: (i) CV-50: 5141; (ii) CV-416: 380; (iii) CV-417: 484; (iv) CV-424: 7369. No official traffic levels data were available for local roads.

\subsubsection{Vehicle instability hazard}

The flows corresponding to the floods in the ravines found in the study area were determined by interpolation techniques using existing flow data about Rambla del Poyo at several basin points for return periods of 1, 2, 5, 10, 25, 50, 100 and 500 years. The flows of all the stream crossings were interpolated using the expression proposed by Leopold et al. (1964), which allows floods with drainage areas and their corresponding return periods to be related:

$$
Q_{T} \propto A_{d}^{b} T
$$

where $Q_{T}$ is the peakflow quantile, $A_{d}$ is the drainage area in each stream crossing, $\mathrm{b}$ is an exponent which, according to Leopold et al. (1964), varies between 0.65 and 0.80 , and $T$ is the return period. With the Rambla del Poyo fit, the determination coefficient significantly increased if an exponent was included in the return period. The final outcome used to estimate the flow quantiles at any point of Rambla del Poyo (including the ravines in the Godelleta municipality) was this expression: 


$$
Q_{T}=0.4929 A_{d}^{0.75} T^{0.6512}
$$

where $Q_{T}$ is given in $\mathrm{m}^{3} / \mathrm{s}, A_{d}$ in $\mathrm{km}^{2}$ and $T$ in years.

The water levels and velocities corresponding to each analysed flow at the sites of interest were calculated using the hydrodynamic modelling of the floods that flowed through ravines by taking a unidimensional stationary flow hypothesis in a river section that included the stream crossing. These modellings were done with the HEC - RAS model, a widely used software in hydraulic engineering. In these modellings, the geometric representation of the riverbed was performed with the cross-sections obtained from the digital elevations model of the Spanish National Centre of Geographic Information of Spain for all Spanish territory (http://centrodedescargas.cnig.es/CentroDescargas/ index.jsp\#, last consulted in September 2019) and based on the field trips of August 2019. The geometry of the fords and vented fords was obtained during field trips.

With the results obtained with the performed modelling, and having implemented the procedure described in Section 3.3.1, instability indices $S_{i}$ were calculated for each analysed vehicle type for the different defined return periods. These indices were calculated by assuming that vehicles were completely watertight and lay perpendicularly to the flow. Table 4.1 presents the instability indices $S_{i}$ obtained for the different vehicle types in all the stream crossings, but only for the flow with the 50-year return period.

The obtained vehicle instability indices $S_{i}$ indicated that the flows with return periods that equalled or exceeded 50 years posed a high risk for the vehicles driving through stream crossings because, for a flood with a 50-year return period, the vehicle stability of roughly $55 \%$ of the vehicles would be lost. This percentage also had a significant value for the flood with a 25 -year return period because it came close to $45 \%$, and it almost reached $90 \%$ for a 500 -year return period.

\subsubsection{Vulnerability}

Vulnerability was calculated by combining susceptibility and vehicles' exposure to floods. Susceptibility was established through the damage function defined in Section 4.2.2.1. The damage function values either equalled 1 for flooding events in which vehicle instability index $S_{i}$ had negative values (destabilisation due to floating) or exceeded or equalled 1 (destabilisation due to dragging). When vehicle instability index $S_{i}$ had positive values below 1 , the damage function equalled 0 .

The exposure function was determined by bearing in mind that, according to that established in Section 4.2.2.2, for a given flooding event, the number of vehicles type $i$ exposed to floods, $\mathrm{N}_{i}$ would correspond to the mean number of cars $i$ that would drive through the flooded site during time interval $\Delta t_{i}$ when the conditions leading to vehicle instability would take place. To know the duration of this time interval, we calculated the flood duration and times when the flow hydrodynamic conditions that would cause loss of vehicle stability would start and stop.

The flood duration time in the studied ravines was calculated by summing the duration time of rainfall events and the concentration time in each basin. The rainfall duration time was obtained from subtracting the concentration time for Rambla del Poyo from its mean 
flood duration time. According to Salazar (2013), the mean flood duration of Rambla del Poyo approximately equalled 12 hours in the hydrometric station called Rambla del Poyo, where the drainage area equalled $184 \mathrm{~km}^{2}$.

The concentration time, $t_{c}$, of both the Rambla del Poyo Basin and ravines was calculated by the following expression proposed by the Generalitat Valenciana (2018):

$$
t_{c}=0.7073 A_{d}^{0.4963}
$$

Table 4.1 presents the flood duration times of the ravines found in the study area, which were obtained by summing the rainfall duration time and the concentration time up to each stream crossing.

The water levels and flow velocities at which the analysed vehicle types would destabilise, and the time interval $\Delta \mathrm{t}_{i}$ during which stability would be lost in each flooding event, were determined by the results obtained with the hydrodynamic models developed for the stream crossings and the calculated vehicle instability indices $S_{i}$. Time interval $\Delta \mathrm{t}_{i}$ was calculated by contemplating the two possible drivers' behaviours set out in Section 4.2.2.2. For calculating under the condition for which it was assumed that drivers would decide to stop at a given time during the flood, a limit water depth equal to $0.3 \mathrm{~m}$ was adopted to interrupt the vehicle traffic.

The number of vehicles type $i$ exposed to floods, $\mathrm{N}_{i}$, was calculated by multiplying the vehicle traffic flow, $q$, by the proportion, $g_{i}$, of vehicles type $i$ in the fleet, by the time interval, $\Delta t_{i}$, during which the conditions that would result in vehicle instability taking place. If official traffic levels data were available for roads, these data were used. However, if they were not available for some roads, then the vehicle levels recorded during field trips were employed. Table 4.1 shows the hourly flow of the vehicles in all the stream crossings.

The exposure function was obtained by relating the vehicle instability index $S_{i}$ calculated for each flooding event to the corresponding number of exposed vehicles $N_{i}$.

Finally, vulnerability was calculated by multiplying the results obtained by the damage and exposure functions for each flooding event.

\subsubsection{Vehicle instability risk}

The vehicle instability risk was calculated by implementing the procedure described in Section 4.2.3. The risk obtained by considering that drivers would stop when flow depth reached the limit water depth was called actual risk, while that obtained by contemplating that drivers would not stop at any time was called estimated potential risk. Table 4.1 offers the values obtained for the estimated actual/potential risks. Figure 4.5 graphically represents the estimated actual risk; with the sole objective of making this representation, this risk was subjectively classified as high for the values that equalled or exceeded 0.2 vehicles/year, medium when ranging between 0.1 and below 0.2 vehicles/year, and low if below 0.1 vehicles/year. 
Table 4.1 Vehicle instability risk due to floods in the stream crossings of the Godelleta municipality

\begin{tabular}{|c|c|c|c|c|c|c|c|c|c|c|c|}
\hline \multirow{4}{*}{$\begin{array}{c}\text { Stream } \\
\text { crossings }\end{array}$} & \multirow{4}{*}{ Stream } & \multirow{4}{*}{$\begin{array}{c}\text { Stream } \\
\text { crossings } \\
\text { with culvert }\end{array}$} & \multirow{4}{*}{$\begin{array}{l}\text { Traffic } \\
\text { flow } q \\
\text { (cars/ } \\
\text { hour) }\end{array}$} & \multirow{4}{*}{$\begin{array}{c}\text { Flood } \\
\text { duration } \\
\text { (hours) }\end{array}$} & \multicolumn{5}{|c|}{ Flood Tr 50 años } & \multicolumn{2}{|c|}{$\begin{array}{c}\text { Instability } \\
\text { risk } \\
\text { (cars/year) }\end{array}$} \\
\hline & & & & & \multirow{3}{*}{$\begin{array}{c}\text { Dis- } \\
\text { charge } \\
\left(\mathbf{m}^{3} / \mathbf{s}\right)\end{array}$} & \multirow{2}{*}{\multicolumn{4}{|c|}{$\begin{array}{c}\text { Hazard index } S_{i} \\
\text { Vehicle type }\end{array}$}} & \multirow{3}{*}{ Actual } & \multirow{3}{*}{$\begin{array}{c}\text { Poten- } \\
\text { tial }\end{array}$} \\
\hline & & & & & & & & & & & \\
\hline & & & & & & $\begin{array}{c}\text { Small } \\
\text { cars }\end{array}$ & $\begin{array}{l}\text { Com- } \\
\text { pacts }\end{array}$ & $\begin{array}{l}\text { SUVs } \\
\text { small }\end{array}$ & $\begin{array}{c}\text { SUVs } \\
\text { med. }\end{array}$ & & \\
\hline 1 & \multirow{11}{*}{$\begin{array}{c}\text { Del } \\
\text { Murtal }\end{array}$} & Yes & 45.32 & 6.2 & 73.71 & -0.42 & -0.43 & -0.45 & -0.52 & 0.35 & 4.67 \\
\hline 2 & & Yes & 0.50 & 6.1 & 70.80 & -0.14 & -0.14 & -0.14 & -0.15 & 0.21 & 1.85 \\
\hline 3 & & Yes & 1.51 & 6.0 & 67.68 & -0.26 & -0.25 & -0.26 & -0.28 & 0.22 & 3.80 \\
\hline 4 & & No & 1.01 & 5.5 & 53.55 & -0.86 & -0.82 & -0.86 & -0.90 & 1.12 & 2.37 \\
\hline 5 & & Yes & 1.51 & 5.3 & 47.71 & -0.22 & -0.21 & -0.22 & -0.23 & 0.11 & 2.99 \\
\hline 6 & & No & 0.21 & 4.7 & 33.13 & -0.13 & -0.12 & -0.13 & -0.13 & 0.11 & 0.46 \\
\hline 7 & & Yes & 214.21 & 4.7 & 32.96 & 0.00 & 0.00 & 0.00 & 0.00 & 0.16 & 2.21 \\
\hline 8 & & Yes & 4.03 & 4.4 & 25.72 & -0.21 & -0.20 & -0.21 & -0.23 & 0.65 & 2.13 \\
\hline 9 & & Yes & 6.04 & 3.8 & 13.41 & -0.22 & -0.21 & -0.22 & -0.24 & 0.08 & 1.56 \\
\hline 10 & & No & 3.02 & 3.5 & 8.58 & -74.99 & 26.73 & 7.79 & 3.80 & 0.39 & 0.48 \\
\hline 11 & & No & 0.33 & 3.0 & 2.87 & -0.72 & -0.89 & -1.14 & -4.20 & 0.01 & 0.02 \\
\hline 12 & \begin{tabular}{|l|}
$\begin{array}{c}\text { Del Bo- } \\
\text { rreguero }\end{array}$ \\
\end{tabular} & Yes & 0.33 & 3.0 & 3.02 & 0.00 & 0.00 & 0.00 & 0.00 & $<10^{-4}$ & $<10^{-4}$ \\
\hline 13 & \multirow{2}{*}{$\begin{array}{c}\text { Del } \\
\text { Gitano }\end{array}$} & Yes & 6.04 & 3.6 & 11.33 & -0.56 & -0.69 & -0.88 & -3.23 & 0.02 & 0.29 \\
\hline 14 & & No & 0.32 & 3.1 & 3.84 & 10.13 & 1.58 & 0.58 & 0.31 & $1 * 10^{-3}$ & 0.01 \\
\hline 15 & Del Moro & Yes & 214.21 & 4.2 & 21.73 & 0.00 & 0.00 & 0.00 & 0.00 & 0.20 & 1.15 \\
\hline 16 & \multirow{2}{*}{$\begin{array}{l}\text { Barran- } \\
\text { quet }\end{array}$} & Yes & 0.28 & 3.6 & 10.36 & 0.11 & 0.09 & 0.01 & 0.00 & $2 * 10^{-4}$ & 0.004 \\
\hline 17 & & Yes & 96.42 & 3.4 & 7.84 & 0.00 & 0.00 & 0.00 & 0.00 & $5 * 10^{-4}$ & 0.001 \\
\hline 18 & \multirow{6}{*}{$\begin{array}{l}\text { Del } \\
\text { Juncar }\end{array}$} & Yes & 307.04 & 3.8 & 14.08 & 0.03 & 0.03 & 0.00 & 0.00 & 0.18 & 3.71 \\
\hline 19 & & Yes & 12.08 & 3.8 & 13.68 & 0.50 & 0.33 & 0.14 & 0.08 & 0.04 & 0.25 \\
\hline 20 & & No & 0.53 & 3.8 & 13.52 & -0.36 & -0.36 & -0.37 & -0.40 & 0.18 & 0.52 \\
\hline 21 & & No & 0.27 & 3.7 & 12.84 & -0.02 & -0.02 & -0.02 & -0.02 & 0.12 & 0.42 \\
\hline 22 & & Yes & 20.17 & 3.6 & 10.58 & 0.05 & 0.05 & 0.00 & 0.00 & 0.02 & 0.20 \\
\hline 23 & & Yes & 15.83 & 3.1 & 4.16 & 0.00 & 0.00 & 0.00 & 0.00 & $3 * 10^{-4}$ & $3 * 10^{-4}$ \\
\hline 24 & \multirow{3}{*}{$\begin{array}{l}\text { De } \\
\text { Pelos }\end{array}$} & Yes & 15.83 & 3.7 & 13.15 & 0.51 & 0.33 & 0.14 & 0.09 & 0.04 & 0.33 \\
\hline 25 & & No & 0.28 & 3.5 & 9.86 & -0.55 & -0.60 & -0.65 & -0.93 & 0.003 & 0.04 \\
\hline 26 & & Yes & 271.75 & 3.2 & 5.86 & 0.00 & 0.00 & 0.00 & 0.00 & $<10^{-4}$ & $<10^{-4}$ \\
\hline
\end{tabular}

NB: the locations of the intersection points are found in the Figure 4.5

The analysis of the results concluded that the actual vehicle instability risk in the stream crossings in the Godelleta municipality was high for $27 \%$ of the existing intersections, medium for $23 \%$ of these stream crossings and low for the remaining $50 \%$.

When analysing the results obtained by considering that vehicle traffic would continue moving throughout flood duration (potential risk), we observed that the values would be 2-fold higher than those obtained after considering that vehicle traffic would cease at a given time. Accordingly, $69.2 \%$ of the stream crossings would obtain values above 0.2 vehicles/year and only $26.9 \%$ of the stream crossings would have values below 0.1 vehicles/year. 
It is highlighted that most of the El Murtal Ravine stream crossings were at risk for vehicle instability. This risk can be considered medium or high, explained by this ravine having the biggest drainage area and greater flows inland of the Godelleta municipality. This condition coincides with the conclusion drawn by Versini et al. (2010), who evaluated the susceptibility of roads to flash floods in a sector of France. These authors found that the basin's area size upstream of the stream crossing was a very important factor for predicting floods in this sector.

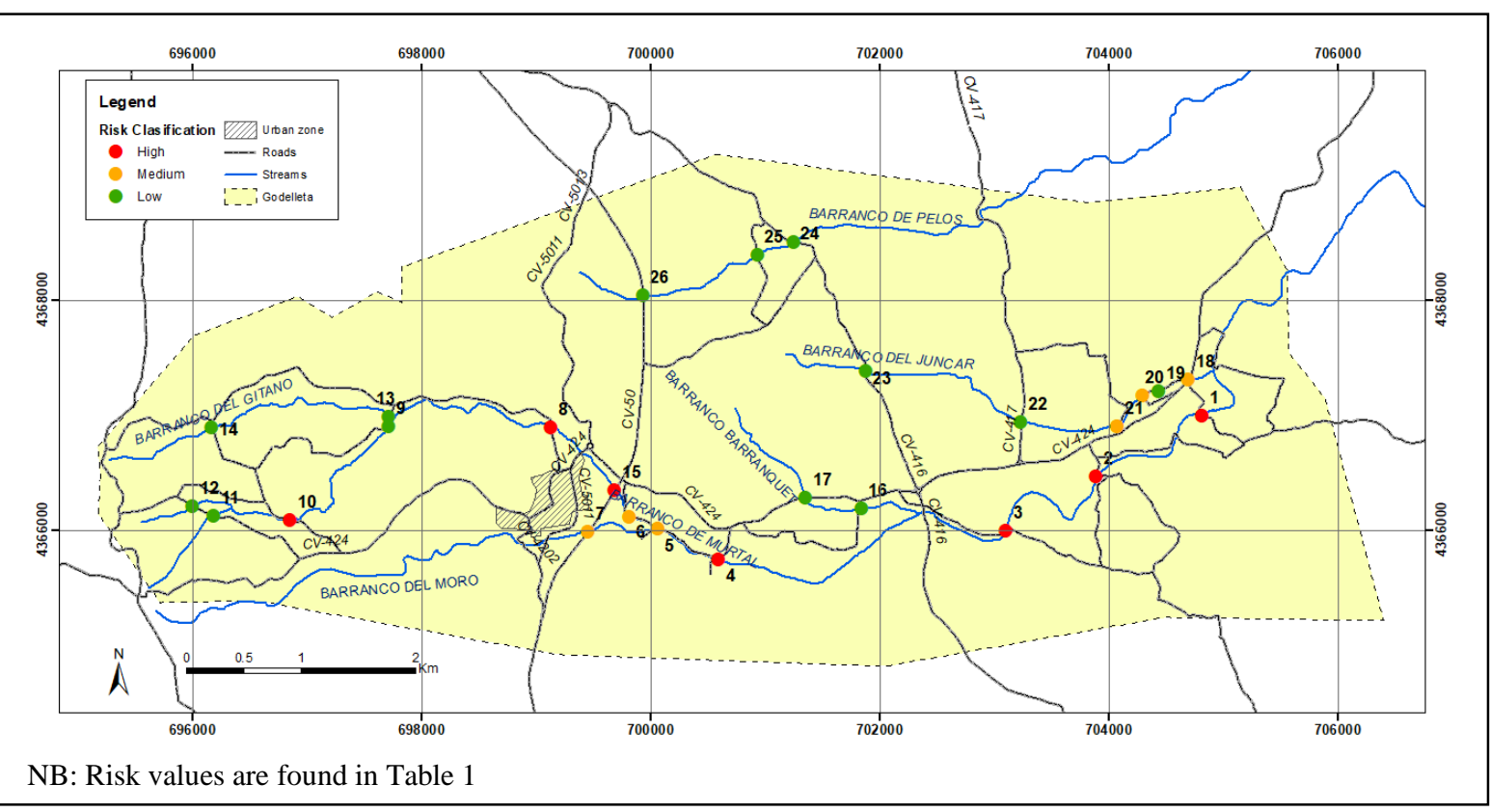

Figure 4.5 Vehicle instability risk due to floods in the stream crossings in the Godelleta municipality

It is noteworthy that the instability risk for the vehicles on roads with low traffic levels could be the same instability risk as those vehicles on roads with heavy traffic levels, as in points 6 and 7, which corresponded to the intersections of the El Murtal Ravine with the local road and road CV-50 with heavy traffic. These two stream crossings are separated from one another by approximately $600 \mathrm{~m}$, with risk values equalling 0.11 and 0.16 vehicles/year, respectively. This was because, despite road CV-50 presenting very heavy traffic, vehicles would only be affected by floods with a 500 -year return period. Although the traffic levels on the local road are much lower, vehicles would be affected by the floods corresponding to a 2-year return period.

According to the Generalitat Valenciana (2018), the diameter of the vented fords with circular culverts must be no less than $1.0 \mathrm{~m}$ to avoid obstructions caused by materials being dragged by flows. For the purpose of analysing the most unfavourable scenario possible, this analysis determined the vehicle instability risk by assuming a $0.3 \mathrm{~m}$ limit water depth and considering that the 10 vented fords with circular culverts whose diameters were less than $1.0 \mathrm{~m}$, or presented equivalent geometries, were completely obstructed when flooding took place. Table 4.2 offers the results of this analysis. One conclusion was made according to this information: in all cases, the instability risk increased when culverts were obstructed or, in some cases, this increment could even 
surpass $100 \%$. This shows the importance of employing vented fords of suitable dimensions and adequate maintenance to minimise the possibility of the vehicle instability risk increasing.

Table 4.2 Vehicle instability risk by taking a limit water depth of $0.3 \mathrm{~m}$ and vented fords with circular vents and a diameter less than $1.0 \mathrm{~m}$, or equivalent geometries, being unblocked or completely obstructed

\begin{tabular}{|l|c|c|c|c|c|c|c|c|c|c|}
\hline \multirow{2}{*}{$\begin{array}{c}\text { Degree of } \\
\text { vented ford } \\
\text { obstruction }\end{array}$} & \multicolumn{10}{|c|}{ Vehicle instability risk (vehicles/year) } \\
\cline { 2 - 12 } & $\mathbf{2}$ & $\mathbf{3}$ & $\mathbf{5}$ & $\mathbf{8}$ & $\mathbf{9}$ & $\mathbf{1 2}$ & $\mathbf{1 3}$ & $\mathbf{1 9}$ & $\mathbf{2 2}$ & $\mathbf{2 3}$ \\
\hline Unblocked & 0.21 & 0.22 & 0.11 & 0.65 & 0.08 & $2 * 10^{-6}$ & 0.02 & 0.035 & 0.017 & 0.0003 \\
\hline $\begin{array}{l}\text { Completely } \\
\text { obstructed }\end{array}$ & 0.39 & 0.47 & 0.13 & 0.87 & 0.26 & $3 * 10^{-6}$ & 0.07 & 0.042 & 0.018 & 0.0004 \\
\hline
\end{tabular}

\subsubsection{Influence of the limit water depth}

The number of vehicles at risk for instability due to floods is directly related to the limit water depth, and the risk becomes higher when drivers take poorly conservative attitudes. Nonetheless, determining this water depth is clearly associated with uncertainty because a large number of parameters influence decision making. For this reason, the effect of variation in this water depth was studied on the values of the at-risk vehicles, for which risk was determined by assuming water depths of $0.2 \mathrm{~m}, 0.4 \mathrm{~m}$ and $0.5 \mathrm{~m}$, where $0.3 \mathrm{~m}$ was the value taken while following the methodology. Figure 4.6 offers the obtained results.

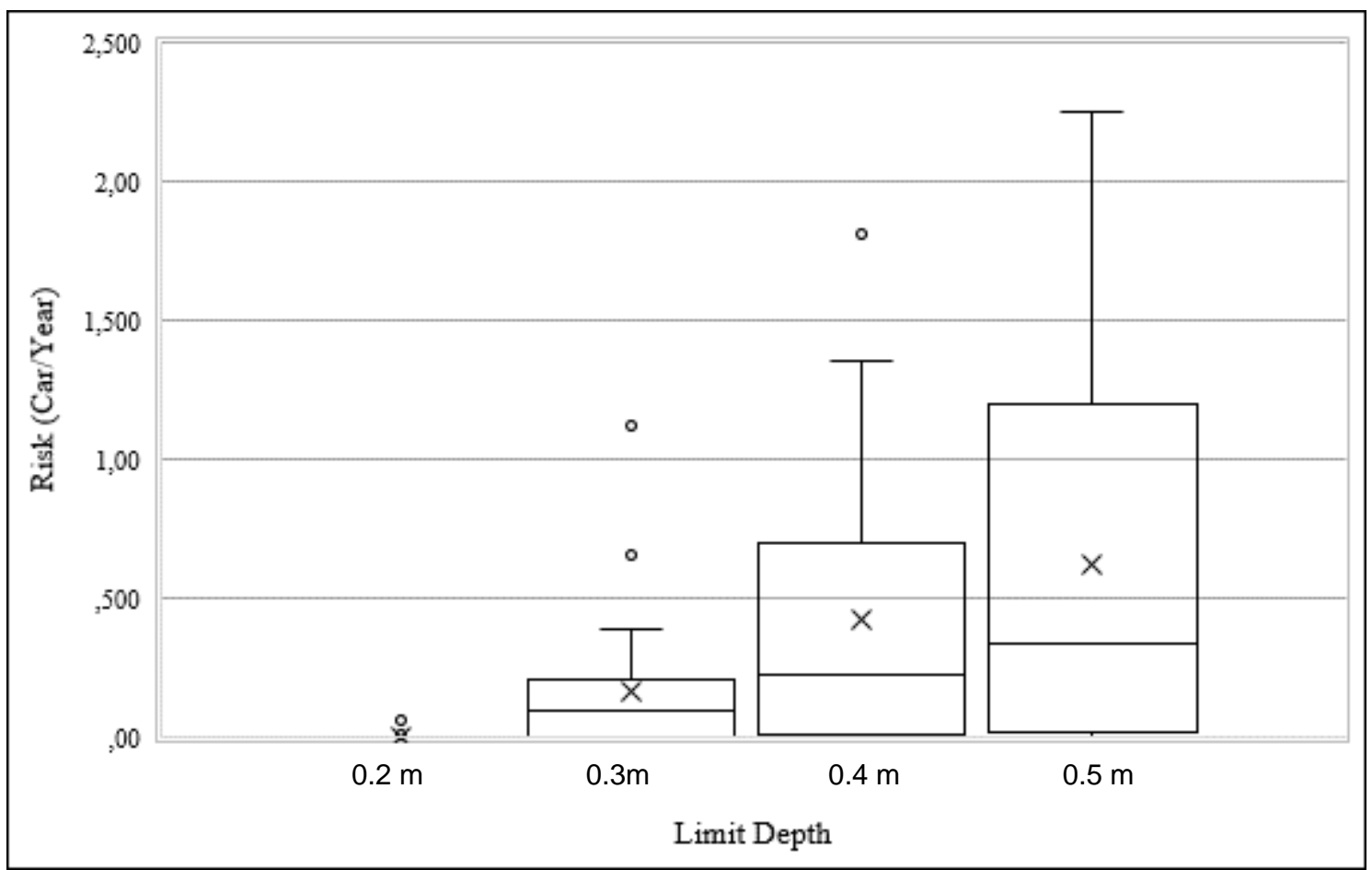

Figure 4.6 Number of vehicles at instability risk in the Godelleta municipality by considering different water depth values from which vehicle traffic could cease 
Our results indicated that the instability risk was extremely sensitive to the water depth from which vehicle traffic stopped. When vehicle traffic was interrupted by a $0.2 \mathrm{~m}$ water depth, the risk equalled zero for almost all the stream crossings. This behaviour did not include the fords corresponding to points 6 and 10, where the risk values were 0.01 and 0.06 vehicles/year, respectively. When taking limit water depth values of $0.4 \mathrm{~m}$ and 0.5 $\mathrm{m}$, we found that, in relation to the values obtained when following the methodology, the mean risk value increased by almost $250 \%$ and $400 \%$, while the maximum values rose by almost $50 \%$ and $100 \%$, respectively. As the minimum risk value did not undergo any major modifications when the limit water depth varied by between $0.2 \mathrm{~m}$ and $0.5 \mathrm{~m}$, as in point 12 where vehicles would only be affected by flows with return periods exceeding 500 years.

The range of variation of the instability risk values for the different stream crossings widened as the limit water depth value increased. The interquartile range equalled $0 \mathrm{~m}$ when considering a limit water depth of $0.20 \mathrm{~m}$. The interquartile range value was 0.20 $\mathrm{m}$ for a limit water depth of $0.3 \mathrm{~m}$. It increased to $0.63 \mathrm{~m}$ with a $0.40 \mathrm{~m}$ limit water depth and to $1.18 \mathrm{~m}$ with one of $0.50 \mathrm{~m}$.

\subsubsection{Final Remarks}

The developed methodology was applied to the Godelleta municipality, and found that roughly one quarter of the stream crossings in this study area presented a relatively high vehicle instability risk due to floods because it exceeded 0.2 vehicles/year. Conversely, the risk of approximately half these stream crossings could be considered relatively low because it did not exceed 0.1 vehicles/year.

It was noteworthy that for road CV-50, where traffic levels are higher in the Godelleta municipality, the instability risk values were lower than or equalled 0.2 vehicles/year, which are low and medium values. This was because, as a result of the characteristics of stream crossings, only the floods corresponding to long return periods would affect the vehicles driving through flooded zones.

The methodology developed in the present study can be implemented by the organisations responsible for town planning and road traffic to identify critical stream crossings in order to contribute to vehicle stability and to take measures that allow the potential negative impact of floods to lower.

Some of the measures that can be taken, and would contribute to cushion the impact of floods, would be to, for instance, suitably maintain fords and vented fords, fit new culverts or increase the size of existing ones. This would allow the lowest return period value from which vehicles would be affected to increase, namely $\mathrm{T}_{\mathrm{min}}$. Drivers' good behaviour can be encouraged by informing that they must stop when the flow depth in the stream crossing reaches a certain limit water depth, which might allow the value of the time interval during which flow could affect vehicle stability, namely $\Delta t_{i}(T)$, to lower. 


\section{RISK ASSESSMENT OF BRIDGE FAILURE DUE TO RIVER FLOODS}

\subsection{Introduction}

Bridges are very important infrastructure works that are exposed to various natural hazards, such as river floods, which can cause them to fail. The main causes of bridge failures due to hydraulic actions include scour, structural deterioration, debris accumulation, increased hydraulic loads and underpressure under the deck. Bridge failure can be caused by damage to one or more parts of the substructure (foundation, piles and abutments) or the superstructure (deck, supporting structure and accessories).

Owing to the disastrous consequences of bridge failures, determining the risk of these structures due to flooding is critical for design purposes and the scheduling of maintenance work. However, there have been very few studies on this topic to date. Most of the studies available focus on determining the vulnerability of structures, but do not assess the hazard or risk of bridges in the event of a flood.

These studies include the method proposed by Federico et al. (2003) to assess the vulnerability of bridges to scour by considering the fluvial phenomena that govern the fluvial dynamics of river floods. This method is based on the estimation of the maximum scour depth in piles and foundations and on the analysis of the bearing capacity of the pile-foundation-soil system. Vallés et al. (2011) proposed a methodology for assessing the vulnerability of bridges over water currents to river floods, based on the analysis of geomorphological, hydraulic-sedimentological and structural aspects. Hung and Yau (2017) developed a method of rational vulnerability assessment of pile-supported eroded bridges using a non-linear three-dimensional model that takes into account interactions between bridge structures, water flow, soil and pile foundations

The works that seek to evaluate the risk of bridges due to floods include the methodology presented by FHWA in 2002, which is actually an improvement of a methodology presented by the same agency in 1994. In this method the relative annual risk of failure due to erosion of a bridge is calculated as the product of the probability of failure by cost associated with such event. Mondoro and Frangopol (2017) presented a methodology that performs a benefit-cost analysis based on the risk of failure of bridges exposed to extreme hydrological events; in this study the total risk is calculated as the sum of anticipated risks according to the various potential failure modes of the structure.

This chapter developed a new methodology to determine the risk of bridge failure due to flooding by analysing the integrity of the structure and the hydrological, hydraulic and morphological characteristics of the water current and watershed. The main objective of this methodology is to provide the necessary elements of judgement to order bridges according to their level of risk and, therefore, the promptness with which the restoration and/or maintenance work must be undertaken.

For this purpose, initially the types of failure that can occur on a bridge and their causes are described. The developed methodology is then presented, indicating the procedure to be followed to obtain the hazard, vulnerability and risk levels. Finally, the implementation of this methodology in a set of bridges located on Spanish roads is presented and this case 
study is used for a sensitivity analysis of the proposed values for vulnerability and the return period from which the structure begins to be affected.

\subsection{Failure of bridges over water currents}

\subsubsection{Typology of fails}

The failure of a bridge is defined as the inability of the bridge to work according to the parameters established during its design and construction in such a way that it cannot be crossed or cannot be crossed safely. According to Wardhana and Hadipriono (2003), this failure can correspond to: (i) a collapse when all or part of the structure falls down; (ii) a deterioration when the structure or some of its components undergo wear that could or could not lead to collapse.

The flow of a water current performs several hydrodynamic actions on a bridge and this can generate different failure mechanisms that interact with each other (Mondoro and Frangopol, 2017). These actions include underpressure and hydrodynamic pressure on the deck, which could cause it to detach from the piles. This detachment can occur vertically when the underpressure exceeds the capacity of the bridge in this direction or in a transverse direction when the hydrodynamic pressures exceed the lateral resistance of the deck-piles assembly.

Another failure mechanism occurs as a result of the overload imposed on the substructure by the hydrodynamic pressures generated by the flow, which can lead to the piles failing. In the same way, undermining near the bridge can cause structure failure due to foundation failure or instability generated in the piles or abutment-foundation system (Liang and Lee 2013).

According to Mondoro and Frangopol (2017), the interaction of these failure mechanisms occurs, for example, when the action of the flow on the deck has not caused its failure but generates an increase in the hydraulic loads on the piles and the foundation, increasing the probabilities of failure of the latter; additionally, the contraction of the flow passing under the deck can increase scour on the foundation of the structure.

Because the independent or combined failure of the deck, piles or foundation makes the bridge unusable, the bridge is considered to have failed when any of these three parts have failed.

\subsubsection{Causes of failures}

The failure of a bridge due to the action of a water current can be the result of multiple causes, including scour, deterioration of materials, accumulation of debris and instability of the stream. Scour is the most common cause of bridge failure during flooding as the removal of material from the supporting soil reduces the bearing capacity of the foundation and increases the load on the piles and abutments. (Yanmaz and Apaydin, 2012; Hung and Yau, 2017; Kim et al., 2017). Total scour is equal to the sum of general scour, localized scour and local scour (Barbetta et al., 2017). General scour corresponds to a decrease of the bed level in long sections of the watercourse due to the transport of 
sediments; localized scour occurs as a result of the narrowing of the watercourse affecting a short section; and local scour occurs due to the obstruction to the flow by the piles and abutments.

The location of bridges over water currents favours the deterioration of the materials with which the structure is built, caused by the permanent presence of water and sediments transported by rivers. Deterioration mechanisms include corrosion of reinforcing steel and concrete wear in reinforced concrete structures, corrosion of metallic parts on metallic bridges and deterioration of the elements with which masonry bridges are built.

The accumulation of debris has been the cause or part of the set of causes of the failure of many bridges. Owing to this accumulation, the hydraulic capacity of the bridge decreases, the water level upstream of the bridge and the flow velocity increases and the flow patterns change. The increase in water levels increases the hydraulic loads on the structure, the increase in speeds favours erosion processes and the change in flow patterns can generate strong lateral currents and, consequently, large local scour (FHWA, 2005).

The problems generated in bridges by the instability of watercourses are due to morphological changes in them and have been the cause of the failure of many of such structures (Johnson, 2005). These problems could also be considered as caused by scour and can be reflected in phenomena such as a widening of the channel, a lateral migration or a cut by meanders that can affect the structure.

\subsection{Methodology}

According to equation 1.2 the risk can be calculated by means of the statistical integral of the product of the flood hazard by the vulnerability. In this methodology the risk indicates the probability of annual failure and the vulnerability indicates the probability of failure at the occurrence of the magnitude event $y$, therefore, its value fluctuates between 0 and 1 . The process by which the hazard, the vulnerability and the risk are obtained is described in the following sections

\subsubsection{Hazard}

The flood hazard corresponds to the probability of occurrence of a potentially damaging event, considering that the damage could occur because there are elements exposed to such flood (Schanze, 2006). According to Salazar (2013), this type of event is physically characterized by indicators of its magnitude or intensity.

To quantify the hazard of a bridge regarding floods, consideration must be given to the fact that the hydrodynamic actions generated on the structure and the erosive phenomena that cause changes in the cross section of the river are proportional to the magnitude of such floods, since with more intense floods, stronger impacts are expected both in the bridge and in the cross section of the river. Considering that the structure of a bridge can be affected by the increase in both water levels and flow velocity, in this study the magnitude of the floods was established by the maximum discharge, as it implicitly considers these two parameters. 
In order to define the hazard, the cross section of the flow was divided into four bands (see Figure 5.1): the first band covers from the level of the thalweg of the channel to the level reached by a discharge such that it does not generate damage to the structure and whose magnitude could be similar to the magnitude of the dominant or equivalent discharge; in this methodology, the level reached by this discharge has been labelled $\mathrm{T}_{\min }$. The second band is located between the level of the $T_{\min }$ and the level reached by the discharge corresponding to $66 \%$ of the full-bank discharge. The third band is located between the level that reaches the discharge corresponding to $66 \%$ of the full-bank discharge and the full-bank level. The fourth and last band is located above the full-bank level.

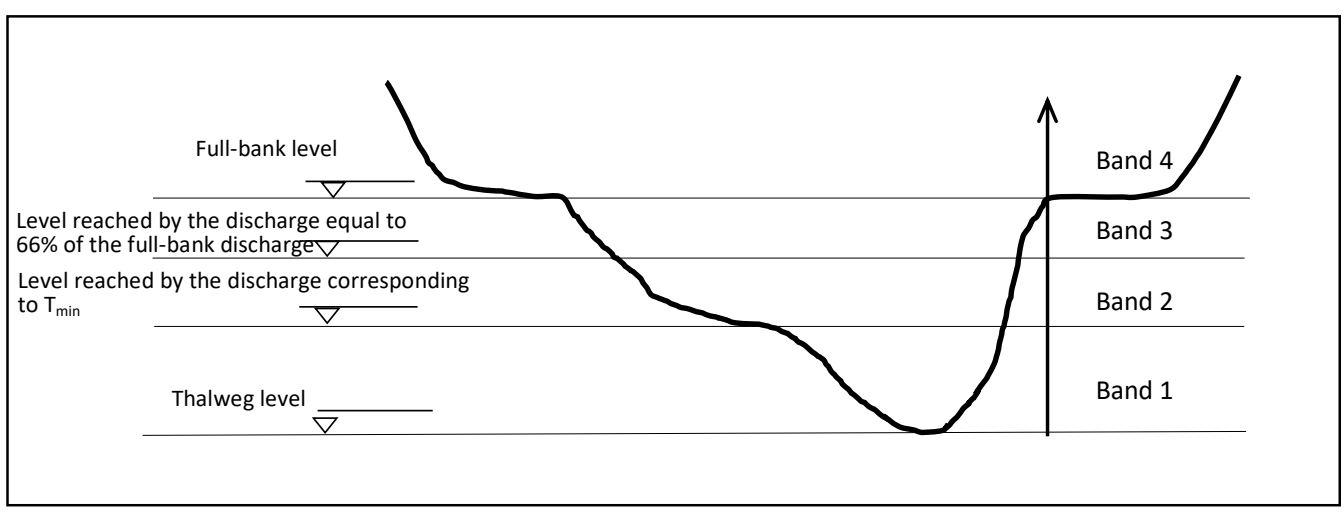

Figure 5.1 Scheme representing the bands into which the cross section of a watercourse is divided for the purpose of the magnitude of a flood

It is considered that the discharges located in the first band (low discharges) are below the threshold from which important erosive actions would be generated in the cross section, so its effect on the stability of the structure is quite small. The potential impact of the flood on the structure increases as the magnitude of the discharges in the second and third bands increases, in such a way that the full-bank discharge would have an impact close to the maximum potential impact; this is due to the fact that once the river has overflowed, the discharges grow with no significant increase in flow velocity and depth (Vide, 2003). Owing to this, in the fourth band the destabilizing effect on the structure is expected to not be much greater than that which would be produced with full-bank discharges.

In this methodology, hazard is defined as the probability of the discharge being in each of the four bands into which the cross section was divided.

\subsubsection{Vulnerability}

In determining the vulnerability of a bridge, it should be noted that during a flood the degree of affectation of the superstructure may differ from the degree of affectation of the substructure, whereby the probability of bridge failure is established as the probability of joint failure of both parts of the structure. 
The vulnerability of a bridge to flooding is determined by several factors, such as the state of the structure, the stability of the stream channel in which it is located, the capacity of the bridge to accumulate debris and the deterioration of the structure due to its age and the environment in which it is located.

In this study, a base vulnerability of the substructure and superstructure was first and separately identified. This base vulnerability considers only their condition and integrity. Second, the impact of the remaining aspects was established through multiplication factors of this base vulnerability, as given in Equations 5.1 and 5.2:

$$
\begin{gathered}
V_{b}=V_{B b} F_{s} F_{d} F_{t} \\
V_{s}=V_{B s} F_{d} F_{t}
\end{gathered}
$$

where:

$V_{b}=\quad$ Vulnerability of the substructure

$V_{B b} \quad$ Base vulnerability of the substructure

$V_{S}=\quad$ Vulnerability of the superstructure

$V_{B s} \quad$ Base vulnerability of the superstructure

$F_{s}=\quad$ Multiplication factor due to the stability of the stream channel

$F_{d}=\quad$ Multiplication factor due to the potential of the structure to accumulate debris

$F_{t}=\quad$ Multiplication factor due to deterioration of the structure

The multiplication factor due to the stability of the stream channel is not included in Equation 5.2 because, with a few exceptions, this aspect is unlikely to affect the superstructure. The different components of these equations are described in more detail in the following sections.

\subsubsection{Base vulnerability}

The base vulnerability of the structure is a function of various aspects that determine the susceptibility of its current condition and integrity to flood damage. According to Vallés (2011), the most relevant of these factors are the following:

- Type of foundation. It could be superficial (the most susceptible), semi-deep or deep (the least susceptible).

- Structural specifications of the bridge. It refers to the materials with which the bridge is built and the various types of abutments, piles and decks.

- Condition of the structure. The substructure and superstructure units could suffer severe or minor damage.

- Scour. It could be severe, advanced, moderate, incipient or non-existent.

- Material of the watercourse in the vicinity of the abutments and piles. It could be, for example, alluvial, solid terrain or rock.

To estimate the base vulnerability of the structure, an assessment of the condition of the structure must initially be made based on the assessment of the factors listed above. In this study, this assessment was made through the procedure proposed by Vallés et al. 
(2011), which classifies structures by assigning a code between 0 and 9 based on the assessment of these factors. The better the condition of the structure, the greater the corresponding code, such that 0 corresponds to bridges that have already failed and 9 to bridges in excellent condition (Table 5.1).

In order to classify the structure, each of the units that make up the structure must be independently evaluated and classified. The classification of the bridge shall correspond to the classification of the structural unit in the worst condition.

To each one of the codes in which the structure can be classified correspond vulnerability values that depend on the bands into which the cross section was divided, since vulnerability increases as the intensity of the flood increases. Since band 1 corresponds to discharges below the discharge from which the cross section and/or structure may be affected, the vulnerability for this band is zero. The vulnerability values defined for the remaining bands and each of the classification codes are given in Table 5.1. The values presented in this table correspond to the probability that the bridge will fail when the considered flood occurs.

Table 5.1 Base vulnerability of the substructure (VBb) and superstructure (VBs) of a bridge in floods adopted in this proposal

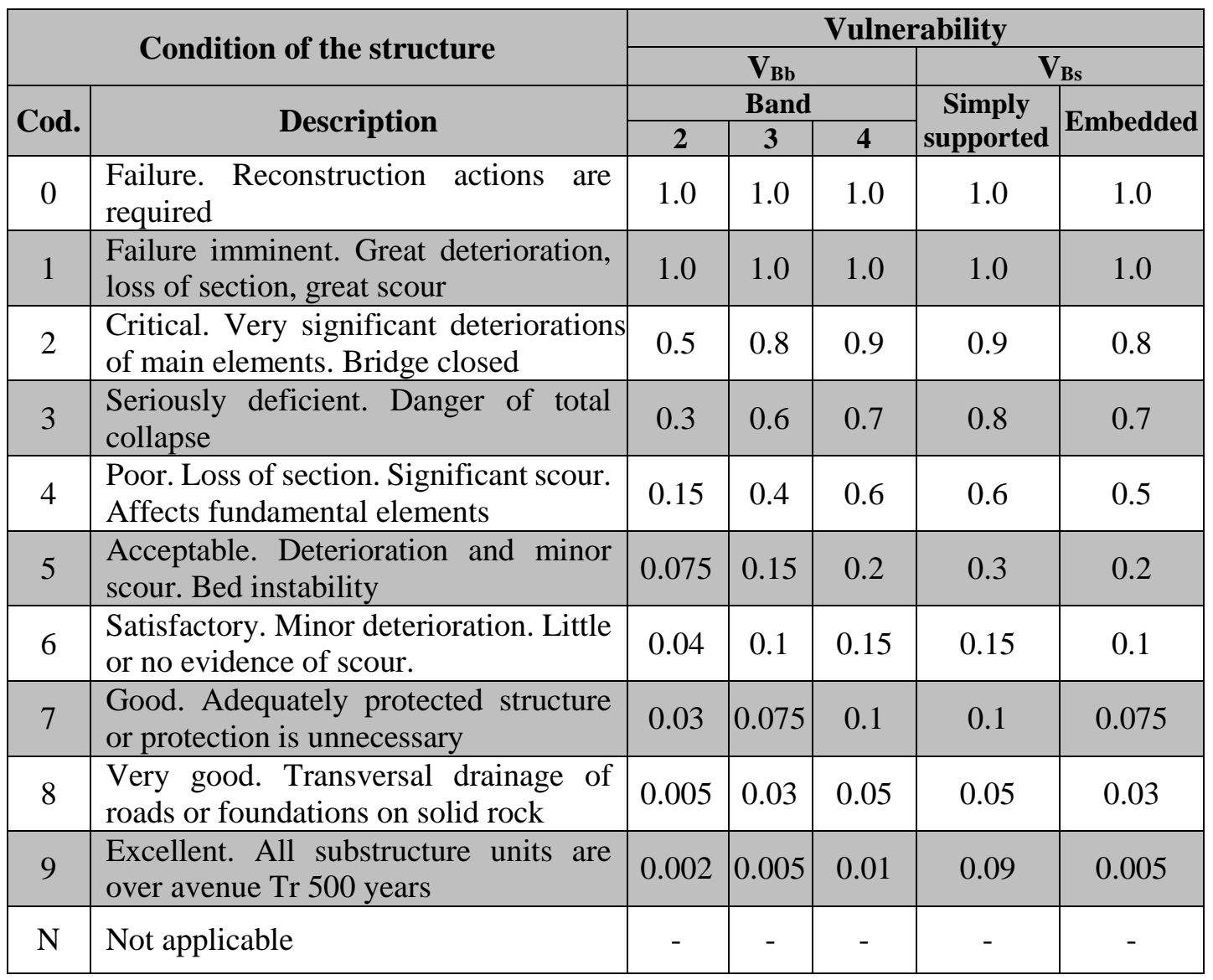




\subsubsection{Stream channel stability}

The lack of horizontal and vertical stability of a stream channel can lead to the collapse of important infrastructure works, including bridges. However, despite the potential negative effects of this phenomenon, to date there are few methods available to assess the degree of stability of a river (Yanmaz et al., 2007; Johnson et al., 2011).

Determining the stability of a water current should include an assessment of the existing and potential processes of bed aggradation and degradation, cross section widening and lateral migration. This assessment must take into account both the local characteristics (in this case, the location of the bridge) and those of the entire watershed.

Factors to be considered at basin level include land use (natural, light or highly anthropized, etc.), flow regime (e.g. perennial, intermittent, rapid, slow, etc.), and type of watercourse (straight, meandering or braided). The factors of the channel to be considered in the place where the bridge is located include in particular the slope, granulometry of the bed material (e.g. cohesive material, granular material, pebbles, etc.), the degree of confinement of the channel, the presence of bars and obstructions to the flow, the orientation of the structure with respect to the flow, the presence of vegetation on the banks and the floodplain, the state and inclination of the banks and the characteristics (e.g. concrete works, bioengineering works, gabions, etc.) and condition (good, seriously deteriorated, minor damage, etc.) of the protection measures.

In this methodology, stream channel stability is determined by the most unfavourable condition obtained by implementing the procedure proposed by Johnson (2005) and by evaluating the condition of the channel by means of item 61 of FHWA guide PD-96-001 (FHWA, 1995). The method proposed by Johnson (2005) corresponds to an improvement of a methodology previously proposed by Johnson et al. (1999). This procedure seeks to establish the general stability of the stream channel by evaluating the following 13 parameters: watershed and floodplain activity and characteristics, flow habit, channel pattern, entrenchment/channel confinement, bed material, bar development, obstructions, bank soil texture and coherence, bank slope angle, vegetative or engineered bank protection, bank cutting, mass wasting or bank failure, upstream distance to bridge from meander impact point and alignment (Johnson, 2005).

Johnson (2005) assigns each of these 13 parameters a value between 1 and 12, with a rating of 1 for the best possible rating and 12 for the worst. The sub-ratings are added together to obtain a final rating, which varies between 13 and 156 and provides an overall assessment of the stability of the current.

Data item 61 of the FHWA guide PD-96-001 (FHWA, 1995) allows an evaluation of the stability conditions of the sector in which the bridge is located, evaluating parameters different from those considered by Johnson (2005). This item defines the stability of the watercourse by establishing a scale of between 0 and 9 , with 0 as the worst condition and 9 as the best condition. Since the scales used by Johnson (2005) and FHWA (1995) are different from each other, Johnson et al. (2011) made an equivalence between these two scales to establish the general stability of the water current, which could be classified as excellent, good, acceptable or poor (Table 5.2). 
Considering that, as already noted, the two methods used evaluate different parameters, it is possible to obtain two different stability conditions for the same current. As a result, in this methodology the stability of the stream channel is determined by the most unfavourable condition, that is, by the one that indicates the least stability. Thus, the proposal of this methodology for the multiplication factor corresponding to the stability of the stream channel that affects the base vulnerability (Equation 5.1) ranges from 1.0 for an excellent stability condition to 1.3 for a poor stability condition (Table 5.2).

Table 5.2 Proposed values of the base vulnerability multiplication factor due to the stability of the water current $\left(F_{s}\right)$

\begin{tabular}{|c|c|c|c|c|}
\hline \multicolumn{2}{|c|}{$\begin{array}{c}\text { Stability of the stream } \\
\text { channel } \\
\text { Johnson scale }\end{array}$} & \multicolumn{2}{|r|}{$\begin{array}{l}\text { Channel condition } \\
\text { Item } 61 \text { of the FHWA coding system }\end{array}$} & \multirow[t]{2}{*}{$\mathbf{F}_{\mathrm{s}}$} \\
\hline Rating & Description & Cod. & Description & \\
\hline \multirow{3}{*}{$>120$} & \multirow{3}{*}{ Poor } & 0 & $\begin{array}{l}\text { Bridge closed because of channel failure. } \\
\text { Replacement necessary }\end{array}$ & \multirow{3}{*}{1.3} \\
\hline & & 1 & $\begin{array}{l}\text { Bridge closed because of channel failure. } \\
\text { Corrective action may put back in light service }\end{array}$ & \\
\hline & & 2 & $\begin{array}{l}\text { The channel has changed to the extent the bridge } \\
\text { is near a state of collapse }\end{array}$ & \\
\hline \multirow{3}{*}{$86-120$} & \multirow{3}{*}{ Acceptable } & 3 & Bank protection has failed & \multirow{3}{*}{1.2} \\
\hline & & 4 & $\begin{array}{l}\text { Bank and embankment protection is severely } \\
\text { undermined }\end{array}$ & \\
\hline & & 5 & Bank protection is being eroded & \\
\hline \multirow{2}{*}{$50-85$} & \multirow{2}{*}{ Good } & 6 & Bank is beginning to slump & \multirow{2}{*}{1.1} \\
\hline & & 7 & Bank protection is in need of minor repairs & \\
\hline \multirow[b]{2}{*}{$12-49$} & \multirow[b]{2}{*}{ Excellent } & 8 & Banks are protected or well vegetated & \multirow[b]{2}{*}{1.0} \\
\hline & & 9 & $\begin{array}{l}\text { There are no deficiencies which affect the } \\
\text { condition of the channel }\end{array}$ & \\
\hline- & - & $\mathrm{N}$ & Not applicable & - \\
\hline
\end{tabular}

\subsubsection{Potential of the structure to accumulate debris}

The accumulation of debris in bridges is a widespread problem that has been among the causes of the collapse of several structures of this type. The accumulation of debris can generate several problems, including the decrease in transport capacity across the bridge, the increase in local and localized erosion, the increase in hydraulic loads and the generation or increase in flooding upstream of the structure (FHWA, 1997).

According to NCHRP (2010), the potential of the structure to accumulate debris is a function of: (i) the potential of the upstream watershed of the structure to produce debris and the capacity of the stream to transport it; (ii) the location of the piles and abutments of the bridge with respect to the watercourse, which could be protected (forest area or with other obstructions that could trap the debris upstream of the bridge), in the floodplain and top of the bank (areas without trees or prone to being left without trees), in the channel or in the sector of the cross section in which the transport of debris is concentrated; (iii) 
the type of pile of the bridge, which could be solid or with openings; and (iv) the dimensions of the spans between the different elements of the bridge and the cross section.

FHWA (2005) establish the potential of the piles and spans to accumulate debris through the information given in Table 5.3, which is based on the evaluation of the above aspects. In order to establish the potential of the bridge to accumulate debris, the potential of each pile and each span for such accumulation must be determined independently and then the most unfavourable option, i.e. the highest potential, must be selected.

Table 5.3 also shows the values proposed in this methodology for the base vulnerability multiplication factor due to the potential of the structure to accumulate debris (Equations 5.1 and 5.2).

Table 5.3 Proposed values of the base vulnerability multiplication factor due to the potential of the structure to accumulate debris (Fd)

\begin{tabular}{|c|c|c|c|c|c|}
\hline \multicolumn{2}{|c|}{ Element of the structure } & \multirow{2}{*}{ Location } & \multirow{2}{*}{\begin{tabular}{|c|} 
Potential for \\
debris \\
transport and \\
delivery
\end{tabular}} & \multirow{2}{*}{$\begin{array}{c}\text { Potential to } \\
\text { accumulate } \\
\text { debris }\end{array}$} & \multirow{2}{*}{$\mathbf{F}_{\mathbf{d}}$} \\
\hline Type & Classification & & & & \\
\hline \multirow{12}{*}{ Pile } & - & Sheltered & - & \multirow{4}{*}{ Low } & \multirow{4}{*}{1.0} \\
\hline & \multirow{2}{*}{ Solid } & Top bank-Flood plain & - & & \\
\hline & & Channel & Low & & \\
\hline & With openings & Top bank-Flood plain & Low & & \\
\hline & \multirow[b]{2}{*}{ Solid } & Channel & High & \multirow{4}{*}{ Medium } & \multirow{4}{*}{1.1} \\
\hline & & $\begin{array}{l}\text { Path of concentrated } \\
\text { debris transport }\end{array}$ & Low & & \\
\hline & \multirow{2}{*}{ With openings } & Top bank-Flood plain & High & & \\
\hline & & Channel & Low & & \\
\hline & Solid & $\begin{array}{c}\text { Path of concentrated } \\
\text { debris transport }\end{array}$ & High & \multirow{3}{*}{ High } & \multirow{3}{*}{1.2} \\
\hline & \multirow[t]{2}{*}{ With openings } & $\begin{array}{c}\text { Path of concentrated } \\
\text { debris transport }\end{array}$ & Low & & \\
\hline & & Channel & High & & \\
\hline & With openings & $\begin{array}{c}\text { Path of concentrated } \\
\text { debris transport }\end{array}$ & High & $\begin{array}{l}\text { High- } \\
\text { Chronic }\end{array}$ & 1.3 \\
\hline \multirow{8}{*}{ Span } & - & Sheltered & - & \multirow{4}{*}{ Low } & \multirow{4}{*}{1.0} \\
\hline & $\begin{array}{l}\text { Width greater than } \\
\text { design log length }\end{array}$ & - & - & & \\
\hline & \multirow{2}{*}{$\begin{array}{l}\text { Width smaller than } \\
\text { design log length }\end{array}$} & Top bank-Flood plain & Low & & \\
\hline & & Channel & Low & & \\
\hline & \multirow{2}{*}{$\begin{array}{l}\text { Width smaller than } \\
\text { design log length }\end{array}$} & $\begin{array}{l}\text { Path of concentrated } \\
\text { debris transport }\end{array}$ & Low & \multirow[t]{2}{*}{ Medium } & \multirow[t]{2}{*}{1.1} \\
\hline & & Top bank-Flood plain & High & & \\
\hline & $\begin{array}{l}\text { Width smaller than } \\
\text { design trunk length }\end{array}$ & Channel & High & High & 1.2 \\
\hline & $\begin{array}{l}\text { Width smaller than } \\
\text { design log length }\end{array}$ & $\begin{array}{c}\text { Path of concentrated } \\
\text { debris transport }\end{array}$ & High & $\begin{array}{l}\text { High- } \\
\text { Chronic }\end{array}$ & 1.3 \\
\hline
\end{tabular}




\subsubsection{Deterioration of the structure due to its age and the environment in which it is located}

The deterioration of a bridge due to its ageing and the environment in which it is located increases its vulnerability to flooding. In this methodology, the impact of this deterioration on vulnerability is established on the basis of the material in which the structure is built.

\section{$\underline{\text { Reinforced concrete bridges }}$}

In this type of structure, consideration must be given to the deterioration of the concrete and the reinforcing steel. The location of bridges on water currents favours the deterioration of the concrete as most of the mechanisms that generate such deterioration require the presence of high moisture content or liquid water. In fact, attacks on concrete by dry chemicals are rare (Boyd and Skalny, 2007). The main causes of concrete deterioration include the alkali-aggregate reaction, abrasion by external agents, frost and thaw cycles and the attack of sulphates.

The alkali-aggregate reaction refers to the chemical reaction of certain aggregates with the hydroxyl ions and alkaline components of the cement paste, which generates expansive reactions, concrete cracking and loss of resistance and elastic modulus (Mehta and Monteiro, 2006). This reaction requires the presence of moisture, is more severe when structures are subject to wetting and drying cycles and occurs more rapidly at higher temperatures. According to Malhotra (2011), when using a similar type of reactive greywacke aggregate in Cape Province in South Africa, the deterioration of structures due to this phenomenon occurs after a period of between 4 and 7 years, while in Canada, where the temperature is much lower, the deterioration usually appears after 15-20 years.

Deterioration due to sulphate attack occurs when the structure is exposed to soil, groundwater or agricultural or industrial waste containing sulphate ions (Boyd and Skalny, 2007). The penetration of sulphate into the concrete structure generates expansive chemical reactions that cause a loss of strength due to the loss of adhesion between the cement paste and the aggregates (Maes et al., 2012). The degree of deterioration depends mainly on the concentration of sulphate ions in the soil or water that is in contact with the concrete (Aguirre and Mejía de Gutiérrez, 2013).

External agents, such as the action of the sediments carried by water, ice or waves on a pile or abutment of a bridge, can generate significant abrasion on the concrete surface, especially during large floods (Ministerio de Fomento de España, 2012). Ragab et al. (2012) found average concrete abrasion rates of between 0.2 and $0.8 \mathrm{~mm} /$ year in waves repellent blocks of different ages (between 4 and 62 years) built on the northern coast of the Mediterranean Sea in Egypt.

The ice and water thawing cycles generate a significant deterioration of the concrete, as the water contained in the pores of the concrete freezes, increasing its volume by approximately $9 \%$, generating stress forces that cause cracks in and delamination of the concrete (Mejía and Rodríguez, 1999). The deterioration of the structure depends on the 
permeability of the concrete, the amount of water available for ice formation, the degree of saturation of the concrete and the rate at which ice is formed.

Corrosion of reinforcing steel has been the cause of the collapse of many bridges (Wardhana and Hadipriono, 2003; Concrete Society, 2002) and is mainly due to carbonation phenomena and chloride attack. Steel corrosion occurs when aggressive agents $\left(\mathrm{CO}_{2}\right.$ and chloride ions) enter the cement matrix and reach the metal (Instituto Mexicano del Transporte IMT, 2001).

Carbonation is due to the entry of $\mathrm{CO}_{2}$ into the concrete from the atmosphere, which is why urban and industrial environments and environmental pollution favour this process. Other factors that favour carbonation correspond to inadequate curing, a high permeability of the concrete and a relative humidity whose ideal values to encourage the phenomenon are between 50 and 70\% (Aguirre and Mejía de Gutiérrez, 2013). According to El-Reedy (2008), the diffusion rate of carbonation can be of the order of $0.25 \mathrm{~mm} / \mathrm{year}$ and $1 \mathrm{~mm} /$ year for good and poor quality concretes, respectively. According to Andrade (2007), the corrosion propagation period up to an acceptable minimum value due to the carbonation phenomenon would be between 20 and 40 years assuming a corrosion rate of $5 \mu \mathrm{m} /$ year.

The chloride attack can come from two main sources: the first is chloride ions in the concrete, e.g. due to aggregates or contaminated water, seawater or additives with high chloride content. In the second source, the chlorides come from outside due to exposure to marine environments, the use of de-icing salts and chemicals containing chlorides (ElReedy, 2008). The advancement of chlorides in concrete is related to its permeability (Aguirre and Mejía de Gutiérrez, 2013). According to Andrade (2007), in this case the maximum period to be considered until the corrosion reaches an acceptable limit value is 5-10 years, since in cases of localized corrosion the deterioration of the structure can be significant. For example, Costa and Appleton (2002) reported corrosion rates of 7 $\mu \mathrm{m} / \mathrm{year}$ due to chloride attack on a deteriorated bridge near the sea in Portugal.

According to Andrade (2007), for service lives of more than 75 years or when the structure is located in very aggressive environments, reinforced concrete requires a minimum quality and coverage thickness or even additional protection methods to prevent corrosion.

The multiplication factors of the base vulnerability due to the deterioration of bridges built in reinforced concrete are given in Table 5.4.

\section{Metallic Bridges}

The main durability problem of this type of structure is represented by the corrosion of the metallic elements, which are very sensitive to climatic and environmental factors. The rate of corrosion depends on the temperature, humidity and aggressiveness of the air in contact with the structure (Matute and Pulido, 2012). The most adverse conditions correspond to those in which structures are exposed to marine environments, in direct contact with water for long periods of time, exposed to permanent humidity or industrial 
atmospheres or contaminated with aggressive agents such as $\mathrm{SO}_{2}$ (Sánchez, 2012; Ministerio de Fomento de España, 2012).

Several strategies are available to counteract or control corrosion, including the application of a coating (zinc, aluminium, etc.), paints that act as a physical barrier and the use of corten steels, which first appeared in civil and architectural works in the 1960s (Sánchez, 2012).

The base vulnerability multiplication factors adopted as a consequence of the deterioration of metal bridges are given in Table 5.4.

\section{Masonry Bridges}

These structures have high strength and rigidity, which gives them very long service lives. Their strength is defined by the mortar, which has a much lower strength than that of stone materials (Sharhosis, 2016).

The deterioration of these structures is caused mainly by water, sediments transported by rivers, the effect of traffic and unfavourable environmental and climatic conditions such as those found in urban and industrialized areas. There are also more problems with bridges built with bricks than with bridges built with stone materials (Ministerio de Fomento de España, 2012)

The values of the base vulnerability multiplication factor adopted in this methodology due to the deterioration of masonry bridges are given in Table 5.4.

Table 5.4 Proposed values of the base vulnerability multiplication factor due to the deterioration of the bridge structure $(\mathrm{Ft})$

\begin{tabular}{|c|c|c|c|c|}
\hline \multicolumn{4}{|c|}{ Specifications of the Structure } & \multirow[b]{2}{*}{$\mathbf{F}_{\mathbf{t}}$} \\
\hline \multicolumn{2}{|c|}{ Type } & Location & $\begin{array}{c}\text { Age } \\
\text { (vears) }\end{array}$ & \\
\hline \multirow{8}{*}{\multicolumn{2}{|c|}{ Reinforced Concrete }} & \multirow{4}{*}{$\begin{array}{l}\text { Non-marine environments and } \\
\text { no de-icing salts }\end{array}$} & $0-20$ & 1.0 \\
\hline & & & $20-40$ & 1.1 \\
\hline & & & $40-75$ & 1.2 \\
\hline & & & $>75$ & 1.3 \\
\hline & & \multirow{4}{*}{$\begin{array}{l}\text { Marine environments or de-icing } \\
\text { salts }\end{array}$} & $0-10$ & 1.0 \\
\hline & & & $10-20$ & 1.1 \\
\hline & & & $20-40$ & 1.2 \\
\hline & & & $>40$ & 1.3 \\
\hline \multirow{4}{*}{\multicolumn{2}{|c|}{ Metallic }} & \multirow{2}{*}{ Rural or urban environment } & $<50$ & 1.0 \\
\hline & & & $>50$ & 1.2 \\
\hline & & \multirow{2}{*}{ Marine or industrial environment } & $<50$ & 1.1 \\
\hline & & & $>50$ & 1.3 \\
\hline \multirow{4}{*}{$\begin{array}{l}\text { Masonry } \\
\text { bridges }\end{array}$} & \multirow{2}{*}{$\begin{array}{l}\text { Stone } \\
\text { materials }\end{array}$} & Rural environment & - & 1.0 \\
\hline & & Urban or industrial environment & - & 1.1 \\
\hline & \multirow{2}{*}{$\begin{array}{l}\text { Ceramic } \\
\text { materials }\end{array}$} & Rural environment & - & 1.2 \\
\hline & & Urban or industrial environment & - & 1.3 \\
\hline
\end{tabular}




\subsubsection{Risk of bridge failure due to river floods}

The risk of bridge failure due to river floods is calculated as the product of the probability of a flood occurring multiplied by its possible negative consequences on the structure. By solving Equation 1.2 discretely, considering that the substructure and superstructure can fail independently, one obtains that the risk of failure of a bridge corresponds to:

$$
R i s k=\sum_{i=2}^{4} V_{b_{i}} \Delta P_{i}+V_{s} P_{S}
$$

where:

$V_{b i}=$ Vulnerability of the substructure for flows located in the $\mathrm{i}$ band of the cross section $\Delta P_{i}=$ Probability of discharges occurrence in band $\mathrm{i}$

$V_{s}=$ Vulnerability of the superstructure

$P_{s}=$ Probability of the flood reaching the superstructure

By replacing Equations 5.1 and 5.2 in Equation 5.3 one has:

$$
R i s k=\sum_{i=2}^{4} V_{B b_{i}} F_{S} F_{d} F_{t} \Delta P_{i}+V_{B S} F_{d} F_{t} P_{S}
$$

In determining risk, only the vulnerability and the probability of discharges occurrence in bands 2, 3 and 4 are considered; information related to band 1 is not considered since, as already noted, the discharges in this band are lower than the discharges corresponding to the $T_{\min }$, so they do not have a negative impact on the structure. It should also be noted that the maximum value of the product of the base vulnerability, both of the substructure and of the superstructure, by multiplication factors may not exceed the value of 1 .

\subsection{Application in a case study}

The methodology developed was applied to 12 Spanish river bridges, 4 of which were railway bridges and the others road bridges. Ten of these bridges are still in operation, the bridge over the Cervera river collapsed in October 2000 and the bridge over the Girona River failed in October 2007. The information related to the structures and water currents in which they are located was taken from Vallés (2011). Figure 5.2 shows the location of these bridges and Table 5.5 shows their main specifications.

$58 \%$ of the bridges studied are reinforced concrete structures and $42 \%$ are masonry bridges. In terms of size, $25 \%$ of the bridges have large dimensions, $50 \%$ correspond to bridges with a span greater than 10 metres and the remaining $25 \%$ to pontoons with a span of less than 10 metres. As far as typology is concerned, it should be noted that $42 \%$ correspond to vault bridges, $25 \%$ to arch bridges and $33 \%$ to conventional structures (beams, slabs, etc.). 


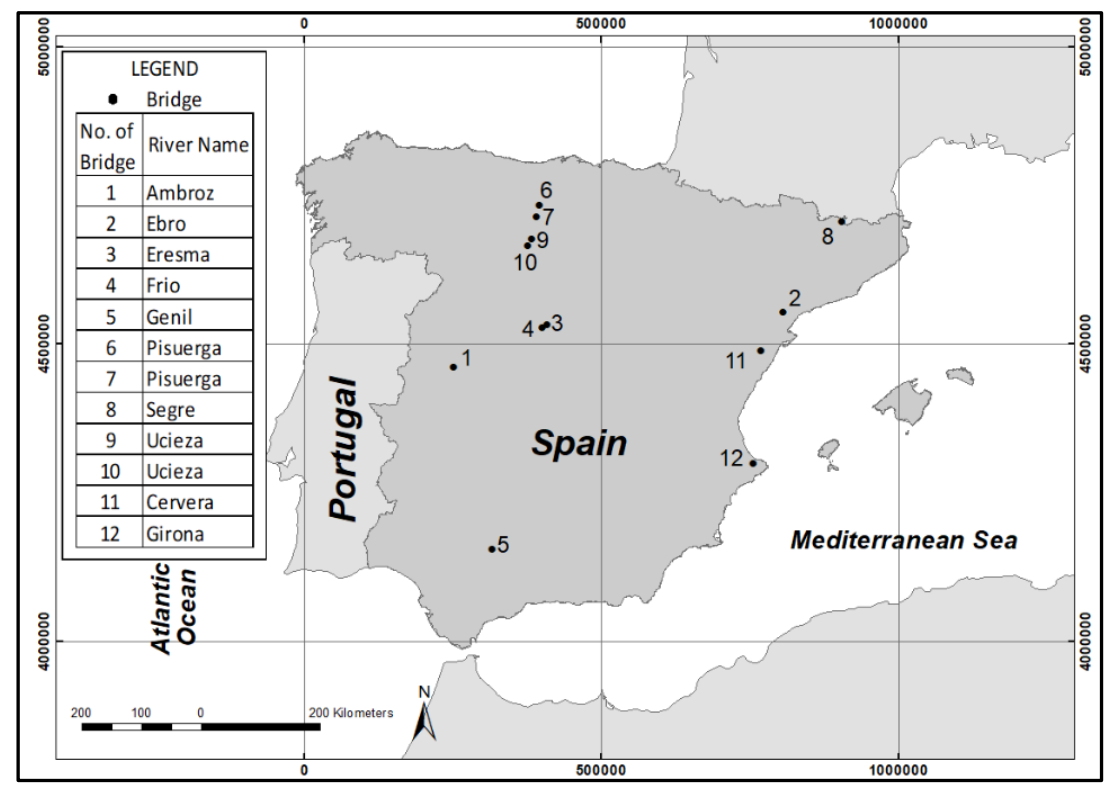

Figure 5.2 Location of the bridges to which the methodology was applied

Table 5.5 Specifications of the bridges to which the developed methodology was applied

\begin{tabular}{|c|c|c|c|c|c|c|c|}
\hline \multirow{2}{*}{$\begin{array}{l}\text { Condi- } \\
\text { tion }\end{array}$} & \multirow{2}{*}{ No. } & \multirow{2}{*}{ River } & \multirow{2}{*}{ Road } & \multicolumn{3}{|c|}{ Specifications of the structure } & \multirow{2}{*}{$\begin{array}{c}\text { Date of } \\
\text { inspection }\end{array}$} \\
\hline & & & & Classification & Type & No. Span & \\
\hline \multirow{10}{*}{$\begin{array}{l}\text { In } \\
\text { Operation }\end{array}$} & 1 & Ambroz & A-66 & Pontoon $\mathrm{L}<10 \mathrm{~m}$ & Conventional & 1 & $12 / 03 / 2010$ \\
\hline & 2 & Ebro & $\mathrm{N}-420$ & Large structure & Conventional & 7 & $28 / 02 / 2007$ \\
\hline & 3 & Eresma & SG-020 & Large structure & Arch & 7 & $23 / 03 / 2010$ \\
\hline & 4 & Frío & $\mathrm{N}-110$ & Pontoon $\mathrm{L}<10 \mathrm{~m}$ & Vault & 2 & $09 / 04 / 2010$ \\
\hline & 5 & Genil & A-4 & Large structure & Conventional & 7 & $13 / 02 / 2002$ \\
\hline & 6 & Pisuerga & Railway & Bridge $\mathrm{L}>10 \mathrm{~m}$ & Arch & 4 & $12 / 12 / 2007$ \\
\hline & 7 & Pisuerga & Railway & Bridge $\mathrm{L}>10 \mathrm{~m}$ & Arch & 4 & $12 / 12 / 2007$ \\
\hline & 8 & Segre & $\mathrm{N}-260$ & Bridge $\mathrm{L}>10 \mathrm{~m}$ & Vault & 3 & $15 / 07 / 2008$ \\
\hline & 9 & Ucieza & Railway & Bridge $\mathrm{L}>10 \mathrm{~m}$ & Vault & 1 & $11 / 12 / 2007$ \\
\hline & 10 & Ucieza & Railway & Pontoon $\mathrm{L}<10 \mathrm{~m}$ & Vault & 1 & $10 / 12 / 2007$ \\
\hline \multirow{2}{*}{ Collapsed } & 11 & Cervera & CV-132 & Bridge $\mathrm{L}>10 \mathrm{~m}$ & Conventional & 24 & - \\
\hline & 12 & Girona & $\mathrm{CV}-732$ & Bridge $\mathrm{L}>10 \mathrm{~m}$ & Vault & 5 & - \\
\hline
\end{tabular}

(1) Date on which Vallés (2011) performed the field inspection

The determination of the condition of each of the analysed structures, the stability of the stream channel, the potential of the structures to accumulate debris and their deterioration were defined according to the guidelines provided in Section 5.3 and are given in Table 5.6. This information made it possible to determine the base vulnerability of the superstructure and substructure and their multiplication factors, which are given in Table 5.7 (columns six to twelve).

The hazard corresponding to the probability of occurrence of floods was calculated from information published by the Sistema Nacional Floodplain de Cartografía de Zonas Inundables (2019). This mapping defines the discharges for floods corresponding to 
return periods of $2,5,10,25,100$ and 500 years. The probabilities of occurrence $(\mathrm{P}$ in Table 5.7) of the discharges for each of the bands into which the cross section was divided were interpolated from this information.

\section{Table 5.6 Stability of water currents and condition of the structures of the bridges analysed}

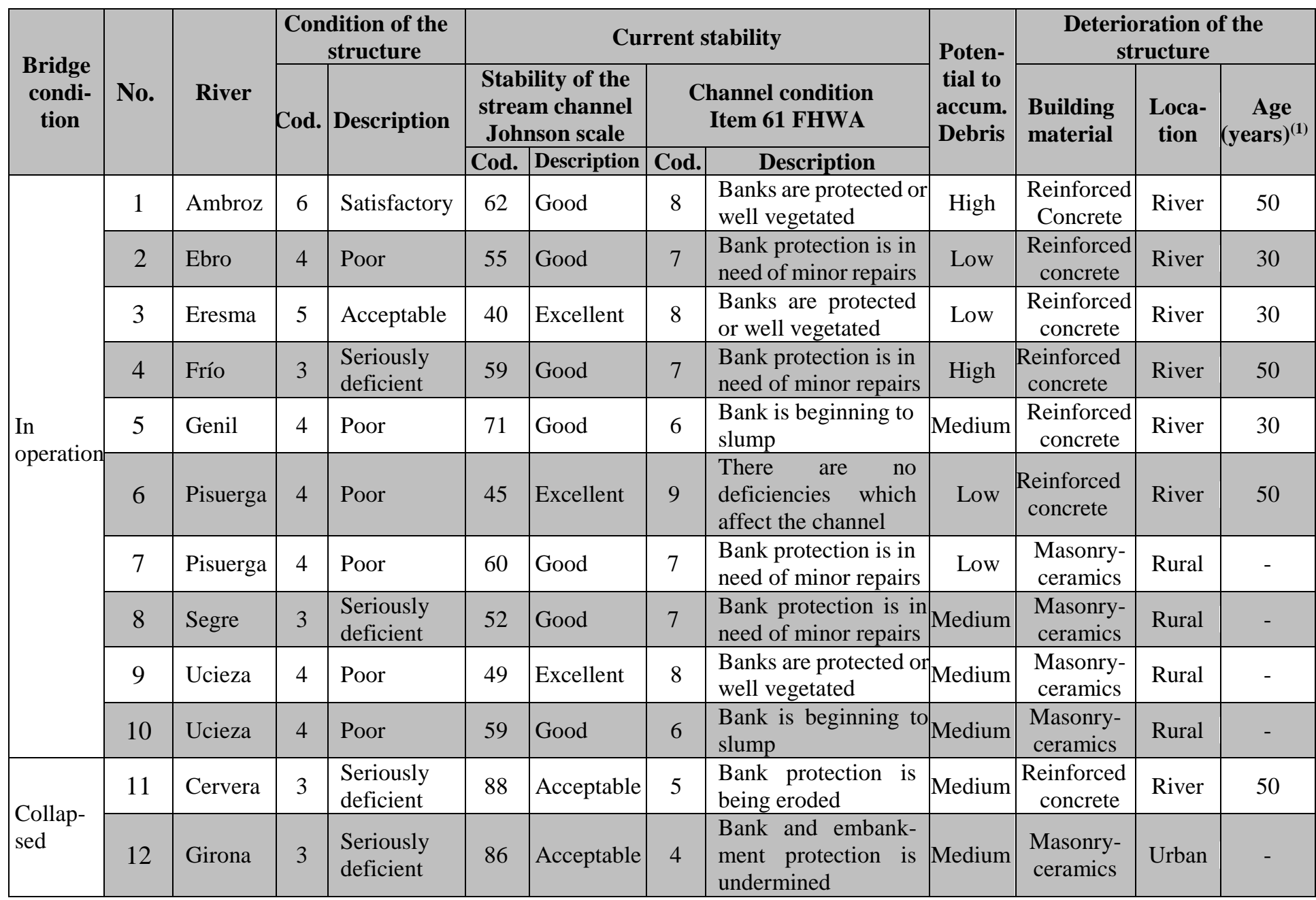

(1) Exact information on the age of bridges is not available, so this is approximate.

In order to define the upper limit of band 1, the minimum affectation threshold $\left(\mathrm{T}_{\min }\right)$ corresponded to the flood with a return period of 7 years. This flood corresponds to the upper limit of the range between 1.5 and 7 years, which, according to Vide (2003), constitutes the range in which the return periods of the dominant discharges of the Spanish rivers could fluctuate. The selected value is considered relatively conservative, so the results obtained are on the safe side.

The risk of failure due to river floods for each of the bridges analysed was calculated using Equation 5.4. The results obtained are given in the last column of Table 5.7. The bridges over the Cervera River and the Girona River, which have already collapsed, present risks of failure of 0.11 and 0.14 , respectively, which are very high values and 
indicate the need for urgent intervention to guarantee the integrity of the structure. This result in some way validates the proposed methodology and could be indicating that this method takes into account the most important elements to be considered when establishing the risk of bridge failure in the event of flooding.

Table 5.7 Risk of failure of bridges located on Spanish roads due to river floods

\begin{tabular}{|c|c|c|c|c|c|c|c|c|c|c|c|c|}
\hline \multirow{3}{*}{$\begin{array}{l}\text { Condition } \\
\text { of } \\
\text { bridge }\end{array}$} & \multirow{3}{*}{ No. } & \multirow{3}{*}{ River } & \multirow{3}{*}{$\begin{array}{l}\mathbf{Q B}(\mathbf{1}) \\
\left(\mathbf{m}^{3} / \mathbf{s}\right)\end{array}$} & \multicolumn{5}{|c|}{$\begin{array}{l}\text { Base vulnerability of structure } V_{\mathrm{B}} / \\
\text { Probability of occurrence of flows } P\end{array}$} & \multicolumn{3}{|c|}{$\begin{array}{l}\text { Multiplication } \\
\text { factors }\end{array}$} & \multirow{3}{*}{$\begin{array}{l}\text { Risk } \\
\text { (annual } \\
\text { failure } \\
\text { proba- } \\
\text { bility) }\end{array}$} \\
\hline & & & & \multirow{2}{*}{ Parameter } & \multicolumn{3}{|c|}{$V_{\text {Bb }}$} & \multirow{2}{*}{$\mathbf{V}_{\text {Bs }}$} & \multirow{2}{*}{$\mathbf{F}_{\mathrm{s}}$} & \multirow{2}{*}{$\mathbf{F}_{\mathbf{d}}$} & \multirow{2}{*}{$\mathbf{F}_{\mathbf{t}}$} & \\
\hline & & & & & $\frac{\text { Bands }}{2}$ & $\frac{\text { ross S }}{3}$ & $\frac{\text { tion }}{4}$ & & & & & \\
\hline \multirow{20}{*}{$\begin{array}{l}\text { In } \\
\text { operation }\end{array}$} & \multirow{2}{*}{1} & \multirow{2}{*}{ Ambroz } & \multirow{2}{*}{383} & $\mathrm{~V}_{\mathrm{B}}$ & 0.04 & 0.10 & 0.15 & 0.10 & \multirow{2}{*}{1.1} & \multirow{2}{*}{1.3} & \multirow{2}{*}{1.3} & \multirow{2}{*}{0.01} \\
\hline & & & & $\mathrm{P}$ & 0.24 & 0.01 & 0.00 & 0.00 & & & & \\
\hline & \multirow{2}{*}{2} & \multirow{2}{*}{ Ebro } & \multirow{2}{*}{8798} & $\mathrm{~V}_{\mathrm{B}}$ & 0.15 & 0.40 & 0.60 & 0.50 & \multirow{2}{*}{1.1} & \multirow{2}{*}{1.0} & \multirow{2}{*}{1.1} & \multirow{2}{*}{0.04} \\
\hline & & & & $\mathrm{P}$ & 0.21 & 0.03 & 0.01 & 0.01 & & & & \\
\hline & \multirow{2}{*}{3} & & 2724 & $V_{B}$ & 0.05 & 0.15 & 0.20 & 0.20 & & & & \\
\hline & & Eresma & 2724 & $\mathrm{P}$ & 0.25 & 0.00 & 0.00 & 0.00 & 1.0 & 1.0 & 1.1 & 0.01 \\
\hline & & & & $\mathrm{V}_{\mathrm{B}}$ & 0.30 & 0.60 & 0.70 & 0.70 & & & & \\
\hline & 4 & Frío & 39 & $\mathrm{P}$ & 0.25 & 0.00 & 0.00 & 0.00 & 1.1 & 1.3 & 1.3 & 0.09 \\
\hline & & & & $\mathrm{V}_{\mathrm{B}}$ & 0.15 & 0.40 & 0.60 & 0.50 & & & & \\
\hline & 5 & Genil & 1522 & $\mathrm{P}$ & 0.13 & 0.07 & 0.05 & 0.05 & 1.1 & 1.1 & 1.1 & 0.09 \\
\hline & & & & $\mathrm{V}_{\mathrm{B}}$ & 0.15 & 0.40 & 0.60 & 0.50 & & & & \\
\hline & 6 & Pisuerga & 1207 & $\mathrm{P}$ & 0.25 & 0.00 & 0.00 & 0.00 & 1.0 & 1.0 & 1.3 & 0.03 \\
\hline & 7 & Disurar & 648 & $\mathrm{~V}_{\mathrm{B}}$ & 0.15 & 0.40 & 0.60 & 0.50 & 11 & 10 & 11 & 002 \\
\hline & 7 & Pisuerga & 648 & $\mathrm{P}$ & 0.23 & 0.02 & 0.00 & 0.00 & 1.1 & 1.0 & 1.1 & 0.03 \\
\hline & 8 & Sorro & 223 & $\mathrm{~V}_{\mathrm{B}}$ & 0.30 & 0.60 & 0.70 & 0.70 & 11 & 11 & 11 & 010 \\
\hline & 8 & Segre & 323 & $\mathrm{P}$ & 0.17 & 0.05 & 0.03 & 0.03 & 1.1 & 1.1 & 1.1 & 0.10 \\
\hline & 0 & Ucieza & 04 & $\mathrm{~V}_{\mathrm{B}}$ & 0.15 & 0.40 & 0.60 & 0.50 & 11 & 11 & 11 & 006 \\
\hline & 9 & Ucieza & 94 & $\mathrm{P}$ & 0.16 & 0.07 & 0.02 & 0.02 & 1.1 & 1.1 & 1.1 & 0.00 \\
\hline & 10 & Uсірта & 710 & $\mathrm{~V}_{\mathrm{B}}$ & 0.15 & 0.40 & 0.60 & 0.50 & 10 & 1 & 11 & 008 \\
\hline & 10 & Ucieza & 710 & $\mathrm{P}$ & 0.11 & 0.11 & 0.03 & 0.03 & 1.0 & 1.1 & 1.1 & 0.08 \\
\hline & 11 & Ceryaro & 300 & $\mathrm{~V}_{\mathrm{B}}$ & 0.30 & 0.60 & 0.70 & 0.70 & 13 & 11 & 13 & 011 \\
\hline Collansed & 11 & Cervera & 300 & $\mathrm{P}$ & 0.19 & 0.02 & 0.03 & 0.03 & 1.3 & 1.1 & 1.3 & 0.11 \\
\hline Collapsed & 12 & Girot & 147 & $V_{B}$ & 0.30 & 0.60 & 0.70 & 0.70 & 13 & 11 & 13 & 014 \\
\hline & 12 & Girona & 147 & $\mathrm{P}$ & 0.12 & 0.05 & 0.08 & 0.08 & 1.3 & 1.1 & 1.3 & 0.14 \\
\hline
\end{tabular}

(1) $\mathrm{QB}=$ Discharge at full section

$50 \%$ of the bridges analysed still in operation show a high risk of failure due to floods (between 0.05 and 0.10), which suggests that they require immediate attention; in particular, the bridge over the River Segre presents the most adverse conditions with a 0.10 risk. $30 \%$ of the bridges analysed show a medium risk (between 0.03 and 0.04 ), indicating that action must be taken to improve this condition in the short term. The remaining $20 \%$ return a low risk of failure (equal to 0.01 ), suggesting that no extraordinary intervention is required on these structures and that the routine inspection and maintenance plan must be continued.

Multiplication factors for stream channel stability, potential for debris accumulation and structure deterioration can lead to a significant increase in the base vulnerability of the structure. In the case of the bridges on the Ambroz, Frío, Cervera and Girona rivers, this increase was almost $86 \%$. With the exception of the bridge over the Ambroz River, the methodology indicates that these bridges present or presented a high risk of failure. 
It is also generally observed that, as expected, in rivers where there is a greater probability of finding discharges close to or higher than full-bank, the risk of failure of the structures increases. The River Frío seems to escape this trend, since although the probability of reaching high flows is low, the structure presents a high risk of failure.

\subsection{Sensitivity analysis}

Considering that the main objective of this methodology consists of ordering the level of intervention required by a set of bridges, that the values established for vulnerability are associated with a high degree of subjectivity and that the value of $\mathrm{T}_{\min }$ is uncertain, the sensitivity of the risk to the values of vulnerability and $\mathrm{T}_{\min }$ was determined.

This analysis made it possible to establish the extent to which the risk values and the order of the bridges vary when these parameters are modified. The analysis is local and univariate. Accordingly, on the one hand, $\mathrm{T}_{\min }$ values equal to 1.5, 4, 15 and 50 years were adopted; the value of 1.5 years corresponds to the lower limit of the range in which, according to Vide (2003), the return periods of the dominant discharges of the Spanish rivers could fluctuate, while the value of 4 years corresponds approximately to the average value of this range. On the other hand, the effect of vulnerability was studied through the modification of vulnerability, for which its value was increased by 50 and $100 \%$ and decreased by 25 and $50 \%$.

The results obtained by performing this test are given in Table 5.8, in which the bridges studied are classified according to the values of risk obtained during the implementation of the methodology. The analysis of this information allows us to conclude that the threshold above which both the structure and the watercourse are considered to be affected due to the action of the flood has a high influence on risk values, since these increase on average by almost 350 and $150 \%$ when $\mathrm{T}_{\min }$ values of 1.5 years and 4 years, respectively, are considered; and they decrease on average by 43 and $78 \%$ when considering $\mathrm{T}_{\min }$ values of 15 and 50 years, respectively. However, the order of the rivers when considering their risk values remains without major modifications since, when considering a $\mathrm{T}_{\min }$ of 50 years, the order remains the same; when considering a $\mathrm{T}_{\min }$ of 15 years, only the Frío and Genil rivers would exchange positions; and when considering $\mathrm{T}_{\min }$ values of 1.5 and 4 years, only the Frío and Segre rivers would exchange positions.

When modifying the values of vulnerability, a similar behaviour to that obtained when modifying the values of $\mathrm{T}_{\min }$ is observed, since, as expected, on average the risk increases by 67 and $36 \%$ when vulnerability is affected by factors of 2.0 and 1.5 and, similarly, it is reduced by 21 and $45 \%$ when vulnerability is affected by factors of 0.75 and 0.5 , respectively. As with the $\mathrm{T}_{\min }$, the order of the bridges does not undergo major variations since, when the vulnerability increases by $50 \%$, the order remains the same; when duplicating the vulnerability, the only change observed is that the River Ucieza would be located after the Genil and Frío Segre rivers; and when reducing the vulnerability by 25 and 50\%, only the bridges over the Genil and Frío rivers would exchange positions. 
Table 5.8 Fail Risk Sensitivity Test

\begin{tabular}{|c|c|c|c|c|c|c|c|c|c|c|c|}
\hline \multirow{4}{*}{$\begin{array}{c}\text { Bridge } \\
\text { condition }\end{array}$} & \multirow{4}{*}{ No. } & \multirow{4}{*}{ River } & \multicolumn{9}{|c|}{ Risk (probability of failure/year) } \\
\hline & & & \multirow{3}{*}{$\begin{array}{l}\text { Proposed } \\
\text { Methodo- } \\
\quad \text { logy }\end{array}$} & \multicolumn{8}{|c|}{ Sensitivity analysis } \\
\hline & & & & \multicolumn{4}{|c|}{$\mathbf{T}_{\min }($ years$)$} & \multicolumn{4}{|c|}{ Vulnerability } \\
\hline & & & & 1.5 & 4 & 15 & 50 & $\begin{array}{c}\text { Method. } \\
* 2.0\end{array}$ & $\begin{array}{c}\text { Method } \\
* 1.5\end{array}$ & $\begin{array}{c}\text { Method. } \\
* 0.75\end{array}$ & $\begin{array}{l}\text { Method. } \\
* 0.5\end{array}$ \\
\hline \multirow{10}{*}{ In } & 1 & Eresma & 0.008 & 0.037 & 0.014 & 0.004 & 0.001 & 0.016 & 0.012 & 0.006 & 0.004 \\
\hline & 2 & Ambroz & 0.013 & 0.051 & 0.021 & 0.007 & 0.003 & 0.025 & 0.019 & 0.009 & 0.006 \\
\hline & 3 & Pisuerga & 0.028 & 0.130 & 0.049 & 0.013 & 0.004 & 0.056 & 0.042 & 0.021 & 0.014 \\
\hline & 4 & Pisuerga & 0.035 & 0.130 & 0.054 & 0.021 & 0.011 & 0.068 & 0.052 & 0.026 & 0.018 \\
\hline & 5 & Ebro & 0.044 & 0.139 & 0.063 & 0.030 & 0.014 & 0.079 & 0.062 & 0.034 & 0.023 \\
\hline & 6 & Ucieza & 0.064 & 0.168 & 0.085 & 0.042 & 0.017 & 0.110 & 0.090 & 0.049 & 0.034 \\
\hline & 7 & Ucieza & 0.079 & 0.174 & 0.098 & 0.044 & 0.018 & 0.136 & 0.109 & 0.061 & 0.042 \\
\hline & 8 & Genil & 0.086 & 0.191 & 0.108 & 0.055 & 0.018 & 0.127 & 0.111 & 0.069 & 0.049 \\
\hline & 9 & Frío & 0.087 & 0.379 & 0.146 & 0.044 & 0.018 & 0.132 & 0.122 & 0.067 & 0.045 \\
\hline & 10 & Segre & 0.100 & 0.309 & 0.143 & 0.060 & 0.020 & 0.143 & 0.122 & 0.080 & 0.057 \\
\hline \multirow{2}{*}{ Collapsed } & 11 & Cervera & 0.105 & 0.398 & 0.165 & 0.063 & 0.020 & 0.143 & 0.129 & 0.089 & 0.065 \\
\hline & 12 & Girona & 0.135 & 0.427 & 0.195 & 0.067 & 0.020 & 0.143 & 0.140 & 0.124 & 0.095 \\
\hline
\end{tabular}

\subsection{Final Remarks}

The developed methodology was applied to 12 river bridges located on Spanish roads. The results obtained were satisfactory, which could indicate that the proposed method takes into account the most important elements to be considered when establishing this type of risk.

The implementation of the methodology in the selected case study indicates that only $20 \%$ of the bridges currently in operation return a low or acceptable risk and therefore do not require special action, while the remaining $80 \%$ require interventions in the medium and short term.

Given its ease of implementation and the relatively low demand for information needed for its application, the proposed method could become a support tool for decision-makers responsible for the design, maintenance, repair and reconstruction of bridges. The adequate and timely implementation of this method would make it possible to detect alerts on the state of the structure in a reasonable time and at a reasonable cost. 


\section{CONCLUSIONS AND FUTURES RESEARCH LINES}

\subsection{Conclusions}

In this research, a methodology was developed to estimate the risk that river floods generate on a road network in three different scenarios, which corresponded to floodplains, stream crossings and bridges. The procedure developed allows calculating in the first two scenarios the average annual number of vehicles at risk due to flooding when they are driven or parked at a given area or at stream crossings, which can correspond to fords, vented fords or bridges. The third scenario allows establishing the probability of annual failure of bridges due to floods. In the three scenarios, which allowed studying several of the elements that may be affected during floods, a common methodology was used based on the statistical integration of the flooding hazard and the vulnerability of the exposed elements.

Given the importance of vehicles and transport systems for society, determining the vehicle instability risk due to flooded rivers is an extremely important factor for planning, designing and managing roads. Determining this risk can also allow suitable efforts and resources to be assigned to invest in transport systems' sustainability. Hence implementing this methodology can help to reduce negative effects before and during flooding events, which is extremely helpful for those organizations in charge of urban planning and civil protection to design and take actions that cushion the negative effects of flooding.

\subsubsection{Vehicle stability models during floods}

In recent years several authors have proposed different models to establish vehicle stability thresholds during a flood event, most of them have considered that vehicles are watertight, some have considered that water can enter the vehicles exposed to flooding and others allow considering both watertightness and non-watertightness conditions. Also, the criterion to determine the stability threshold varies among the studied stability models. These differences in the way of approaching vehicle watertightness, the decision criterion adopted to determine the stability of the cars and, more importantly, different driving factors, lead to quite a wide range of stability thresholds as obtained by the various models.

The comparison of the studied stability models with the experimental data suggests that most stability models seem to be conservative for low flow velocities and that the models proposed by the DIPNR (2005), Ausroads (2008), Kramer et al. (2016), MartínezGomariz et al. (2017) for high velocities and the AR\&R (2011) and Smith (2017) for speeds over $3.0 \mathrm{~m} / \mathrm{s}$ seem to be excessively conservative. Additionally, it could be observed that the stability models proposed by Moore and Power (2002) for small passenger cars and by Oshikawa and Komatsu (2014) establish limits of stability threshold higher than the combinations of velocity and depth for which several of the studied experimental cars lost their stability. Because of this, these models could be unsafe for certain types of car. 
The stability model proposed by Arrighi et al. (2016a) seems to provide an acceptable fit for the experimental data for medium and high velocities while the model proposed by Martínez-Gomariz seems to have a similar goodness of fit for the measured data in the case of medium velocities. It should be highlighted that these models are the only ones that allow calculating a stability threshold for any vehicle.

All the stability models have made simplifications in the experimental part or in the theoretical deduction of the stability thresholds that can influence the final result. Due to this, the experimental data and the stability models present excessive sample dispersion. This is why it is necessary to conduct new researches that focuses on to overcome these simplifications and to try to standardise the decision criteria which should be adopted to define stability thresholds for vehicles of different characteristics.

\subsubsection{Assessing the risk of vehicle instability due to flooding}

A methodology that allows vehicle instability risk estimates to be made during flooding while being driven or parked at a given point on the territory was developed. This methodology estimates the annual mean number of at-risk cars by classifying these by vehicle type and being representative of the vehicle fleet in any given area.

Efforts were made to develop a rigorous methodology from the statistical point of view, but a relatively simple one to implement. To determine the vehicle instability risk, it is necessary to have the water depths and maximum velocities of floods, which may affect the area of interest, as well as the basic characteristics of the vehicles in this area. The instability hazard is determined according to a stability function of partially submerged vehicles. Vehicles' vulnerability is established by combining exposure and susceptibility; exposure is calculated by multiplying vehicle density by each vehicle's proportion in the fleet; susceptibility is determined with the damage function, which takes values of 0 (unharmed vehicles) and 1 (100\% vehicle damage) depending on whether the vehicle is stable or not. Finally, the risk at each point is obtained by doing a numerical approximation of the statistical integral of the instability hazard and vehicles' vulnerability.

The number of vehicles at risk for overflowing rivers can be sensitive to the return period corresponding to the event in which the area of interest starts to flood, which is known as $T_{\min }$ in this methodology. The most accurate estimation for this return period would allow values for at-risk vehicles to be obtained, which would come closer to real values.

Representation of the vehicle fleet in the flood-prone area significantly impacts the overall value of the vehicles at risk for instability. Therefore, any mistaken or inaccurate selection of the vehicles that represent the vehicle fleet may distort the results.

\subsubsection{Determining the vehicle instability risk in stream crossings}

A methodology that allows instability risks due to floods to be estimated for vehicles driving through stream crossings was developed. The stream crossing may correspond to fords, vented fords or bridges. With bridges, this methodology can be used for hypothesising that bridge structures would not fail during floods. The calculated risk 
corresponded to the annual mean number of vehicles that would float or be dragged by the flow.

With this methodology, instability risk was calculated by combining hazard and vulnerability. To determine hazard, the stability function of partially submerged vehicles, the geometric characteristics of vehicles, the hydrodynamic characteristics of floods (water depths and velocities) and the probability of them occurring were employed. Vulnerability was determined by combining exposure and susceptibility, which are respectively established with the exposure and damage function Finally, risk was calculated by the discrete solution of the statistical integral of the product of hazard by vulnerability.

The number of vehicles at risk for instability due to floods proved extremely sensitive to the magnitude of the limit water depth from which drivers would decide to stop driving through flooded zones. The magnitude of the risk increased as drivers would take poorly conservative attitudes; that is, if decided to drive through higher water levels. Determining a safe limit water depth, that is, one associated with a low risk level, can help to encourage drivers' good behaviour.

The number of vehicles at risk for instability can also vary according to the extent that vented fords are obstructed. This risk can significantly increase when these stream crossings are obstructed or possibly blocked. To avoid this risk increasing, vented fords and periodically performing maintenance tasks should minimise this possibility.

\subsubsection{Risk assessment of bridge failure due to river floods}

A methodology was developed to evaluate the risk of failure of bridges due to river floods. The methodology is probabilistic with a detailed determination of the vulnerability to bridge failure. The end result is an annual probability of failure, at least in theory. This uncertainty disappears to a large extent when the results are used for planning the level of intervention required for a given set of bridges which, for example, could belong to the same geographical or administrative area. Accordingly, the methodology makes it possible to identify the bridges that are most at risk, which would require much more immediate intervention than bridges with medium and low risk.

The information needed to implement the methodology is of two types: vulnerability and frequency of floods. Vulnerability can be obtained through field visits and by analysing other normally available sources of information, such as aerial photographs of both the bridge and the watercourse downstream and upstream and the watershed upstream of the structure. The frequency of floods can be established through available discharges information.

To determine vulnerability, certain successfully implemented methods available in the literature are used to establish the state and integrity of the bridge, the potential of the bridge to accumulate debris and the stability of the stream channel. The strategic implementation of these methods, together with other analyses, makes it possible to reliably establish the risk of bridge failure during floods. 
The risk values are in direct function of a discharge from which both the structure and the watercourse begin to be affected by the action of the flood, which in this methodology has been called $\mathrm{T}_{\min }$. Therefore, in order to achieve realistic results, this discharge must be obtained as accurately as possible.

The hydrology of the watercourses in which the bridge is located plays an important role in determining the risk to which the structure is subjected, since the greater the probability of large floods, the greater the susceptibility of the structure to damage and, therefore, the greater the risk of failure.

\subsection{Futures research lines}

With regard to the vehicle stability models, in order to reduce the sample dispersion of the experimental data and the stability models, research should be carried out with the following objectives:

- Accompanying the laboratory experiments with the development of mathematical modelling of the vehicle-flow interaction, similar to that done by Arrighi et al. in 2015, since this can contribute to a better understanding of the hydrodynamic phenomena that cause vehicle stability loss.

- Trying to standardize the decision criterion that must be adopted to define the stability thresholds. The aspects that have a greater impact on the stability of the vehicles should be better identified and laboratory tests and theoretical analyses should be carried out with greater emphasis on these aspects.

- Performing more experiments on a representative number of vehicles of various characteristics, including the most vulnerable ones in each car category. Also, some kind of safety factor could be considered.

- Establishing the friction coefficients between the tyres and the surface by conducting tests with real-scale vehicles and variable water depths. These tests should be carried out considering different surface materials and tyres in different wear conditions.

- Carrying out experiments at 1:1 scale in which the vehicles lose their stability. Since making these measurements in laboratory flumes is very complex (because very large flows and huge flumes would be required), at least these tests could be performed in tanks with water at rest to study the flotation and leaking of water inside the vehicles, increasing the number of experiments done by Kramer et al. in 2016 and Smith et al. in 2017. In order to include the full-scale flow velocity, experiments could be carried out downstream of dams, as also suggested by Xia et al. in 2011. This research could be difficult to accomplish due to the environmental legislation.

Regarding the methodology to calculate the risk of vehicle instability and bridge failure, it is recommended to carry out researches that focus mainly on the following aspects:

- Establishing stability functions for partially submerged cars that consider moving vehicles. This is because the magnitude of the flows that generate the destabilization 
of the vehicles at rest could differ from the magnitude of the flows that cause the loss of stability of the moving vehicles.

- Studying carefully the factors that influence drivers' decision-making when driving through flooded areas. In addition to the depth, factors such as, for example, the velocity of the flow and the extent of the flooded area can affect drivers' decisions in aspects such as slowing down or stopping the car.

- Studying the impact of the variation of vehicular traffic throughout the day in the risk of vehicles instability. Daytime traffic can vary significantly of the nighttime traffic and this can lead to significant variations in the risk value to which cars are subject.

- Studying the uncertainty associated with the calculated risk values for both vehicles and bridges. Several parameters are involved in the process of obtaining the risk, each of which has a certain uncertainty, so the risk finally obtained also has an associated uncertainty. The quantification of this uncertainty would indicate the degree of reliability of the calculated risk values.

- Considering the vulnerability of vehicles and vehicular traffic in the calculation of the risk of bridges failure. Other ways of weighing the importance of bridges could also be considered, such as the economic impact that the failure of these structures would generate and the cost of repairing or rebuilding them.

Other aspects that should also be studied are the following:

- Analysing the possibility of obtaining from the morphological characteristics of the basin the necessary parameters to establish the flood hazard. This would decrease the amount of information needed to calculate the risk of vehicle instability due to flooding.

- Defining the impact that the duration of the flood and the circulation of vehicles have on the risk values in urban areas. Depending on the duration of the flood, the density of vehicles moving could vary over time and this would lead to changes in the value of risk.

- Making a more detailed definition of the damage function of vehicle due to flooding. Even though vehicles lose their stability, the damage may not be $100 \%$. The degree of damage could, for example, be a function of the topography of the terrain, the direction of flow circulation and the variation in depth and flow velocity. 


\section{REFERENCES}

Aguirre, A. M. \& Mejía de Gutiérrez, R. (2013) Durabilidad del hormigón armado expuesto a condiciones agresivas. Materiales de Construcción, 63(309), 7-38. doi: $10.3989 / \mathrm{mc} .2013 .00313$

Algarra B.I. (2016). Estudio de impacto ambiental de un proyecto de modernización de regadíos en la localidad de Godelleta (Valencia). Tesis. Director: José Luis Fuentes Bargues. Universidad Politécnica de Valencia - España.

Andrade, C. (2007). Corrosion of steel reinforcement. In Moncmanová A., ed., Environmental Deterioration of Materials. Southamptom: Wit Press, 185 - 216. doi: 10.2495/978-1-84564-032-3/06.

ANFAC, Spanish Association of Truck and Automobile Manufacturers (2018). http://www.anfac.com/estadisticas.action (last accessed 2018/12/22).

Arrighi, C., Alcérreca-Huerta, J., Oumeraci, H., \& Castelli, F. (2015). Drag and lift contribution to the incipient motion of partly submerged flooded vehicles. Journal of Fluids and Structures, 57, 170-184. https://doi.org/10.1016/j.jfluidstructs.2015.06.010

Arrighi, C., Castelli, F., \& Oumeraci, H. (2016). Effects of flow orientation on the onset of motion of flooded vehicles. In Proceedings of the 4th IAHR Europe Congress. Liege, DOI: https://doi.org/10.1201/b21902-140.

Arrighi, C., Huybrechts, N., Ouahsine, A., Chaseé, P., Oumeraci, H., \& Castelli, F. (2016). Vehicles instability criteria for flood risk assessment of a street network. Proceedings of the IAHS, 373, 143-146. https://doi.org/10.5194/piahs-373-143-2016

Austroads. (2008). Guide to road design, Part 5: Drainage design. Sidney, Australia: AusRoads Inc.

Barbetta, S., Camici, S. \& Moramarco, T. (2017) A reappraisal of bridge piers scour vulnerability: a case study in the Upper Tiber River basin (central Italy). Journal of Flood Risk Management, 10(3), 283-300. doi: 10.1111/jfr3.12130

Bocanegra RA, Vallés- Morán FJ, Francés F. 2020a. Review and analysis of vehicle stability models during floods and proposal for future improvements. J Flood Risk Management. 2020;13(Suppl. 1):e12551. https://doi.org/10.1111/jfr3.12551

Bocanegra RA, Francés F. 2020b. Assessing the risk of vehicle instability due to flooding. J. Flood Risk Management. Under review.

Bonham, A. J., \& Hattersley, R. T. (1967). Low level causeways. WRL Report No. 100. University of New South Wales. Sydney, Australia. 
Boyd, A. J., \& Skalny. J. (2007). Environmental deterioration of concrete. In Moncmanová A., ed., Environmental Deterioration of Materials. Wit Press, Southamptom: Wit Press, 143-184. doi: 10.2495/978-1-84564-032-3/05.

Cal y Mayor R., Cardenas J. (2007). Ingeniería de tránsito fundamentos y aplicaciones. Alfaomega. México D.F.

Caneva V. (2004). Reemergencia de ciudadanía en momentos de crisis eco-ambientales y político sociales: una mirada comunicacional sobre las organizaciones de vecinos autoconvocadas post inundación en la ciudad de la plata. Proc. ALAIC 2014. Lima, Perú.

Castejón P. G., Romero D. A. (2014). Inundaciones en la región de Murcia en los inicios del siglo XXI. Revista bibliográfica de geografía y ciencias sociales, 1 -40.

Centro Nacional de Información Geográfica de España (2019). http://centrodedescargas.cnig.es/ CentroDescargas/index.jsp\#, last accessed 2019/09/16.

CHJ (Confederación Hidrográfica del Júcar) (2011). Asistencia técnica para el desarrollo del sistema nacional de cartografía de zonas inundables en la Demarcación Hidrográfica del Júcar.

Concrete Society (2002). Durable post-tensioned concrete bridges. 2nd edition. Concrete Bridge Development Group. Technical Report No. 47

Costa, A., Appleton, J., (2002). Case studies of concrete deterioration in a marine environment in Portugal. Cem. Concr. Compos. 24 (2002), 169-179. doi.org/10.1016/S0958-9465(01)00037-3

Cox, R. J., Shand, T. D., \& Blacka, M. J. (2010). Appropriate safety criteria for people in floods. Australian Rainfall and Runoff. WRL Research Report 240. Report for Institution of Engineers Australia.

Dawson, R.J., Gosling, S., Chapman, L., Darch, G., Watson, G., Powrie, W., Bell, S., Paulson, K., Hughes, P., Wood, R., Thompson, D., Johns, D., 2016. Chapter 4: Infrastructure in UK Climate Change Risk Assessment 2017 (CCRA 2017). In: Adaptation Sub-Committee (ASC) of the Committee on Climate Change, London (UK).

Department of Infrastructure, Planning and Natural Resources DIPNR (New South Wales Government). (2005). Floodplain development manual: The management of flood liable land. Sydney, Australia:Department of Infrastructure, Planning and Natural Resources.

Diputació de Valencia (2018). Libro de Aforos 2017. Área Carreteras Servicio de Seguridad Vial y Supervisión. Valencia, España.

Drobot, S. D., Benight, C., \& Gruntfestd, E. C. (2007). Risk factors for driving into flooded roads. Environmental Hazards, 7(3), 227-334. https://doi.org/10.1016/j.envhaz. 2007.07.003 
El-Reedy, M. A. (2008). Steel reinforced concrete structures. CRC Press, Boca Ratón.

El Tiempo (2008). Reportan un menor desaparecido tras fuerte aguacero en Barranquilla. Barranquilla, Mayo 5, 2018.

Federal Highway Administration (FHWA) (1995). Recording and coding guide for the structure inventory and appraisal of the nation's bridges. U.S. Department of Transportation Federal Highway Administration. Publication No. FHWA-PD-96-001.

Federal Highway Administration (FHWA) (1997). Potential Drift Accumulation at Bridges. U.S. Department of Transportation Federal Highway Administration. Publication No. FHWA-RD-97-028.

Federal Highway Administration (FHWA) (2002). Hyrisk methodology and user guide. U.S. Department of Transportation Federal Highway Administration. Publication No. FHWA-RD-02-XXX

Federal Highway Administration (FHWA) (2005). Debris Control Structures Evaluation and Countermeasures, 3rd ed. U.S. Department of Transportation Federal Highway Administration. Publication No. FHWA-IF-04-016

Federico F., Silvagni G. \& Volpi F. (2003). Scour vulnerability of river bridge piers. $J$ Geotech Geoenviron Eng, 129 (10), 890 - 899. doi: 10.1061/(ASCE)10900241(2003)129:10(890).

Fhola de S. Paulo. (2020). Com chuvas perto do triplo da média, MG tem 53 mortos em cinco dias. https://www1.folha.uol.com.br/cotidiano/2020/01/numero-de-mortos-emdecorrencia-das-chuvas-em-mg-sobe-para-50.shtml

Fitzgerald, G., Du, W., Jamal, A., Clark, M., \& Hou, X. (2010). Flood fatalities in contemporary Australia (1997-2008). Emergency Medicine Australasia, 22, 180-186. https://doi.org/10.1111/j.1742-6723.2010.01284.x

Frances, F., Marco, J. B., Cayuela, A. (2001). Regional flood - risk mapping and its use in land use planning: the region of Valencia case study. IAHS Publication No. 272, 311 318

Francés F., et al. (2008). ERA-NET CRUE Research Report No I-6: Efficiency of nonstructural flood mitigation measures: "room for the river" and "retaining water in the landscape". General Directorate for Research in the European Commission

Generalitat Valenciana (2019). Tráfico de las carreteras gestionadas por la Conselleria 2018 y 4 años anteriores. Conselleria de Política Territorial, Obras Públicas y Movilidad.

Gordon, A. D., \& Stone, P. B. (1973). Car stability on road causeways. WRL Technical Report No. 73/12. University of New South Wales. Sydney, Australia. 
Hung, C.C., Yau, W.G., (2017). Vulnerability evaluation of scoured bridges under floods. Eng. Struct,. 132 (2017), 288-299. doi.org/10.1016/j.engstruct.2016.11.044

Instituto Mexicano del Transporte (IMT) (2001). El fenómeno de la corrosión en estructuras de concreto reforzado. Secretaría de Comunicaciones y Transporte. Publicación Técnica No. 182.

Johnson, P. A., Gleason, G., Hey, R. (1999). Rapid assessment of channel stability in vicinity of road crossing. J. Hydraul. Eng., 125(6), 645-651.

Johnson, P. A. (2005). Preliminary assessment and rating of stream channel stability near bridges. J. Hydraul. Eng., 131 (10), 845-52. doi: 10.1061/(ASCE)07339429(2005)131:10(845).

Johnson, P. A. \& Whittington R. M. (2011). Vulnerability-Based Risk Assessment for Stream Instability at Bridges. J. Hydraul. Eng., 137 (10), 1248-1256. doi: 10.1061/(ASCE)HY.1943-7900.0000443.

Jones, J.A., Swanson, F.J., Wemple, B.C., Snyder, K.U., 2000. Effects of roads on hydrology, geomorphology, and disturbance patches in stream networks. Conserv. Biol. 14, 76-85. http://dx.doi.org/10.1046/j.1523-1739.2000.99083.x.

Jonkman, N., \& Kelman, I. (2005). An analysis of the causes and circumstances of flood disaster deaths. Disasters, 29(1), 75-97.

Kalantari, Z., Nickman, A., Lyon, S., Olofsson, B., \& Folkeson, L. (2014). A method for mapping flood hazard along roads. Environmental Management, 133, 69-77. https://doi.org/10.1016/j.jenvman.2013.11.032.x

Kellar, M., \& Schmidlin, T. W. (2012). Vehicle-related flood deaths in the United States, 1995-2005. Journal of Flood Risk Management, 5, 153-163. https://doi.org/10.1111/j.1753-318X.2012.01136.x

Keller, R. J., \& Mitsch, B. (1993). Safety aspects of the design of roadways as floodways. Research Report No. 69, Urban Water Research Association of Australia.

Khelifa, A., Garrow, L. A., Higgins, M. J., Meyer \& M. D. (2013). Impacts of climate change on scour-vulnerable bridges: assessment based on Hyrisk. J Infrastruct Syst., 19 (2), 138-46. doi: 10.1061/(ASCE)IS.1943-555X.0000109.

Kim, H., Sim S. H., Lee, J., Lee, Y. J., Kim, J. M. (2017). Flood Fragility Analysis for Bridges with Multiple Failure Modes. Advances in Mechanical Engineering, 9 (3), 1-11. doi: $10.1177 / 1687814017696415$

Ko, Y. Y., Chiou J. S., Tsai Y. C., Chen C. H., Wang H., Wang C. Y. (2014). Evaluation of Flood-Resistant Capacity of Scoured Bridges. J Mater Eng Perform., 28 (1), 61-75. doi: 10.1061/(ASCE)CF.1943-5509.0000381. 
Kramer, M., Terheiden, K., \& Wieprecht, S. (2016). Safety criteria for trafficability of inundated roads in urban floodings. International Journal of Disaster Risk Reduction, 17, 77-84. https://doi.org/10.1016/j.ijdrr.2016.04.003

Leopold L.B., Wolman G.M., Miller J.P. (1964). Fluvial Processes in Geomorphology. Dover Publications. Mineola, United States

Levante (2019). La gota fría deja 5 muertos, 3.500 evacuados y daños catastróficos en el sureste. https://www.levante-emv.com/sucesos/2019/09/14/gota-fria-deja-5-muertos/ 1921561.html

Liang, Z. \& Lee, G. (2013). Bridge Pier Failure Probabilities under Combined Hazard Effects of Scour, Truck and Earthquake. Part I: Occurrence Probabilities Earthq Eng Eng Vi.b, 12 (2), 229-240. doi:10.1007/s11803-013-0166-0

Maes, M., Gruyaert, E., De Belie, N. (2012). Resistance of concrete against combined attack of chlorides and sulphates. In Proceedings of resistance of concrete against combined attack of chlorides and sulphates, pp. 1-14. Trondheim.

Malhotra, V. M. (2007). Durability of concrete. In Revie W., ed., Uhlig's Corrosion Handbook, 3rd ed. New Jersey: John Wiley \& Sons, 439 - 449. doi: $10.1002 / 9780470872864$.

Maples, L., Tiefenbacher, J. (2009). Landscape, development, technology and drivers: The geography of drownings associated with automobiles in Texas floods, 1950-2004. Applied Geography, 29, 224-234

Martínez-Gomariz, E., Gómez, M., Russo, B., \& Djordjevi_c, S. (2016). Stability criteria for flooded vehicles: A state-of-the-art review. Journal of Flood Risk Management, 11, S817-S826. https://doi.org/10.1111/jfr3.12262

Martínez-Gomariz, E., Gómez, M., Russo, B., \& Djordjevi_c, S. (2017). A new experiments-based methodology to define the stability threshold for any vehicle exposed to flooding. Urban Water Journal, 14(9), 930-939. https://doi.org/10.1080/ 1573062X.2017.1301501

Matute R. L. \& Pulido S. I. (2012). Medidas Eficientes En La Conservación de Puentes. In Procedings of VI Congreso Nacional de Ingeniería Civil, pp. 1 -33. Valencia.

Mehta, P. K., Monteiro P. J. (2006). Concrete Microstructure, Properties, and Materials, 3rd ed. McGraw-Hill, New York. doi: 10.1036/0071462899

Mejía, R., Rodríguez, P. (1999). Durabilidad y Corrosión en Materiales Cementicios, CYTED, Costa Rica (1999). In Proceedings of the Seminario Internacional CYTED, pp185. San José 
Mens, M. J., Erlich, M., Gaume, E., Lumbroso, D., Moreda, Y., Van der Vat M., \& Versini, P. A. (2008). Frameworks for flood event management. Report Number T19-0703. WL Delft Hydraulics. Delft, Netherlands.

Messner, F., \& Meyer, V. (2006). Flood damage, vulnerability and risk perception challenges for flood damage research. In Jochen Schanze, Evzen Zeman, Jiri Marsalek, eds., Flood Risk Management: Hazards, Vulnerability and Mitigation Measures NATO Science Series IV, Springer, 149 - 167. doi.org/10.1007/978-1-4020-4598-1_13

Ministerio de Fomento de España (2012). Guía para la realización de inspecciones principales de obras de paso en la red de carreteras del estado. Dirección General de Carreteras.

Mitsakis, E., Stamos, I., Diakakis, M., Salanova Grau J. M., 2014. Impacts of highintensity storms on urban transportation: applying traffic flow control methodologies for quantifying the effects. Int. J. Environ. Sci. Technol. 11, 2145-2154. doi: 10.1007/s13762014-0573-4

Molarius, R., Könönen, V., Leviäkangas, P., Zulkarnain, Rönty, J., Hietajärvi, A.M., Oiva, K., 2014. The extreme weather risk indicators (EWRI) for the European transport system. Nat. Hazards 72, 189-210. http://dx.doi.org/10.1007/s11069-013-0650-x.

Mondoro, A., Frangopol, D. (2018). Risk-Based Cost-Benefit Analysis for the Retrofit of Bridges Exposed to Extreme Hydrologic Events Considering Multiple Failure Modes. Eng. Struct., 159 (2018): 310-319. doi: 10.1016/j.engstruct.2017.12.029

Moore, K. A., \& Power, R. K. (2002). Safe buffer distances for offstream earth dams. Australasian Journal of Water Resources, 6(1), 1-15. https://doi.org/10.1080/ 13241583.2002.11465206

Muñoz, D. E. (2002). Estudio de las causas del colapso de algunos puentes en Colombia. Pontificia Universidad Javeriana, Bogotá.

National Cooperative Highway Research Program (NCHRP) (2010). Effects of Debris on Bridge Pier Scour. Transportation Research Board. Report 953

Oshikawa, H., \& Komatsu, T. (2014). Study on the risk evaluation for a vehicular traffic in a flood situation. Proceedings of the 19th IAHR-APD Congress, Hanoi, Vietnam.

Patricova (2018). Guía de aplicación del plan de acción territorial sobre prevención del riesgo de inundación en la Comunitat Valenciana (Patricova). Valencia, España

Pregnolato, M., Ford, A., Wilkinson, S. M., \& Dawson, R. J. (2017). The impact of flooding on road transport: A depth-Disruption function. Transportation Research Part D, 55, 67-81. https://doi.org/10.1016/j.trd.2017.06.020 
Ragab, A.M., Elgammal, M.A., Hodhod, O.A.G., Ahmed, T.E. (2016). Evaluation of field concrete deterioration under real conditions of seawater attack. Constr. Build. Mater. 119 (2016), 130-144. doi.org/10.1016/j.conbuildmat.2016.05.014

Salazar, S., Francés F., Komma J., Blume T., Francke T., Bronstert A., Bloschl G. (2012), A comparative analysis of the effectiveness of flood management measures based on the concept of "retaining water in the landscape" in different European hydro-climatic regions. Nat. Hazards Earth Syst. Sci., 12, 3287-3306. DOI:10.5194/nhess-12-32872012.

Salazar., G. S. (2013). Metodología para el análisis y la reducción de riesgo de inundaciones: aplicación en la rambla del Poyo (Valencia) usando medidas de "retención de agua en el territorio". PhD thesis, Universidad Politécnica de Valencia, Valencia.

Samuels, P., Gouldby, B., Klijn, F., Messner, F., Van Os, A, Sayers, P., Schanze, J., Udale-Clare, H. (2009). Language of Risk - Project definition. FLOODsite Consortium. Report: T32-04-01, 2nd edition. http://www.floodsite.net/html/partner_area/project_ docs/ T32_04_01_FLOODsite_Language_of_Risk_D32_2_v5_2_P1.pdf

Sánchez, T. A. (2012). Aspectos del diseño y la construcción de puentes de acero. Sismica Magazine, 2 (2012), 10-12.

Sarhosis, V., Santis, S. \& Felice G. (2016). A review of experimental investigations and assessment methods for masonry arch Bridges. Struct Infrastruct E, 12, 1 - 26. doi:10.1080/15732479.2015.1136655

Schanze, J. (2006). Flood Risk Management - A basic Framework. In Schanze, J., Zeman, E., Marsalek, J., eds; Flood Risk Management: Hazards, Vulnerability and Mitigation Measures NATO Science Series IV, 67, Springer, 1 -20. doi:10.1007/978-1-4020-4598$1 \_1$

Shand, T., Cox, R., Blacka, M., \& Smith, G. (2011). Australian Rainfall and Runoff (AR\&R). Appropriate safety criteria for vehicles. Australian rainfall and runoff, revision project 10: Report Number: P10/S2/020. Sidney, Australia.

Shu, C., Xia, J., Falconer, R. A., \& Lin, B. (2011). Incipient velocity for partially submerged vehicles in floodwaters. Journal of Hydraulic Research, 49(6), 709-717. https://doi.org/10.1080/00221686. 2011.616318

Sistema Nacional de Cartografía de Zonas Inundables (2019). Ministerio de Agricultura, pesca y Alimentación - Ministerio para la Transición Ecológica. https://sig.mapama.gob.es/redes-seguimiento/

Smith, G. P., Davey, E. K., \& Cox, R. J. (2014). Flood hazard. WRL Technical Report 2014/07. University of New South Wales. Sydney, Australia. 
Smith, G. P., Modra, B. D., Tucker, T. A., \& Cox, R. J. (2017). Vehicle stability testing for flood flows. WRL Technical Report 2017/07. University of New South Wales. Sydney, Australia.

Suárez, P., Anderson, W., Mahal, V., \& Lakshmanan, T. (2005). Impacts of flooding and climate change on urban transportation: A system wide performance assessment of the Boston metro area. Transportation Research Part D, 10, 231-244. https://doi.org/10.1016/ j.trd.2005.04.07.

Teo, Y., Falconer, R., Lin, B., \& Xia, J. (2012a). Investigations of hazard risks relating to vehicles moving in flood. Water Resources Management, 1, 52-66.

Teo, Y., Xia, J., Falconer, R., \& Lin, B. (2012b). Experimental studies on the interaction between vehicles and floodplain flows. International Journal of River Basin Management, 10(2), 149-160. https://doi.org/10.1080/15715124.2012.674040

Terrasa S. O., Merino S. M., García E. M., Casado R. E., Pareja M. R., Quesada M. L., Vives R. N., Troyano G. J., Estevens M. E., Ruíz G. J., Barelles A. J., Gaja S. P. (2018). Plan general de ordenación urbana Informe de sostenibilidad ambiental. Godelleta, España

Toda, K., Ishigaki, T., \& Ozaki, T. (2013). Experiment study on floating car in flooding. In International conference on flood resilience experiences in Asia and Europe. Exeter, England.

UNISDR, (2009). Terminology on Disaster Risk Reduction. Strategy for Disaster Reduction of United Nations.

Vallés. M. F. (2011). Cuantificación de la Vulnerabilidad de puentes sobre cauces frente a avenidas fluviales basada en inspecciones de campo. Propuesta de una nueva metodología. PhD thesis, Universidad Politécnica de Valencia, Valencia.

Vallés. M. F., Marco, S. J., Arias H. G., INES Ingenieros, Rodríguez, B. F. (2011). Aplicación de un modelo de vulnerabilidad de puentes sobre cauces frente a avenidas a 100 casos de la red de carreteras española. Universidad Politécnica de Valencia, Valencia.

Versini, P. A., Gaume, E., \& Andrieu, H. (2010a). Application of a distributed hydrological model to the design of a road inundation warning system for flash flood prone areas. Natural Hazards and Earth System, 10, 805-817.

Versini, P. A., Gaume, E., \& Andrieu, H. (2010b). Assessment of the susceptibility of roads to flooding based on geographical information-test in a flash flood prone area (the Gard region, France). Natural Hazards and Earth System, 10, 793-803. http://dx.doi.org/ 10.5194/nhess-10-793-2010.

Vide, J. P. (2003). Ingeniería de ríos. Ediciones UPC Universidad Politécnica de Cataluña, Barcelona. 
Wardhana, K., Hadipriono, F. C. (2003). Analysis of Recent Bridge Failures in the United States. J Perform Constr Fac., 17 (3): 144-50. doi: 10.1061/(ASCE)08873828(2003)17:3(144).

Wemple, B.C., Swanson, F.J., Jones, J.A., 2001. Forest roads and geomorphic process interactions, Cascade Range, Oregon. Earth Surf. Process. Landforms 26, 191-204.

Xia, J., Falconer, R. A., Xiao, X., \& Wang, Y. (2014). Criterion of vehicle stability in floodwaters based on theoretical and experimental studies. Natural Hazards, 70(2), 16191630. https://doi.org/10.1007/s11069-013-0889-2

Xia, J., Teo, F., Lin, B., \& Falconer, R. (2011). Formula of incipient velocity for flooded vehicles. Natural Hazards, 58(1), 1-14. https://doi.org/10.1007/s11069-010-9639-X

Yanmaz, A. M., Caner a. \& Berk, A. (2007). Renovation of a Safety-Inspection Methodology for River Bridges. $J$ Perform Constr Fac., 21 (5): 382-89. doi.org/10.1061/(asce)0887-3828(2007)21:5(382).

Yanmaz, A. M \& Apaydin, M. (2012). Bridge Scour Risk Assessment and Countermeasure Design. J Perform Constr Fac., 26 (4): 499-506. doi.org/10.1061/(asce)cf.1943-5509.0000254.

Yin J, Yu D., Yin Z., Liu M., He Q. 2016. Evaluating the impact and risk of pluvial flash flood on intra-urban road network: A case study in the city center of Shanghai, China. Journal of Hydrology, 537, 138-145. Doi.org/10.1016/j.jhydrol.2016.03.037 